Aus der Medizinischen Klinik 1 mit Poliklinik der

Friedrich-Alexander-Universität

zu Erlangen-Nürnberg

Direktor: Prof. Dr. med. Markus F. Neurath

\title{
Evaluierung der anti-tumoralen Eigenschaften von Thymoquinon am hepatozellulären Karzinom
}

\author{
Inaugural-Dissertation \\ zur Erlangung der Doktorwürde der medizinischen Fakultät \\ der Friedrich-Alexander-Universität \\ zu Erlangen-Nürnberg
}

Vorgelegt von

Anna Machleidt

aus

Hannover 


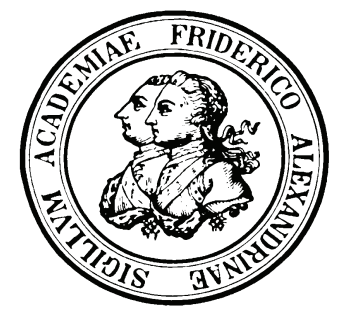

Gedruckt mit der Erlaubnis der

Medizinischen Fakultät der Friedrich-Alexander-Universität Erlangen-Nürnberg

Dekan:

Prof. Dr. med. Dr. h.c. J. Schüttler

Referent:

Prof. Dr. med. M. Ocker

Koreferent:

Prof. Dr. med. Eckhart G. Hahn

Tag der mündlichen Prüfung: 19.01.2011 
Meinen Eltern gewidmet 


\section{Inhaltsverzeichnis}

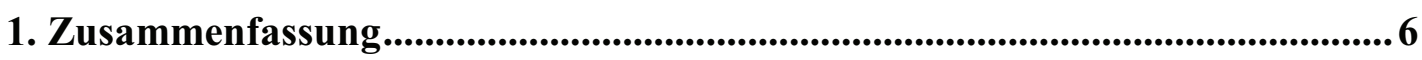

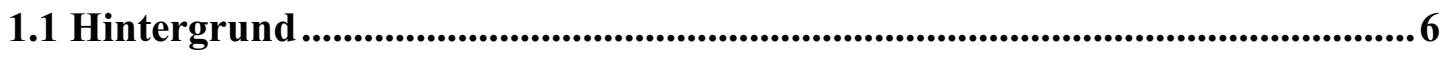

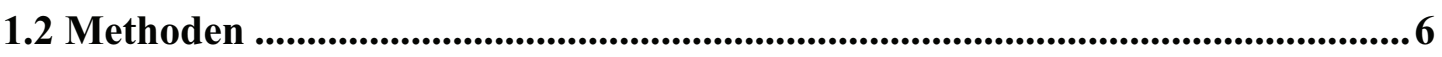

1.3 Ergebnisse und Beobachtungen .......................................................................66

1.4 Praktische Schlussfolgerungen ............................................................................

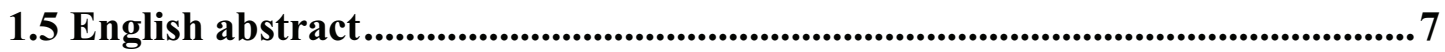

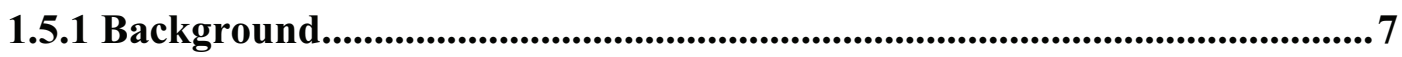

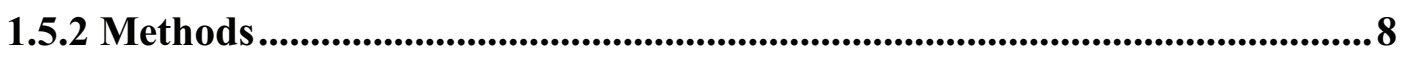

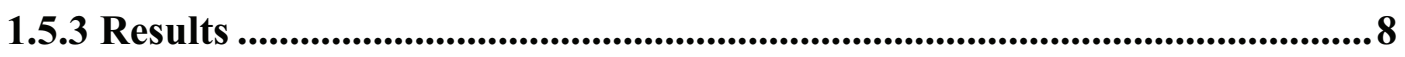

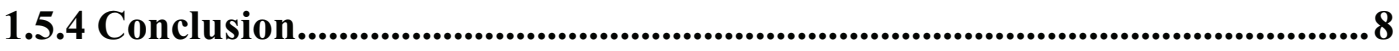

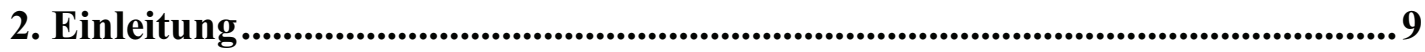

2.1 Epidemiologie, Ätiologie und Risikofaktoren des hepatozellulären

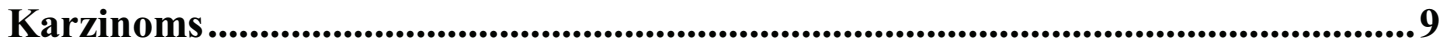

2.2 Diagnostik und Staging des HCC ............................................................................10

2.3 Therapie und Prognose..............................................................................................12

2.3.1 Leberteilresektion und Orthotope Lebertransplantation (OLT) ............13

2.3.2 Transarterielle Interventionen..........................................................................14

2.3.3 Lokal-ablative Verfahren ............................................................................15

2.3.4 Radio- und Chemotherapie ..................................................................................15

2.3.6 Hormon-, Gen- und Immuntherapie ....................................................16

2.4 Thymoquinon .............................................................................................................................17

3. Material und Methoden ............................................................................20

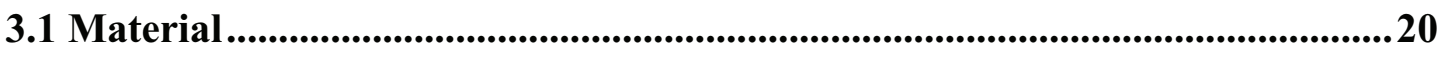

3.1.1 Zelllinien ................................................................................................................................. 20

3.1.2 Nährmedien ........................................................................................................................20

3.1.3 Medikamente ..........................................................................................................20

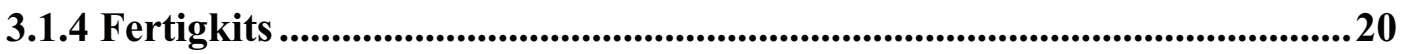

3.1.5 Antikörper ...................................................................................................................21

3.1.6 Lösungen und Puffer .........................................................................21

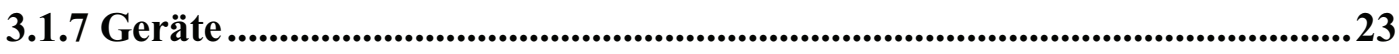

3.1.8 Chemikalien und Verbrauchsmittel .....................................................................23

3.2. Methoden ......................................................................................................................................25

3.2.1 Zellkultur und Passagierung........................................................................25 


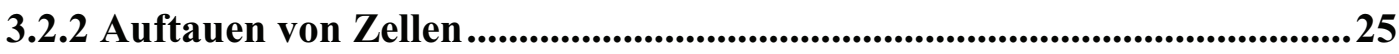

3.2.3 Herstellen des Medikaments ..................................................................26

3.2.4 Bestimmung der Zellzahl...............................................................................26

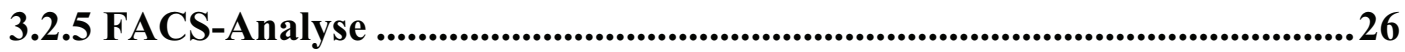

3.2.6 BrdU-Inkorporations-ELISA ...........................................................27

3.2.7 Mitochondriales Membranpotential (JC-1).....................................................28

3.2.8 Qualitativer Apoptosenachweis durch Immunfluoreszenzfärbung von Zytokeratin-18-Fragmenten (M30-Antikörper)...................................................29

3.2.9 Semiquantitativer Westernblot.............................................................29

3.2.10 Bestimmung der Caspase-3 Aktivität....................................................31

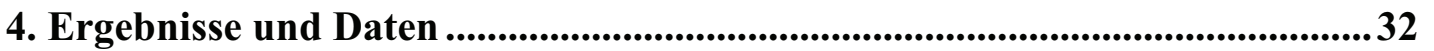

4.1 Bestimmung der Zellzahl.......................................................................32

4.2 Bestimmung der Apoptoseinduktion mittels FACS- Analyse...........................34

4.3 Ergebnisse BrdU-Inkorporations-ELISA................................................................37

4.4 Ergebnisse mitochondriales Membranpotential (JC-1) ..................................38

4.5 Ergebnisse der Immunfluoreszenzfärbung von Zytokeratin-18-Fragmenten

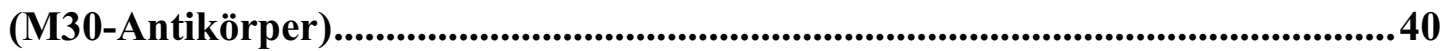

4.6 Ergebnisse Caspase 3/7-Assay..................................................................42

4.7 Semiquantitativer Westernblot.................................................................43

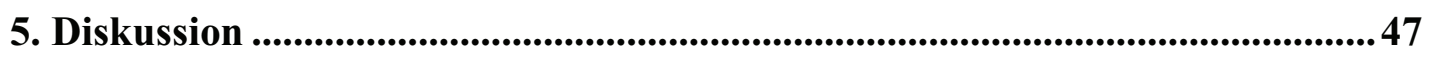

5.1 Diskussion der Methoden ......................................................................................47

5.2 Diskussion der Ergebnisse ...................................................................................48

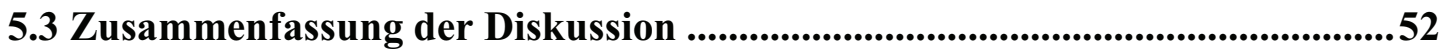

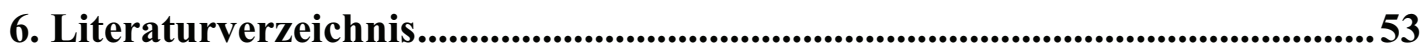

7. Abkürzungsverzeichnis.........................................................................................57

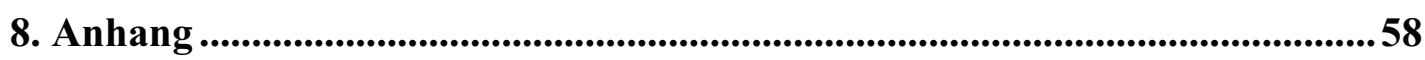

8.1 Ergebnisse Zellzahl ..............................................................................59

8.1.1 Ergebnisse Hep3B .......................................................................................................59

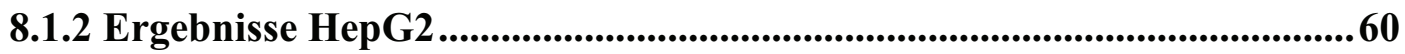

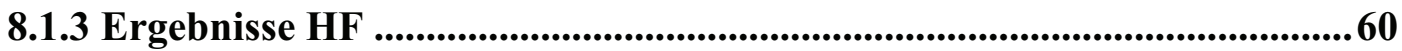

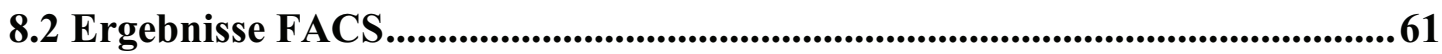

8.2.1 Ergebnisse Hep3В ....................................................................................61

8.2.2 Ergebnisse HepG2 ..........................................................................62

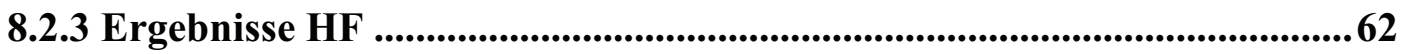

8.3. Ergebnisse BrdU ....................................................................................................662 
8.3.1 Ergebnisse Hep3B .......................................................................................62

8.3.2 Ergebnisse HepG2 .........................................................................................62

8.3.3 Ergebnisse HF-Zellen .............................................................................63

8.4 Ergebnisse Caspase-3/7-Assay .............................................................................63

8.4.1 Ergebnisse Нep3В .................................................................................63

8.4.2 Ergebnisse HepG2 ...............................................................................................6 63

8.4.3. Ergebnisse HF-Zellen ...............................................................................64

8.5 Ergebnisse JC-1 .................................................................................................................6 64

8.5.1 Ergebnisse HepG2 und Hep3B ............................................................64

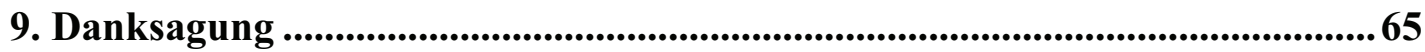

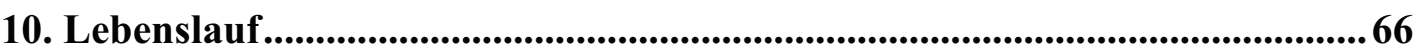




\section{Abbildungsverzeichnis}

Abbildung 1: vorgeschlagener Alghorithmus zur Diagnostik des HCC bei Zirrhose (10) ......... 10

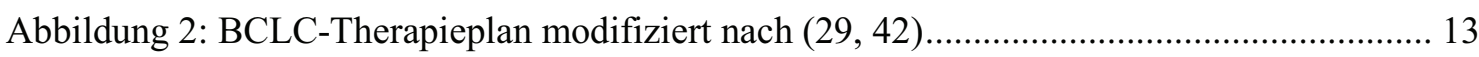

Abbildung 3: Struktur des Thymoquinons: 2-Isopropyl-5-Methyl-1,4-Benzoquinon (14) ........ 17

Abbildung 4: Zellzahl der Hep3B-Zellen nach Inkubation mit Thymoquinon............................ 32

Abbildung 5: Zellzahl der HepG2-Zellen nach Inkubation mit Thymoquinon .......................... 33

Abbildung 6: Zellzahl der HF-Zellen nach Inkubation mit Thymoquinon................................. 33

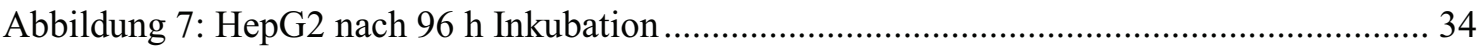

Abbildung 8: Apoptoserate in \% der Hep3B-Zellen nach Inkubation mit Thymoquinon ........... 35

Abbildung 9: Apoptoserate in \% der Hep3B-Zellen nach Inkubation mit Thymoquinon ........... 35

Abbildung 10: Apoptoserate in \% der HepG2-Zellen nach Inkubation mit Thymoquinon......... 36

Abbildung 11: Apoptoserate in \% der HF-Zellen nach Inkubation mit Thymoquinon .............. 36

Abbildung 12: Relativer BrdU-Einbau bei HepG2- und HF-Zellen nach $24 \mathrm{~h}$ Inkubation mit

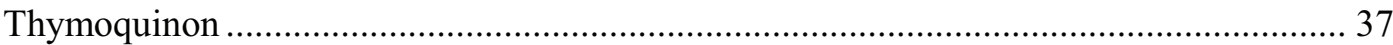

Abbildung 13: Relativer BrdU-Einbau bei Hep3B-Zellen nach 24 h Inkubation mit

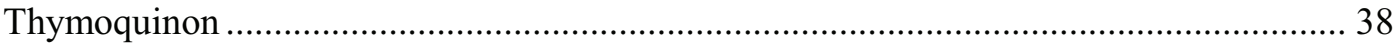

Abbildung 14: Nachweis intakter Mitochondrien durch JC-1-Fluoreszenz bei HepG2- und

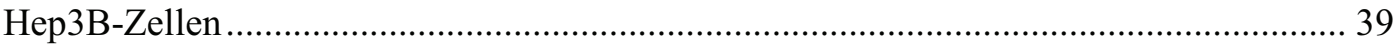

Abbildung 15: Apoptosewerte und JC-1-Fluoreszenz bei HepG2- und Hep3B-Zellen............... 39

Abbildung 16: M30, Hep3B unbehandelt nach 24 h, Vergrößerung 10fach 40

Abbildung 17: M30, Hep3B behandelt mit Thymoquinon $10 \mu \mathrm{M}$ nach 24 h, Vergrößerung 20 fach 40

Abbildung 18: M30, Hep3B behandelt mit Thymoquinon $10 \mu \mathrm{M}$ nach 48 h, Vergrößerung $20 \mathrm{fach}$

Abbildung 19: M30, Hep3B behandelt mit Thymoquinon $100 \mu \mathrm{M}$ nach 24 h, Vergrößerung 5 fach

Abbildung 20: M30, HF unbehandelt nach 24 h, Vergrößerung 20fach.....

Abbildung 21: M30, HF behandelt mit Thymoquinon $10 \mu \mathrm{M}$ nach $24 \mathrm{~h}$, Vergrößerung $20 \mathrm{fach} 41$

Abbildung 22: M30, HF behandelt mit Thymoquinon $100 \mu \mathrm{M}$ nach $24 \mathrm{~h}$, Vergrößerung 10 fach

Abbildung 23: M30, HF behandelt mit Thymoquinon $100 \mu \mathrm{M}$ nach 24 h, Vergrößerung $20 \mathrm{fach}$

Abbildung 24: M30, HepG2 behandelt mit Thymoquinon $10 \mu \mathrm{M}$ nach 48 h, Vergrößerung $10 \mathrm{fach}$ 42

Abbildung 25: M30, HepG2 unbehandelt nach 24 h, Vergrößerung 10fach 42

Abbildung 26: Relative Caspaseaktivität nach Inkubation mit $50 \mu \mathrm{M}$ Thymoquinon 43 
Abbildung 27: Semiquantitativer Westernblot zum Nachweis von ß-Aktin und Bax. Abgebildet sind unbehandelte, mit $50 \mu \mathrm{M}$ und $100 \mu \mathrm{M}$ TQ behandelte HF-Zellen zu den Zeitpunkten $24 \mathrm{~h}$ und $48 \mathrm{~h}$

Abbildung 28: Semiquantitativer Westernblot zum Nachweis von B-Aktin und Bax. Abgebildet wurden unbehandelte, mit $50 \mu \mathrm{m}$ und mit $100 \mu \mathrm{m}$ TQ behandelte HepG2-Zellen zu den Zeitpunkten 24 und $48 \mathrm{~h}$.

Abbildung 29: Semiquantitativer Westernblot zur Abbildung von B-Aktin und Bax. Abgebildet sind unbehandelte, mit $50 \mu \mathrm{M}$ und mit $100 \mu \mathrm{M}$ TQ behandelte Hep3B-Zellen zu den Zeitpunkten 24 und $48 \mathrm{~h}$.

\section{Tabellenverzeichnis}

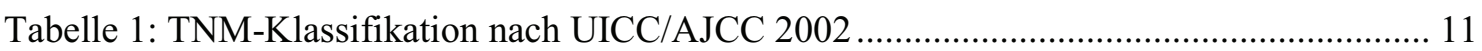

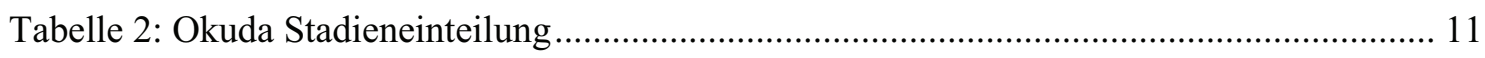

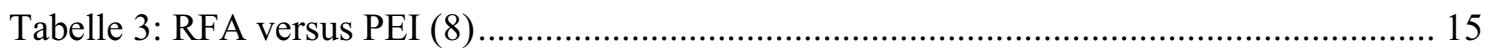

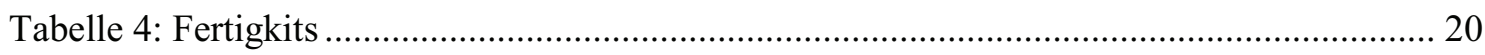

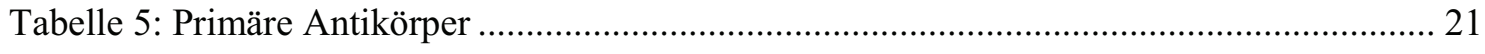

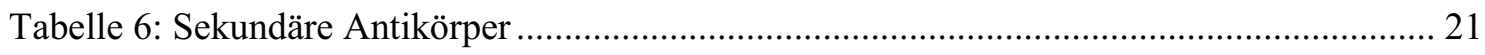

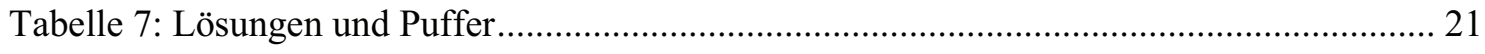

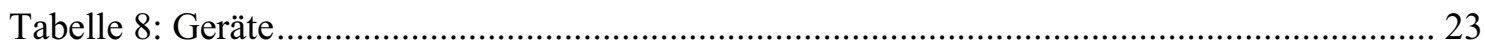

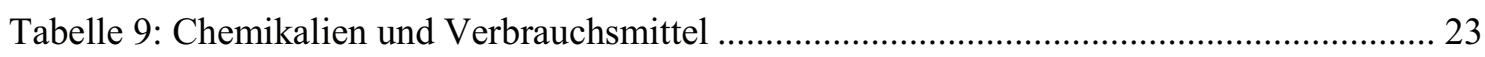

Tabelle 10: Schweregradeinteilung der Leberzirrhose nach Child-Pugh................................... 58

Tabelle 11: Barcelona Clinic Liver Cancer (BCLC)-Klassifikation nach Llovet et al. (2)......... 58 


\section{Zusammenfassung}

\subsection{Hintergrund}

Das hepatozelluläre Karzinom ist das sechsthäufigste Malignom der Welt und ist ursächlich für über 500.000 Todesfälle pro Jahr. Die Hauptrisikofaktoren der Erkrankung sind neben chronischer Hepatitis B und C Infektion vor allem auch in westlichen Ländern die Alkohol-induzierte Leberzirrhose. Die Inzidenz steigt in Europa und den USA und trotz der bekannten Risikofaktoren wird das HCC durch fehlende Frühsymptomatik oft erst spät diagnostiziert. So können nur wenige Patienten einer kurativen operativen Therapie zugeführt werden. In der palliativen Therapie kommen verschiedene Chemotherapeutika und Immunmodulatoren in lokal-ablativen und systemischen Therapieverfahren zum Einsatz. Dennoch ist die Prognose der Patienten weiterhin nicht zufriedenstellend und bedarf weiterer Forschung.

Thymoquinon, das Extrakt des schwarzen Kümmelöls, wird schon seit Jahrhunderten in der Naturmedizin des arabischen Raumes verwendet. Mehrere in vitro und in vivo Studien zeigen neben antiinflammatorischen auch antiproliferative und proapoptotische Effekte auf verschiedene Tumorzellen. In dieser Dissertation wurden die Effekte auf zwei Zelllinien des hepatozellulären Karzinoms evaluiert.

\subsection{Methoden}

Die anti-tumoralen Eigenschaften Thymoquinons wurden in vitro an den Hepatomzelllinien Hep3B und HepG2, sowie den humanen Vorhautfibroblasten (HFZellen) als nicht-maligne Kontrollzellen getestet. Konzentrationen zwischen $0,1 \mu \mathrm{M}$ und $1000 \mu \mathrm{M}$ wurden verwendet.

Das Wachstum und die Zellvitalität wurden durch Bestimmung der relativen Zellzahl und durch BrdU-Inkorporations-ELISA ermittelt. Die Beurteilung der Apoptoserate erfolgte durchflußzytometrisch nach Propidiumjodidfärbung, sowie durch Messung des mitochondrialen Membranpotentials (JC-1) und durch immunzytochemische Analyse der Zytokeratinfragmentierung (M30 Cytodeath). Ein semiquantitativer Westernblot und ein Caspase-3/7-Assay verifizierten die Expression apoptoserelevanter Proteine.

\subsection{Ergebnisse und Beobachtungen}

Thymoquinon hemmt abhängig von Konzentration und Inkubationszeit das Wachstum der Hepatomzelllinien und humanen Vorhautfibroblasten.

Schon nach 24 Stunden Inkubationszeit zeigten sich die ersten Auswirkungen des Thymoquinons. So fiel die Anzahl der vitalen Zellen sowohl bei den Hepatomzellen, als 
auch bei der nicht-malignen Kontrolle zu diesem Zeitpunkt bei einer Konzentration von $100 \mu \mathrm{M}$ auf $\leq 10 \% \mathrm{ab}$. Auch in der durchflußzytometrischen Apoptosemessung werden ab $100 \mu \mathrm{M}$ Konzentration signifikant erhöhte Apoptoseraten gemessen, die sich mit zunehmender Inkubationszeit auf Maximalwerte zum Zeitpunkt 120 Stunden steigern.

Eine Konzentration von $50 \mu \mathrm{M}$ beeinträchtigt die Zellen in geringerem Maße. Es zeigen sich aber für alle Zelllinien vereinzelt signifikante Werte und bei den HepG2-Zellen in der Zellzahlbestimmung kontinuierlich absinkende Zellzahlen.

Im qualitativen Apoptosenachweis M30 Cytodeath konnte eine beginnende TQWirkung auch schon für $10 \mu \mathrm{m}$ Konzentration gezeigt werden, so wie eine gewisse Resistenz der HF-Zellen im Vergleich zu den Tumorzelllinien. Der Caspase-3/7-Assay und der semiquantitative Westernblot konnten Hinweise auf die Beeinflussung apoptoserelevanter Signaltransduktionswege geben.

\subsection{Praktische Schlussfolgerungen}

Thymoquinon hat proapoptotische und wachstumshemmende Wirkung auf Zellen des hepatozellulären Karzinoms. Konzentrationen von $100 \mu \mathrm{M}$ zeigen hierbei eindeutige Wirkung, geringere Konzentrationen sollten im Rahmen weiterer Forschung genauer evaluiert werden.

\subsection{English abstract}

\subsubsection{Background}

Hepatocellular carcinoma is the sixth most common malignancy in the world and it is estimated to cause about 500.000 deaths annually. The major risk factors are chronic Hepatitis B and C infection and especially in western countries chronic alcohol abuse.

The incidence increases in Europe and the United States. Although risk factors are known, hepatocelluar carcinoma is frequently diagnosed at late stages because of the absence of pathognomonic symptoms. This is why most of the patients fall out of the criteria for curative therapy. For palliative therapy there are several other treatment modalities available, such as systemic chemotherapy, molecularly targeted therapy and local ablative therapies.

With a median survival of approximately 6 to 20 months the prognosis is still poor and more research is needed.

Black seed oil and its active compound Thymoquinone have been used for the treatment of diseases for centuries in the Arabic countries. Thymoquinone is known to have antiinflammatory and antineoplastic effects on tumor cells in vitro and in vivo. 
In this dissertation project two cell types of hepatocllular carcinoma were exposed to TQ treatment.

\subsubsection{Methods}

The anti-cancer properties of TQ were examined in HepG2 and Hep3B hepatoma cells and non-neoplastic human fibroblastic cells. Concentrations between 0.1 and $1000 \mu \mathrm{M}$ were used.

Growth and cell vitality were determined by cell count and BrdU-incorporation ELISA. The rate of apoptosis was measured using flow cytometry after propidium jodide staining, M30-antibody immunofluorescence and analysis of the mitochondrial membrane potential. Semiquantitative Westernblot and a Caspase-3/7-activity-assay were performed to evaluate the expression of proapoptotic proteins.

\subsubsection{Results}

TQ inhibits the growth of hepatoma cells and fibroblast cells in a concentration- and time-dependent manner beginning after 24 hours. The rate of vital cells decreased to less than $10 \%$ at a TQ-concentration of $100 \mu \mathrm{M}$. Also in the flow cytometric measurement of apoptosis, significant higher values were found for $100 \mu \mathrm{M}$ concentration. These values increased to a maximum after 120 hours.

Treatment with $50 \mu \mathrm{M}$ TQ showed less effect. Only the cell count of the HepG2 cells showed a continous decrease of vital cells. The M30-antibody immunofluorescence demonstrated an initiating effect of TQ at $10 \mu \mathrm{M}$ concentration and a resistance of the fibroblasts compared to hepatoma cells. The Westernblot and Caspase-3/7-activityassay provided an indication of TQ's influence on apoptotic pathways.

\subsubsection{Conclusion}

Thymoquinone has proapoptotic and growth-inhibiting effects on cells of hepatocellular carcinoma. $100 \mu \mathrm{M}$ TQ shows definite results, lower concentrations should be evaluated more precisely in the future. 


\section{Einleitung}

\subsection{Epidemiologie, Ätiologie und Risikofaktoren des hepatozellulären Karzinoms}

Das hepatozelluläre Karzinom (HCC) ist das sechsthäufigste Malignom weltweit und die dritthäufigste tumorassoziierte Todesursache (56).

Die Inzidenz des HCC variiert stark in verschiedenen Regionen der Welt (33). So zeigen sich in Teilen Afrikas und Südostasiens hohe Inzidenzen mit 15-140 Fällen/100.000 Einwohner/Jahr (39), in Teilen Nord- und Südamerikas, Westeuropas und Australiens niedrige Fallzahlen von weniger als 3 Fällen/100.000 Einwohner/Jahr (49), allerdings mit steigender Inzidenz in den letzten 20-30 Jahren $(13,16,17)$.

Dies lässt sich vor allem durch die unterschiedliche Ätiologie der HCCs erklären. In Entwicklungsländern mit hohen Fallzahlen ist die Durchseuchung mit Hepatitis B (HBV) und Hepatitis C (HCV) Viren hoch. Das HCC entsteht hier auf dem Boden einer viralen Hepatitis oft schon um das 30. Lebensjahr $(44,49)$. In westlichen Ländern mit niedrigeren Infektionsraten entsteht das HCC meist um das 50-60. Lebensjahr auf dem Boden einer Leberzirrhose unterschiedlicher Genese (44), zum Beispiel langjähriger Alkoholkonsum. Der Trend zur steigenden Inzidenz in den Industriestaaten wird auf das Hepatitis C Virus zurückgeführt (47).

Insgesamt sind Männer zwei- bis dreifach häufiger betroffen als Frauen (39).

Das HCC entsteht zumeist in vorgeschädigtem Lebergewebe, das ständigen, oft langjährigen entzündlichen Umbauvorgängen unterliegt. In histologischen Untersuchungen der Leber von Patienten mit HCC wurde in $80 \%$ der Fälle eine Zirrhose gefunden, weshalb sie auch als Präkanzerose gilt $(11,51)$.

Infektionen durch HBV, HCV und auch HDV sind entscheidende Risikofaktoren bei der Entwicklung des HCC. In Teilen Asiens und Afrikas dominieren hierbei die HBVassoziierten chronischen Hepatitiden, die für ein 100 fach erhöhtes relatives Erkrankungsrisiko verantwortlich sind.

In den westlichen Industrienationen und Japan ist dagegen die chronische HCVInfektion der entscheidende Risikofaktor bei der Entstehung des HCC (30) und auch verantwortlich für zunehmende Häufigkeit $(17,47)$.

Genauso sind auch hereditäre Lebererkrankung, wie die Hämochromatose oder der alpha1-Antitrypsin-Mangel, chemische Karzinogene, wie das Aflatoxin B1, und in westlichen Ländern vor allem auch die Alkohol-induzierte chronische Hepatopathie Ursachen für das HCC $(33,54)$. Als protektiver Faktor für die Leber ist der Konsum von Kaffee zu nennen $(9,28)$. 


\subsection{Diagnostik und Staging des HCC}

Die Diagnostik des HCC setzt sich zusammen aus klinischen, laborchemischen, bildgebenden und histologischen Untersuchungen (55). Weltweit der gebräuchlichste Tumormarker ist das Alpha-Fetoprotein (AFP). Werte $>400 \mathrm{ng} / \mathrm{ml}$ gelten als hochverdächtig bzw. mit positiver Bildgebung als diagnostisch für ein HCC (23), allerdings sind Sensitivität und Spezifität des AFP limitiert (23).

Im Mittelpunkt der bildgebenden Techniken stehen Ultraschall, Spiral-CT und MRT, jeweils mit Kontrastmittelapplikation. Je nach Größe der Läsion werden eine oder auch zwei komplementäre bildgebende Verfahren genutzt. Zeigen sich hier typische Gefäßzeichnungen, die auf ein HCC hindeuten, oder ist zusätzlich der AFP-Wert $>400$ ng/ml kann die Diagnose auch ohne Biopsie gestellt werden.

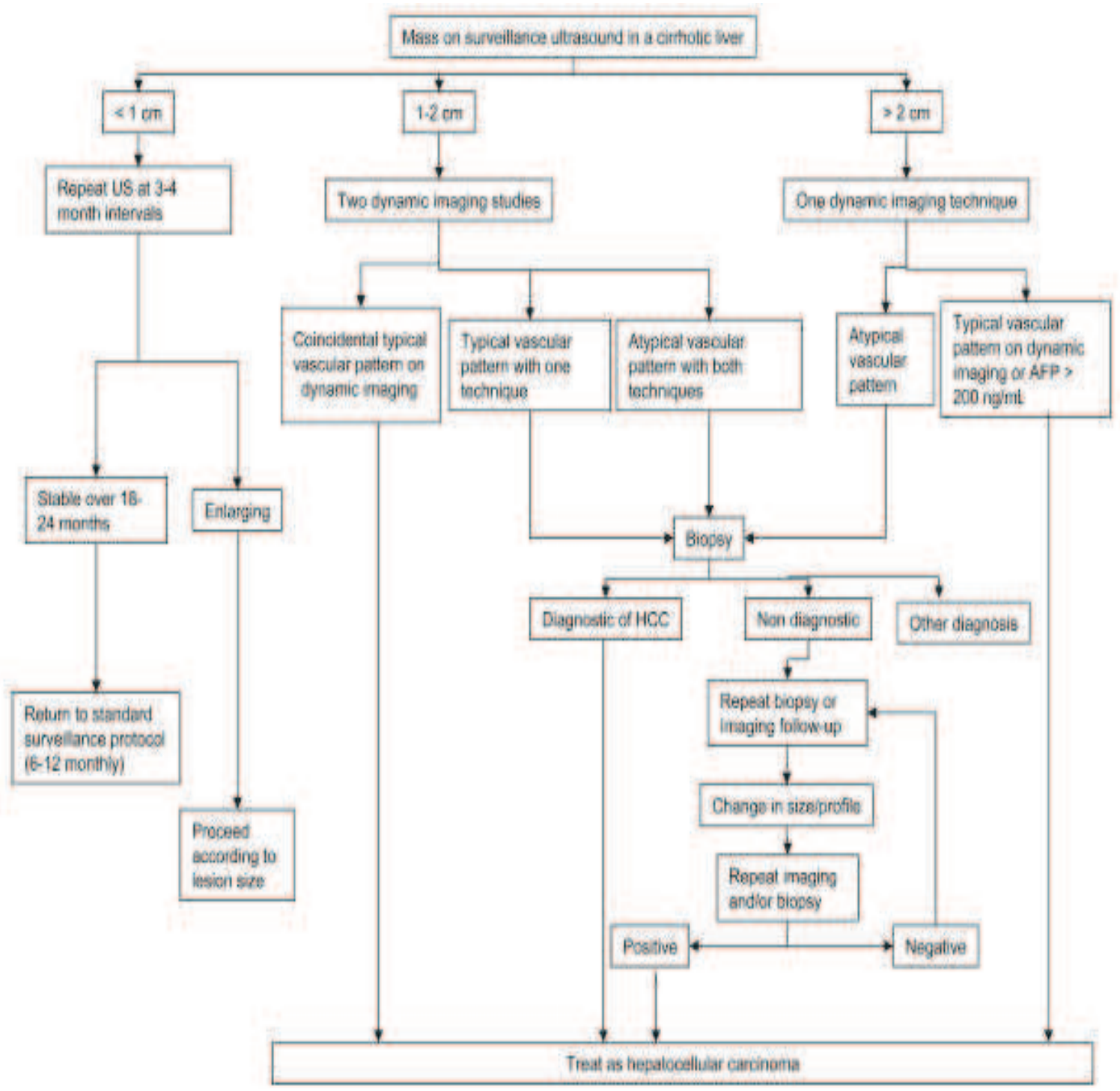

Abbildung 1: vorgeschlagener Alghorithmus zur Diagnostik des HCC bei Zirrhose (10)

Bei kleinen Läsionen ohne typische Gefäßzeichnung oder fokalen Läsionen ohne zugrunde liegende Leberzirrhose wird eine histologische Sicherung empfohlen (52). 
Einige wichtige Faktoren, die die Therapieentscheidung und Prognose des HCC beeinflussen, sind neben der Größe des Tumors, der Ausbreitung in angrenzende Strukturen und der Metastasierung, vor allem auch die zugrunde liegende Leberfunktion (2). Die zur Verfügung stehenden Stagingsysteme berücksichtigen diese und weitere Faktoren in unterschiedlicher Kombination und Schwerpunktsetzung. Die klassischerweise bei Tumorentitäten genutzte TNM-Klassifikation (siehe Tabelle 1) bzw. die hieraus hervorgehende UICC-Stadieneinteilung zeigen neben anderen Stagingsystemen weniger klinische Relevanz (52).

Tabelle 1: TNM-Klassifikation nach UICC/AJCC 2002

\begin{tabular}{|l|l|}
\hline \multicolumn{2}{|l|}{ Primärtumor (T) } \\
\hline TX & Keine Aussage über den Primärtumor möglich \\
\hline T0 & Kein Primärtumor vorhanden \\
\hline T1 & Solitärer Tumor ohne Gefäßinvasion \\
\hline T2 & Solitärer Tumor mit Gefäßinvasion oder mehrere Herde $<5$ cm \\
\hline T3 & $\begin{array}{l}\text { Multiple Tumore }>5 \text { cm oder Tumor mit Infiltration eines großen Pfortader- } \\
\text { oder Lebervenenastes }\end{array}$ \\
\hline T4 & $\begin{array}{l}\text { Tumor(en) mit Invasion benachbarter Organe (ohne Gallenblase) oder mit } \\
\text { Durchbruch durch das viszerales Peritoneum }\end{array}$ \\
\hline Regionäre Lymphknotenmetastasen (N) \\
\hline NX & Regionäre Lymphknoten nicht beurteilbar \\
\hline N0 & Keine regionären Lymphknoten-Metastasen \\
\hline N1 & Regionäre Lymphknoten-Metastasen \\
\hline Fernmetastasen (M) & Fernmetastasen nicht beurteilbar \\
\hline M0 & \begin{tabular}{l} 
Fernmetastasen vorhanden \\
\hline
\end{tabular}
\end{tabular}

Okuda et al. führten 1985 ein Stagingsystem ein, das neben der Tumorausdehnung auch Leberfunktionsparameter berücksichtigt und somit eher klinisch ausgerichtet ist (siehe Tabelle 2). 
Tabelle 2: Okuda Stadieneinteilung

\begin{tabular}{|c|c|c|c|}
\hline \multicolumn{2}{|r|}{0 Punkte } & \multicolumn{2}{|r|}{1 Punkt } \\
\hline $\begin{array}{l}\text { Tumorgröße } \\
\text { (Durchmesser) }\end{array}$ & $<50 \%$ des Lebervolumens & \multicolumn{2}{|r|}{$>50 \%$ des Lebervolumens } \\
\hline Aszites & klinisch nicht nachweisbar & \multicolumn{2}{|r|}{ klinisch nachweisbar } \\
\hline Bilirubin & $<3 \mathrm{mg} / \mathrm{dl}$ & \multicolumn{2}{|r|}{$>3 \mathrm{mg} / \mathrm{dl}$} \\
\hline Albumin & $>3 \mathrm{mg} / \mathrm{dl}$ & \multicolumn{2}{|r|}{$<3 \mathrm{~g} / \mathrm{dl}$} \\
\hline & \multicolumn{2}{|c|}{ Stadium II } & Stadium III \\
\hline Punkte & 0 & $1-2$ & $3-4$ \\
\hline
\end{tabular}

Eine weitere Alternative ist die klinische Barcelona Clinic Liver Cancer (BCLC)Klassifikation (siehe Tabelle $11 \mathrm{im}$ Anhang). Sie bezieht das Okuda-Stagingsystem mit ein und zusätzlich den sogenannten performance status nach ECOG-Klassifikation (Eastern Cooperative Oncology Group), der, ähnlich dem Karnofsky Index, den körperlichen Gesamtzustand des Patienten beschreibt.

Bei der Konferenz des American Joint Commitee on Cancer und der American Hepatico-Pancreatico-Biliary Association 2002 wurde die Empfehlung ausgesprochen primär ein klinisches Stagingsystem zu verwenden. Das TNM-Staging kann sekundär und vor allem bei chirurgisch zu therapierenden Patienten hinzugezogen werden (24).

\subsection{Therapie und Prognose}

Bei der Therapie stehen chirurgische und nicht-chirurgische Methoden zur Verfügung. Chirurgisch und mit potentiell kurativem Ansatz sind die Leberteilresektion und die orthotope Lebertransplantation (OLT) zu nennen. Palliative Behandlungsmethoden sind die Alkoholinjektion (PEI), die Radiofrequenzablation (RFA), die transarterielle Chemoembolisation (TACE) und die Kombination aus PEI und TACE. Außerdem die Strahlen-, Chemo-, Immun-, Gen- und Hormontherapie.

Da bei Diagnosestellung ca. $80 \%$ der Patienten aufgrund der Tumorausdehnung, Leberfunktionsstörung oder anderer Komorbiditäten nicht operabel sind, kommt den nicht-chirurgischen Therapieoptionen eine große Bedeutung zu (7).

Angelehnt an die BCLC-Klassifikation modifiziert nach Llovet et al. (29) wurde von Okamoto et. al (42) folgender Therapiealgorithmus entworfen (siehe Abb.2). 
Abbildung 2: BCLC-Therapieplan modifiziert nach $(29,42)$

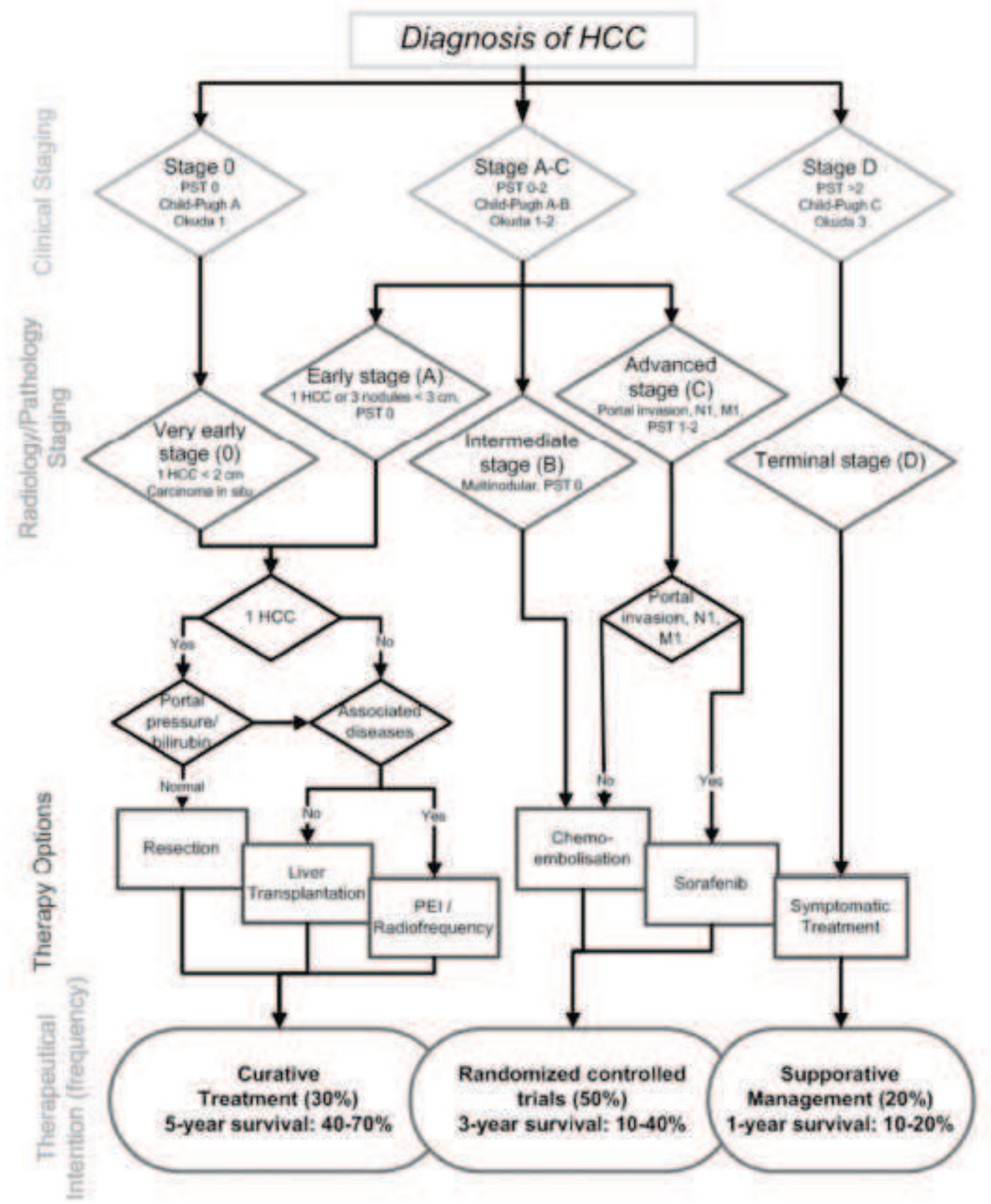

\subsubsection{Leberteilresektion und Orthotope Lebertransplantation (OLT)}

Als kurativer Ansatz ist die Leberteilresektion die optimale Therapie des HCC. Hierfür kommen vornehmlich Patienten mit solitärem Tumor in Frage, wobei über die maximale Größe kein eindeutiger Konsensus besteht (3). Vor einer Operation muss Klarheit über die Leberfunktion bestehen. Fünf Jahre nach Resektion liegt die 
Rezidivrate zwischen 50-70 \% (55), die Überlebensrate schwankt stark je nach Ausmaß der Leberfunktionsstörung zwischen $25 \%$ und ca. $75 \%$ (31).

Patienten mit solitärem Befund $<5 \mathrm{~cm}$ oder weniger als 3 Läsionen $<3 \mathrm{~cm}$, aber dekompensierter Zirrhose sollten laut den Mazzaferro-Kriterien (Mailand-Kriterien) möglichst einer Lebertransplantation zugeführt werden.

Hier zeigte sich eine Überlebensrate von $75 \%$ und ein rezidivfreies Überleben von $83 \%$ nach vier Jahren (38). Die Lebertransplantation führt nicht nur zur Entfernung des malignen Gewebes, sondern kann auch die Leberfunktion wieder komplett herstellen. Ein großes Problem besteht natürlich in der unzureichenden Verfügbarkeit von Spenderorganen und der damit verbundenen Verschlechterung der Befunde im Verlauf der Wartezeit.

\subsubsection{Transarterielle Interventionen}

Bei den transarteriellen Interventionen macht man sich die Tatsache zu nutze, dass die Leber zwar über eine doppelte Gefäßversorgung verfügt, das HCC aber größtenteils über Äste der Leberarterie versorgt wird (10). So kann bei der transarteriellen Chemoembolisation (TACE) bzw. bei der arteriellen Embolisation (TAE) der Katheter je nach Tumorlokalisation und Größe in die entsprechende Segmentarterie oder Subsegmentarterie vorgeschoben werden.

Das Prinzip der TAE besteht darin, durch Gefäßembolisation eine Tumornekrose hervorzurufen. Bei der TACE werden zusätzlich ein oder mehrere Chemotherapeutika über den Katheter injiziert.

Als Chemotherapeutika werden hauptsächlich Mitomycin C, Doxorubicin oder Epirubicin genutzt. Als embolisierend wirkende Substanzen werden Gelatineschaumpuder, Polyvinyl-Alkohol (PVA)-Partikel oder Mikrosphären verwendet (46).

Für transarterielle Interventionen kommen Patienten mit großen oder auch multinodulären unresektablen Tumoren infrage, deren Leberfunktion gut ist (ChildPugh-A, siehe Tabelle 10 im Anhang)(10).

Bei Patienten auf der Warteliste für eine OLT kann TACE eine Tumorausbreitung kontrollieren und die Patienten so innerhalb der Indikationskriterien halten (37). 


\subsubsection{Lokal-ablative Verfahren}

$\mathrm{Zu}$ den lokal-ablativen Verfahren gehören neben der PEI (perkutane Alkoholinjektion) auch die RFA (Radiofrequenzablation), die Hochfrequenz-induzierte Thermotherapie (HiTT), sowie die Laser-induzierte Thermotherapie (LiTT).

Alle diese Verfahren sind perkutan anwendbar, kostengünstig und komplikationsarm.

Bei ausgewählten Patienten mit maximal 3 HCC-Herden, jeweils $<3 \mathrm{~cm}$ wird durch PEI in $80 \%$ der Fälle eine komplette Ablation erreicht. Bei Herden zwischen 3-5 cm immerhin noch in $50 \%$ der Fälle (19). Die Überlebensraten nach PEI sind auch abhängig von der vorbestehenden Leberfunktion (43).

Bei der RFA werden Radiofrequenzwellen über ein nadelähnliches Gerät in das Tumorgewebe emittiert, was eine fokale Erhitzung bewirkt. Um eine exakte Positionierung des Applikators zu erreichen, werden als bildgebende Verfahren die Computertomographie (CT) und Magnetresonanztomographie (MRT) angewandt. Die RFA kann als Monotherapie durchgeführt werden oder aber auch in Kombination mit Embolisation (46).

Mit der RFA wird in 90-98 \% eine komplette Ablation von Herden $<3 \mathrm{~cm}$ erreicht und es werden weniger Therapiesitzungen als bei der PEI benötigt (19). Mehrere Metaanalysen beweisen eine Überlegenheit der RFA gegenüber PEI bezüglich Überlebensraten und tumorfreiem Überleben $(8,45)$.

Tabelle 3: RFA versus PEI (8)

\begin{tabular}{|l|l|l|}
\hline & RFA & PEI \\
\hline Lokalrezidivrate & $7 \%$ & $22 \%$ \\
\hline 1-Jahresüberleben & $96 \%$ & $91 \%$ \\
\hline 3-Jahresüberleben & $73 \%$ & $58 \%$ \\
\hline $\begin{array}{l}\text { Tumorfreies Überleben nach } \\
\text { 3 Jahren }\end{array}$ & $40 \%$ & $19 \%$ \\
\hline
\end{tabular}

Die bereits oben erwähnten ablativen Methoden, die Laser-induzierte und die Hochfrequenz-induzierte Thermotherapie, zeigen ebenfalls gute Ergebnisse, sind komplikationsarm und perkutan in Lokalanästhesie durchzuführen. Jedoch ist der technische Aufwand vergleichsweise hoch.

\subsubsection{Radio- und Chemotherapie}

Das HCC ist im Prinzip ein strahlensensibler Tumor, so dass eine Radiatio als Therapieoption in Frage kommt. Limitierender Faktor ist hierbei allerdings das 
umgebende Lebergewebe, das sehr strahlensensibel ist. Schon etwa 30 Gy reichen aus um eine Hepatitis auszulösen, Tumoren sprechen erst auf höhere Dosen an.

Technische Weiterentwicklungen, wie die image-guided radiation therapy (IGRT), intensity-modulated radiation therapy oder die stereotaktische Bestrahlung werden derzeit in Studien evaluiert (18).

Da die Diagnose des HCC oft erst spät gestellt wird, können nur ca. 20 \% der Patienten einer kurativen Therapie zugeführt werden. Umso wichtiger ist die Forschung und Weiterentwicklung palliativer Therapieoptionen, $\mathrm{zu}$ der auch die systemische Chemotherapie gehört. Eine Reihe von Chemotherapeutika wurde in den letzten Jahrzehnten am HCC evaluiert.

Hierzu gehören Doxorubicin, Cisplatin, Fluorouracil, Mixantrone und Interferone, die in Monotherapie aber auch in verschiedenen Kombinationsmöglichkeiten eingesetzt wurden (40). Das Anthrazyklin Doxorubicin scheint in seiner Wirkung als Monotherapeutikum am vielversprechensten zu sein (Ansprechrate bis zu $20 \%$ ), aber auch Epirubicin kann mit $17 \%$ Ansprechrate in Studien vergleichbare Ergebnisse liefern (25). Ansprechen wird in den meisten Studien definiert als Tumormassenreduktion von mindestens $50 \%$.

Kombinationstherapien zeigten in Studien zwar bessere Überlebens- und Ansprechraten, diese waren jedoch nicht signifikant. Auch waren die Nebenwirkungsraten höher (57). Ein weiterer Hoffnungsträger ist der Wirkstoff Sorafenib, der als Pharmakon Nexavar nicht nur beim HCC, sondern auch beim Nierenzellkarzinom zugelassen ist. Sorafenib ist ein Inhibitor der Raf-Kinase mit gleichzeitiger VEGF-Inhibition und greift somit in typische Signaltransduktionswege der Zellproliferation und Zellzykluskontrolle ein. In einer Phase-III-Studie von Llovet et. al wurde ein Überlebensvorteil der SorafenibGruppe gegenüber der Placebo-Gruppe von 3 Monaten festgestellt (32), was im Rahmen der bisherigen palliativen systemische Therapien ein großer Durchbruch ist. Ähnliche Ergebnisse zeigte auch eine Phase-III-Studie im asiatischen Raum (12). Die Ergebnisse sind dennoch insgesamt nicht zufrieden stellend, die Prognose der Patienten bleibt schlecht.

\subsubsection{Hormon-, Gen- und Immuntherapie}

Da in ca. einem Drittel der hepatozellulären Karzinome Östrogenrezeptoren gefunden werden, wurde in verschiedenen Studien die Wirksamkeit des Antiöstrogens Tamoxifen evaluiert. Eine Metaanalyse von 10 randomisierten Studien konnte jedoch keinen Vorteil im Hinblick auf medianes Überleben und Tumorregression zeigen (41). 
Immunmodulatoren, wie das Interferon- $\alpha$ konnten sowohl in Mono-, als auch in Kombinationstherapien vergleichsweise gute Erfolge erzielen (27).

Die Gentherapie versucht z.B. die Expression von Onkogenen oder Tumorsuppressorgenen zu beeinflussen (52). Sie ist derzeit Gegenstand präklinischer Studien.

\subsection{Thymoquinon}

Thymoquinon (TQ) ist Bestandteil des schwarzen Kümmels (Nigella sativa Linne) aus der Familie der Ranunculaceae. In arabischen Ländern, rund um das Mittelmeer und in Regionen Afrikas wird schwarzer Kümmel schon seit Jahrhunderten angebaut und bei einer Vielzahl von Erkrankungen, vor allem des Verdauungstraktes, aber auch des Respirations-, Immun- und Kreislaufsystems angewandt. Thymoquinon ist das bioaktive Extrakt des Öls des schwarzen Kümmels und wurde zum ersten Mal 1963 von El-Dhakhakany beschrieben.

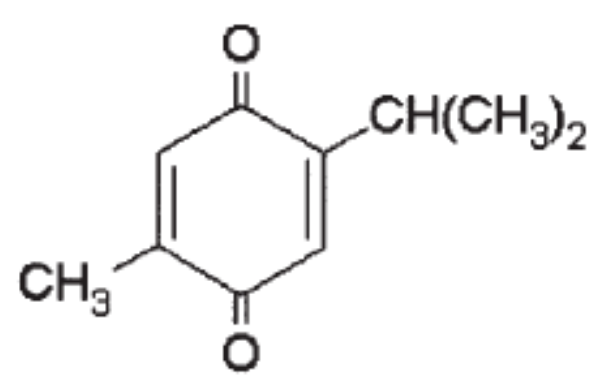

Abbildung 3: Struktur des Thymoquinons: 2-Isopropyl-5-Methyl-1,4-Benzoquinon (14)

In in vitro Studien und Tierversuchen wurden verschiedene Effekte des Thymoquinons bereits in Ansätzen evaluiert. So werden der Substanz neben antioxidativen und antiinflammmatorischen auch proapoptotische und antineoplastische Wirkungsweisen zugeschrieben.

Badary et. al untersuchten die antioxidative Wirkung von TQ und einer synthetisch hergestellten verwandten Substanz, dem tertiären Butylhydroquinon (THBQ). Beide Substanzen fungieren als Radikalfänger für Superoxidanionen und Hydroxy $(\mathrm{OH})$ Radikale (5). Auch Mansour et. al bewiesen, dass TQ und sein Metabolit Dihydrothymoquinon (DHTQ) spezifische Radikalfänger für Superoxidanionen aber auch für freie Radikale sind $(35,36)$.

Mansour et. al untersuchten die antiinflammatorische Wirkung von TQ. Sie beschrieben eine verminderte Bildung von den Entzündungsmediatoren Leukotrienen an humanen Blutzellen, u.a. in Granulozytensuspensionen. Der Effekt scheint auf eine Inhibition der 
5-Lipoxygenase und Leukotrien-C4-Synthase zurückzuführen $\mathrm{zu}$ sein, beides entscheidende Enzyme bei der Synthese der Entzündungsmediatoren aus dem Eicosanoid Arachidonsäure.

Für verschiedene Krebszelllinien konnten TQ antineoplastische und proapoptotische Effekte in in vitro Versuchen nachgewiesen werden. Shoieb et. al untersuchten u.a. Krebszelllinien des humanen Mammakarzinoms und Ovarialkarzinoms (50), GaliMuhtasib et. al evaluierten die antineoplastischen Effekte an neoplastischen Keratinozyten und Zellen des Kolonkarzinoms (HCT116)(20,21). Nicht-maligne Zellen waren hierbei resistenter gegen die TQ-vermittelte Apoptose.

Zellzyklusarrest und Apoptose werden laut Studienergebnissen p53-abhängig und -unabhängig durch TQ getriggert. p53 ist ein Tumorsuppressorgen, das als Transkriptionsfaktor bei Schäden an der DNA die Expression von bestimmten Genen der Apoptose und des Zellzyklus reguliert. So ist beispielsweise p21Waf1 ein Zielgen, welches im folgenden an Cdk/Cyclin-Komplexe bindet und zu einem Zellzyklusarrest in der G1-Phase führt. Ein Verlust an p53 erhöht die Wahrscheinlichkeit Malignome zu entwickeln (48).

In der bereits erwähnten in vitro Studie an den HCT116 Zellen wurde die p53abhängige, Apoptose steigernde Eigenschaft von TQ nachgewiesen. Hier kam es nach der Behandlung mit der Substanz zu einem vermehrten G1-Phase Arrest und einer 2,44,5-fach erhöhten p53-mRNA-Expression (20).

Thymoquinon scheint seine proapoptotische Wirkung aber nicht nur über p53abhängige Mechanismen zu entfalten, sondern auch über die Veränderung von Caspaseaktivitäten. Sogenannte Initiator- und Effektorcaspasen sind Enzyme, die sich kaskadenartig aktivieren, weitere Reaktionen katalysieren, wie z.B. die Freisetzung von Cytochrom c aus Mitochondrien, und so den programmierten Zelltod einleiten können. El-Mahdy et. al zeigten an myeloblastischen Leukämiezellen (p53 negativen HL-60Zellen), dass TQ über einer Aktivierung von Caspase-3 und Caspase-8 antiproliferativ wirkt und zudem Apoptose induziert (14). Auch konnte bei den pro- und antiapoptotischen Proteinen ein Anstieg des Bax/Bcl-2 Quotienten nachgewiesen werden.

Chemoprotektive Wirkung konnte in einer Studie am Tiermodell gezeigt werden. Hierbei wurde Mäusen zusätzlich zu der karzinogenen Substanz Benzopyren Thymoquinon als Trinkwasserzusatz appliziert. Benzopyren (1,2-Benzpyren) ist ein polyzyklischer aromatischer Kohlenwasserstoff, der u.a. auch in Zigarettenrauch 
enthalten ist. In den Versuchen konnte die Inzidenz der durch Benzopyren induzierten Vormagentumoren deutlich gesenkt werden (4).

In den letzten Jahren rücken immer mehr auch pflanzliche Substanzen und Naturextrakte in den Blickwinkel der Arzneimittelforschung. Zum einen wegen der meist geringeren Nebenwirkungen, zum anderen wegen der oft kostengünstigen Verfügbarkeit.

Thymoquinon spielt nun bereits seit Jahrhunderten eine Rolle in der Medizin des arabischen Raumes. Seine antiinflammatorische und antineoplastische Wirkung ist mittlerweise sowohl in vitro, als auch in vivo nachgewiesen. Die ansteigende Inzidenz des hepatozellulären Karzinoms und die vor allem bei inoperablen Tumoren weiterhin unzufrieden stellende Prognose stellen ein großes Problem dar. Das mediane Überleben nach Diagnosestellung beträgt derzeit nur zwischen 6 und 20 Monaten (1). Da TQ schon bei unterschiedlichen Krebszelllinien Erfolge gezeigt hat, soll diese Doktorarbeit nun die Wirkung auf Zellen des HCC evaluieren. Dies könnte vor allem deshalb interessant sein, weil das HCC ein Tumor ist, der in den meisten Fällen aus einer chronischen Entzündung hervorgeht. 


\section{Material und Methoden}

\subsection{Material}

\subsubsection{Zelllinien}

HepG2: adhärent wachsende humane Hepatomzellen ohne integriertes Hepatitis BVirus-Genom (ATCC HB-8065, Rockville, Maryland)

Hep3B: adhärent wachsende Hepatomzellen mit integriertem Hepatitis B-Virus-Genom (ATCC HB-8064, Rockville, Maryland)

HF: primäre humane Vorhautfibroblasten als nicht-maligne Kontrollzellen

\subsubsection{Nährmedien}

Die Reagenzien für die von uns genutzten Nährmedien stammen allesamt von der Firma Biochrom aus Berlin.

Für die HepG2-Zelllinie diente als Nährmedium das RPMI 1640. In der Zellkultur der Hep3B- und HF-Zellen nutzten wir das Dulbecco's modified Eagle's Medium.

Diese Grundmedien wurden jeweils mit einem $10 \%$ igen Anteil von fetal bovinem Serum aufgestockt. Zugesetzt wurden außerdem Penicillin $(10 \mathrm{mg} / \mathrm{ml})$ und Streptomycin $(10 \mathrm{mg} / \mathrm{ml})$ in einer Konzentration von je $1 \%$, sowie Gentamycin (10 $\mathrm{mg} / \mathrm{ml}$ ) in einer Konzentration von $0,5 \%$.

Die Reagenzien wurden unter sterilen Bedingungen den Grundmedien zugesetzt und entstammten sterilen Stammlösungen.

\subsubsection{Medikamente}

Thymoquinon wird hergestellt von der Sigma Aldrich Chemie GmbH in München.

\subsubsection{Fertigkits}

Tabelle 4: Fertigkits

\begin{tabular}{|l|l|}
\hline M30 Cyto Death & Roche, Mannheim, Deutschland \\
\hline $\begin{array}{l}\text { Mitochondrial Membrane Potential } \\
\text { Detection Kit (JC-1) }\end{array}$ & MobiTec, Göttingen, Deutschland \\
\hline Caspase-Glo 3/7 Assay Kit & Promega Corporation, Madison, WI, USA \\
\hline
\end{tabular}




\subsubsection{Antikörper}

Tabelle 5: Primäre Antikörper

\begin{tabular}{|l|l|l|l|}
\hline Antikörper & Spezies & Konzentration & Hersteller \\
\hline ß-Aktin & mouse & $1: 5000$ & $\begin{array}{l}\text { Sigma, Deisen- } \\
\text { hofen, Deutschland }\end{array}$ \\
\hline Bax & rabbit & $1: 500$ & $\begin{array}{l}\text { Abcam, Cambridge, } \\
\text { UK }\end{array}$ \\
\hline Bcl-2 & rabbit & $1: 750$ & $\begin{array}{l}\text { Abcam, Cambridge, } \\
\text { UK }\end{array}$ \\
\hline Caspase-3 & rabbit & $1: 750$ & $\begin{array}{l}\text { BD, Biosciences, } \\
\text { San Jose, CA, USA }\end{array}$ \\
\hline M30-Antikörper & mouse & $1: 50$ & $\begin{array}{l}\text { Roche, Mannheim, } \\
\text { Deutschland }\end{array}$ \\
\hline
\end{tabular}

Tabelle 6: Sekundäre Antikörper

\begin{tabular}{|l|l|l|}
\hline Antikörper & Konzentration & Hersteller \\
\hline Anti-mouse & $1: 1000$ & $\begin{array}{l}\text { Sigma, Deisenhofen, } \\
\text { Deutschland }\end{array}$ \\
\hline Anti-rabbit & $1: 1000$ & $\begin{array}{l}\text { Sigma, Deisenhofen, } \\
\text { Deutschland }\end{array}$ \\
\hline Anti-mouse-FITC & $1: 40$ & DAKO, Glostrup, Dänemark \\
\hline
\end{tabular}

\subsubsection{Lösungen und Puffer}

Tabelle 7: Lösungen und Puffer

\begin{tabular}{|l|l|}
\hline 0,1 M Glycin (zum Strippen) & $\begin{array}{l}3,75 \mathrm{~g} \text { Glycin } \\
500 \mathrm{ml} \mathrm{H}_{2} \mathrm{O} \text {; Einstellen auf } \mathrm{pH} 2,0\end{array}$ \\
\hline Blockierpuffer für Westernblot & $5 \mathrm{mg}$ Magermilchpulver \\
& $100 \mathrm{ml}$ 1x PBS 0,1 \% Twen 20 \\
\hline Propidiumjodidlösung & $2,5 \mathrm{mg}$ Propidiumjodid \\
& $50 \mathrm{mg}$ Natriumcitrat \\
& $50 \mu 1$ Triton X-100 \\
& auf $50 \mathrm{ml} 1 \mathrm{x}$ PBS \\
\hline Transferpuffer Westernblot & $84,9 \mathrm{ml}$ dest. Wasser \\
& $5 \mathrm{ml} 20 \mathrm{x}$ Transferpuffer (Invitrogen) \\
& $100 \mu 1$ Antioxidant NuPAGE \\
& $10 \mathrm{ml}$ Methanol \\
\hline Running Buffer Westernblot & $200 \mathrm{ml}$ MOPS-Puffer \\
\hline
\end{tabular}




\begin{tabular}{|c|c|}
\hline & $500 \mu 1$ Antioxidans (nupage invitrogen) \\
\hline MOPS-Puffer & $\begin{array}{l}475 \mathrm{ml} \text { dest. Wasser } \\
25 \mathrm{ml} \text { 20x MOPS-Stammlösung }\end{array}$ \\
\hline Waschpuffer M30-Antiköper & $\begin{array}{l}100 \mathrm{ml} 10 \mathrm{x} \text { PBS } \\
900 \mathrm{ml} \text { destilliertes Wasser } \\
1000 \mu 1 \text { Twen } 20\end{array}$ \\
\hline 10x PBS & 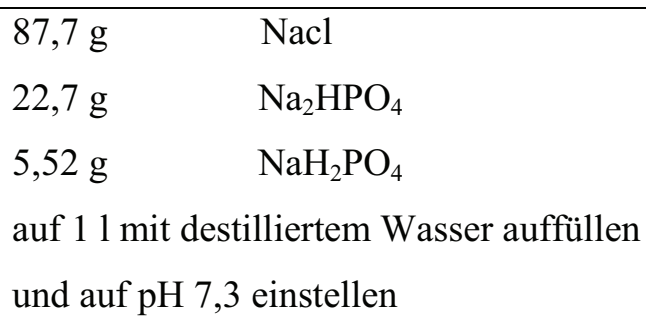 \\
\hline Blockierpuffer M30 Antikörper & $\begin{array}{l}1 \mathrm{x} \text { PBS } \\
0,1 \% \text { Twen } 20 \\
0,3 \% \text { BSA }\end{array}$ \\
\hline Inkubationspuffer M30 Anitkörper & $\begin{array}{l}1 \mathrm{x} \text { PBS } \\
0,1 \% \text { Twen } 20 \\
1 \% \text { BSA }\end{array}$ \\
\hline $\begin{array}{l}\text { Entwicklerflüssigkeit ECL für } \\
\text { Westernblot }\end{array}$ & $\begin{array}{l}20 \mathrm{ml} \text { Solution A } \\
4 \mathrm{ml} \text { Solution } \mathrm{B} \\
12 \mu 1 \mathrm{H}_{2} \mathrm{O}_{2}\end{array}$ \\
\hline Solution A für ECL & $\begin{array}{l}200 \mathrm{ml} \text { 0,1 M Tris } \mathrm{HCl}(\mathrm{pH} 8,6) \\
50 \mathrm{mg} \text { Luminol }\end{array}$ \\
\hline Solution B für ECL & $\begin{array}{l}11 \mathrm{mg} \text { para-Hydroxycoumarinsäure } \\
10 \mathrm{ml} \text { DMSO }\end{array}$ \\
\hline Jie's-Lyse-Puffer & $\begin{array}{l}200 \mu 1 \mathrm{NaCl} \\
250 \mu 1 \mathrm{NP} 4 \mathrm{O} \\
200 \mu 1 \text { Tris-HCl pH 7,4 } \\
50 \mu 1 \mathrm{MgCl}_{2} \\
1 \text { Tablette Complete, Prot-I } \\
100 \mu 1 \text { PMSF } \\
9200 \mu 1 \text { destilliertes Wasser }\end{array}$ \\
\hline Minimalmedium & $\begin{array}{l}\text { Nährmedium } \\
0,125 \% \text { FCS } \\
1 \% \text { Penicillin } \\
1 \% \text { Streptomycin } \\
0,5 \% \text { Gentamycin }\end{array}$ \\
\hline
\end{tabular}




\subsubsection{Geräte}

Tabelle 8: Geräte

Analysenwaage
Autoklav
Biofuge
Brutschrank Hera Cell
ELISA-READER
Eismaschine
FACS-Durchflusszytometer
Feinwaage
Gelelektrophorese-Apparatur
Heizblock
Herafreeze (-80 ${ }^{\circ} \mathrm{C}$ Schrank)
Labofuge 400 R
Magnetrührer
Megafuge 1.0R (Tischzentrifuge)
Mikroliterpipetten $(20 \mu 1,200 \mu 1,1000 \mu 1)$
Mikroskop Axiostar
Mikroskop Axiovert 25
Multipette
Neubauer-Zählkammer
pH-Meter MP 220
Photoanlage Intelligent Dark Box
Picofuge
Pipettierhilfe
Pipettierhilfe pipetus classic
Schüttler
Spannungsgerät LNG $350-03$
Sterilbank
Vortexer Genie 2 TM
Wasserbad

Sartorius, Göttingen, Deutschland

Deutsch \& Neumann, Berlin, Deutschland

Heraeus Christ, Osterode, Deutschland

Heraeus Christ, Osterode, Deutschland

BIO-TEK Instrument, USA

Ziegra, Isernhagen, Deutschland

BD Biosciences, San Jose, USA

Sartorius, Göttingen, Deutschland

GibcoBRL, Karlsruhe, Deutschland

Behr Labortechnik, Düsseldorf, Deutschland

Heraeus Christ, Osterode, Deutschland

Heraeus Christ, Osterode, Deutschland

Heidolph, Schwabach, Deutschland

Heraeus Christ, Osterode, Deutschland

Abimed, Langenfeld, Deutschland

Zeiss, Oberkochen, Deutschland

Zeiss, Oberkochen, Deutschland

Eppendorf, Hamburg, Deutschland

Roth, Karlsruhe, Deutschland

Mettler, Toledo, Schweiz

Fuji Foto Film, Düsseldorf, Deutschland

Tomy, Japan

Integra Biosiences, Brand, Deutschland

Hirschmann, Heilbronn, Deutschland

Stone und Shaker, Deutschland

Pharmacia Biotech, Freiburg, Deutschland

Nuair, Plymouth, USA

Bender + Hobein AG, Zürich, Schweiz

Braun, Melsungen, Deutschland

\subsubsection{Chemikalien und Verbrauchsmittel}

Tabelle 9: Chemikalien und Verbrauchsmittel

12 \% bis-Tris Gele
3,3',5,5'-Tetramethylbenzidin (TMB)
6-Amonium-n-Hexanonsäure
6-Well-Platten
96-Well-Platten
Albumin, Bovine (BSA)
Antifading-Eindeckmedium
Antioxidant NuPAGE
Bromphenolblau
Caspase-Glo 3/7 Buffer
Caspase-Glo 3/7 Substrate

$12 \%$ bis-Tris Gele

3,3',5,5'-Tetramethylbenzidin (TMB)

6-Amonium-n-Hexanonsäure

ell-Platten

Albumin, Bovine (BSA)

Antifading-Eindeckmedium

Antioxidant NuPAGE

Bromphenolblau

Caspase-Glo 3/7 Substrate
Invitrogen, Carlsbad, CA, USA

Sigma, Steinheim, Deutschland

Sigma, Steinheim, Deutschland

BD Biosciences, San Jose, CA, USA

BD Biosciences, San Jose, CA, USA

Sigma, Steinheim, Deutschland

DAKO, Glostrup, Dänemark

Invitrogen, Carlsbad, CA, USA

Merck, Darmstadt, Deutschland

Promega, Madison, WI, USA

Promega, Madison, WI, USA 


\begin{tabular}{|c|c|}
\hline Chamber Slide & Nalge Nunc International, New York, USA \\
\hline Combitips & Eppendorf, Hamburg, Deutschland \\
\hline Deckgläser & Roth, Karlsruhe, Deutschland \\
\hline Diethyl-Pyrocarbonat & Sigma, Steinheim, Deutschland \\
\hline Di-Natriumhydrogenphosphat $\left(\mathrm{Na}_{2} \mathrm{HPO}_{4}\right)$ & Merck, Darmstadt, Deutschland \\
\hline Dithiothreitol (DTT) & Serva, Heidelberg, Deutschland \\
\hline Dulbecco's modified Eagle's Medium DMEM & Biochrom, Berlin, Deutschland \\
\hline ECL, Western Blot Detection Reagent & Amersham Pharmacia, San Francisco,USA \\
\hline Eppendorf Reaktionsgefäße (2 ml; 1,5 ml) & Eppendorf, Hamburg, Deutschland \\
\hline Ethanol & Merck, Darmstadt, Deutschland \\
\hline Ethylendiamintetraacetat (EDTA) & Sigma, München, Deutschland \\
\hline FACS-Röhrchen (5 ml ) & BD Biosciences, San Jose, CA, USA \\
\hline FACS Clean & BD Biosciences, San Jose, USA \\
\hline FACS Rinse & BD Biosciences, San Jose, USA \\
\hline Falcon ${ }^{\circledR}$ Tubes $(15 \mathrm{ml}$ und $50 \mathrm{ml})$ & BD Biosciences, San Jose, USA \\
\hline Fetales Kälberserum (FKS) & Biochrom, Berlin, Deutschland \\
\hline Filterpapier & Whatman, Brentford, UK \\
\hline Gentamycin $(10 \mathrm{mg} / \mathrm{ml})$ & Biochrom, Berlin, Deutschland \\
\hline Glycerol & Merck, Darmstadt, Deutschland \\
\hline Glycin & Roth, Karlsruhe, Deutschland \\
\hline Harnstoff & Merck, Darmstadt, Deutschland \\
\hline Kryoröhrchen (2 ml) & Nalge Nunc International, New York, USA \\
\hline Kunststoffpipettenspitzen & Eppendorf, Hamburg, Deutschland \\
\hline Kunststoffspritzen & Braun, Melsungen, Deutschland \\
\hline LDS Sample Buffer NuPAGE & Invitrogen, CArlsbad, CA, USA \\
\hline M30-Cytodeath & Roche, Mannheim, Deutschland \\
\hline Magermilch & Heirler, Radolfzell, Deutschland \\
\hline Methanol & Merck, Darmstadt, Deutschland \\
\hline MultiMark (Multi-Colored Standard) & Novex, San Diego, USA \\
\hline Natrium-EDTA & Serva, Heidelberg, Deutschland \\
\hline Natriumchlorid & Merck, Darmstadt, Deutschland \\
\hline Natriumhydroxid & Sigma, Steinheim, Deutschland \\
\hline Natriumhydrogenphosphat $\left(\mathrm{NaH}_{2} \mathrm{PO}_{4}\right)$ & Merck, Darmstadt, Deutschland \\
\hline NEM (N-Ethylmaleimide) & Serva, Heidelberg, Deutschland \\
\hline Nitrocellulose Transfer Membrane & Schleicher und Schüll, Dassal, Deutschland \\
\hline Panceaurot & Sigma, Steinheim, Deutschland \\
\hline PBS Dulbecco’s & Biochrom, Berlin, Deutschland \\
\hline Penicillin $(10 \mathrm{mg} / \mathrm{ml})$ & Biochrom, Berlin, Deutschland \\
\hline Petrischalen & Greiner, Nürtingen, Deutschland \\
\hline PMSF (Phenylmethylsulfonylfluorid) & Serva, Heidelberg, Deutschland \\
\hline Propidium Iodid (PI) & Sigma, Steinheim, Deutschland \\
\hline Protein Assay Reagent (BCA) & Pebro Science, Bonn, Deutschland \\
\hline Reagenzgläser (10 ml) & Sarstedt, Nürnbrecht, Deutschland \\
\hline RPMI 1640 & Biochrom, Berlin, Deutschland \\
\hline Sample Reducing Agent NuPAGE & Invitrogen, Carlsbad, CA, USA \\
\hline Salzsäure & Merck, Darmstadt, Deutschland \\
\hline Schwefelsäure $\left(\mathrm{H}_{2} \mathrm{SO}_{4}\right)$ & Merck, Darmstadt, Deutschland \\
\hline SDS (Sodiumdodecylsulfat=Laurylsulfat) & Serva, Heidelberg, Deutschland \\
\hline
\end{tabular}




\begin{tabular}{|ll|}
\hline Sterilpipetten (Stripetten; $5 \mathrm{ml}, 10 \mathrm{ml}, 25 \mathrm{ml})$ & Corning, Lindfield, Australien \\
Streptomycin $(10 \mathrm{mg} / \mathrm{ml})$ & Biochrom, Berlin, Deutschland \\
Tribase & Merck, Darmstadt, Deutschland \\
Tris-HCl & Merck, Darmstadt, Deutschland \\
Trypanblau & Sigma, Steinheim, Deutschland \\
Trypsin & Biochrom, Berlin, Deutschland \\
Tween ${ }^{\circledR} 20$ & Sigma, Steinheim, Deutschland \\
Western-Blot Paper & Schleicher und Schüll, Dassal, Deutschland \\
Zellkulturflaschen $\left(25,75\right.$ und $\left.175 \mathrm{~cm}^{2}\right)$ & Nalge Nunc International, New York, USA \\
Zellzahl-Röhrchen $(5 \mathrm{ml})$ & Greiner, Nürtingen, Deutschland \\
\hline
\end{tabular}

\subsection{Methoden}

\subsubsection{Zellkultur und Passagierung}

Die Kultivierung der adhärenten Zellen fand im Wärmeschrank bei $37{ }^{\circ} \mathrm{C}$ und $5 \% \mathrm{CO}_{2}$ in $175 \mathrm{~cm}^{2}$ großen Kulturflaschen statt. Das vorbereitete Nährmedium wurde hinzugefügt. Alle 2-3 Tage erfolgte unter dem Mikroskop die Kontrolle des Zellwachstums, sowie unter sterilen Bedingungen der Austausch des verbrauchten gegen ca. $30 \mathrm{ml}$ frischen Nährmediums.

Bei einer Konfluenz von etwa $70 \%$ wurde eine neue Passage angesetzt. Hierzu wurde das Nährmedium abpipettiert und die Zellen wurden mit $10 \mathrm{ml}$ Dulbecco's PBS gewaschen. Danach wurden die Zellen in $10 \mathrm{ml}$ Trypsin-EDTA-Lösung für, je nach Zellreihe, 3-7 Minuten bei $37{ }^{\circ} \mathrm{C}$ inkubiert. Hierbei lösten sich die Zellen von der Kulturflasche und wurden mit der Trypsinlösung in eine Pipette aufgenommen.

$1 \mathrm{ml}$ dieser Resuspension wurde als fortlaufende Passage in einer neuen $175 \mathrm{~cm}^{2}$ Zellkulturflasche mit $30 \mathrm{ml}$ sterilem Nährmedium weiterkultiviert.

\subsubsection{Auftauen von Zellen}

Die bei $-80{ }^{\circ} \mathrm{C}$ im Gefrierschrank gelagerten Zellen wurden im Wasserbad bei $37{ }^{\circ} \mathrm{C}$ aufgetaut. Es wurden $10 \mathrm{ml}$ Nährmedium in ein $15 \mathrm{ml}$ Falcon Tube vorgelegt und die aufgetaute Zellsuspension hinzugefügt. Die Suspension wurde bei Raumtemperatur für 10 min. bei 1000 rpm zentrifugiert. Der Überstand wurde abpipettiert und das Zellpellet mit $10 \mathrm{ml}$ frischem Medium resuspendiert, wobei die Suspension mehrfach auf- und abpipettiert wurde. Die im Medium resuspendierten Zellen wurden in $175 \mathrm{~cm}^{2}$ Zellkulturflaschen pipettiert und im Brutschrank bei $37{ }^{\circ} \mathrm{C}$ nach Standardprotokoll kultiviert. 


\subsubsection{Herstellen des Medikaments}

Thymoquinon in pulverisierter Form wurde auf eine Konzentration von $10000 \mu \mathrm{M}$ berechnet und abgewogen. Auf 82,1 mg Thymoquinon wurden 2,5 ml DMSO gegeben. Dies wurde mit weiteren 47,5 ml Nährmedium aufgefüllt. Das Medikament konnte so bei $-20^{\circ} \mathrm{C}$ für 6 Monate aufbewahrt werden.

Für die Durchführung der Experimente wurde die $10000 \mu \mathrm{M}$ Stocklösung mit sterilem Nährmedium auf $1000 \mu \mathrm{M}, 100 \mu \mathrm{M}, 10 \mu \mathrm{M}, 1 \mu \mathrm{M}$ und $0,1 \mu \mathrm{M}$ verdünnt.

\subsubsection{Bestimmung der Zellzahl}

Um das Wachstum der Zelllinien unter Einfluss von Thymoquinon beurteilen zu können wurde die Zellzahl bestimmt. Die Zellzahl wurde in der Neubauer Zählkammer zu den Zeitpunkten 24 h, 48 h, 72 h, 96 h, 120 h ausgezählt. Bei den Versuchszeiten 24 h, 48 h, $72 \mathrm{~h}$ wurden die Vertiefungen der 6-Well-Zellkulturplatten mit einer Anfangszellzahl von 150.000 bestückt, bei den Stundenwerten $96 \mathrm{~h}$ und $120 \mathrm{~h}$ mit einer Anzahl von 50.000. $24 \mathrm{~h}$ nach Kultivierung der Zellen in den 6-Well-Zellkulturplatten wurden die Zellen mit den jeweiligen Medikamentenkonzentrationen behandelt. Es wurde eine unbehandelte Kontrolle, sowie die Konzentrationen $1000 \mu \mathrm{M}, 100 \mu \mathrm{M}, 50 \mu \mathrm{M}, 10 \mu \mathrm{M}$, $1 \mu \mathrm{M}$ und $0,1 \mu \mathrm{M}$ in dem Versuch mitgeführt.

Das überstehende Nährmedium wurde von den Vertiefungen abpipettiert und verworfen. Die Zellen wurden mit $1 \mathrm{ml}$ Dulbecco's PBS gewaschen, auch der Puffer wird verworfen. Zum Ablösen wurden die Zellen in $500 \mu 1$ Trypsin bei $37{ }^{\circ} \mathrm{C}$ im Wärmeschrank inkubiert. Die Zellsuspension wird mit $1 \mathrm{ml}$ Nährmedium in ein $5 \mathrm{ml}$ Zellzahl-Röhrchen gegeben. Nach Durchmischen der Suspension mittels Vortex wurden $10 \mu 1$ in die Neubauerzählkammer pipettiert, unter dem Mikroskop ausgezählt und auf Zellzahl/ml umgerechnet. Der Versuch wird je Konzentration und Zeitpunkt dreifach durchgeführt.

\subsubsection{FACS-Analyse}

Die Apoptoserate wurde durchlaufzytometrisch nach Propidiumjodidfärbung bestimmt (FACS $=$ fluorescence activated cell sorting). Die Messungen erfolgten zu den gleichen Zeitpunkten und mit den gleichen Medikamentenkonzentrationen wie auch bei der Zellzahlbestimmung.

Nach entsprechender Inkubation der Zellen mit dem Medikament wurde das Nährmedium abgenommen und in ein FACS-Tube pipettiert. Die Zellen wurden standardmäßig mit Dulbecco's PBS gewaschen und mit Trypsin gelöst. Die in Trypsin 
gelösten Zellen wurden ebenfalls in das Tube gegeben. Die befüllten Tubes wurden für 10 min mit 10.000 rpm bei Raumtemperatur zentrifugiert. Der entstehende Überstand wurde verworfen, das Zellpellet wurde mit $200 \mu$ l hypotoner Propidiumjodidlösung resuspendiert, auf Eis gelagert und inkubierte für mindestens $1 \mathrm{~h}$ bei $4^{\circ} \mathrm{C}$ unter Lichtabschluss.

Propidiumjodid (PI) ist ein Fluoreszenzfarbstoff, der mit doppelsträngiger DNA interkaliert. Das vom Fluoreszenzfarbstoff emittierte Licht wird von den Photodetektoren des FACS Calibur (Becton Dickinson, Heidelberg) gemessen. PI emittiert bei $612 \mathrm{~nm}$ eine rötliche Fluoreszenz, die durch den Fluoreszenzdetektor FL$2 \mathrm{H}$ erfasst wird.

Bei jeder Probe erfolgte die Messung von 10.000 Ereignissen, bei denen der DNAGehalt durch die Cell Quest Software BD, Heidelberg ermittelt wurde. Durch den DNA-Gehalt konnten die Phasen des Zellzyklus und somit auch die apoptotischen Zellen erkannt werden. In der G0-Phase und in der präsynthetischen G1-Phase besitzen die Zellen einen diploiden Chromosomensatz (2n). Auf die G1-Phase folgt die S-Phase, in der die DNA verdoppelt wird. So liegt anschließend in der G2-Phase der replizierte Chromosomensatz (4n) vor. Bei der Mitose (M-Phase) werden die Chromosomen gleichmäßig auf die beiden entstehenden Tochterzellen verteilt. Die Tochterzellen befinden sich nun in der G1-/G0-Phase mit 2n.

In Apoptose befindliche Zellen haben fragmentierte DNA, so dass alle Zellen mit subdiploidem DNA-Gehalt als apoptotische Ereignisse gewertet wurden.

\subsubsection{BrdU-Inkorporations-ELISA}

Bromodesoxyuridin (BrdU) ist ein Pyrimidinanalogon, das bei der DNA-Replikation anstelle des Thymidins in die neu entstehende DNA eingebaut wird. Durch Bindung eines sekundären BrdU-Antikörpers kann das BrdU im ELISA-Reader nachgewiesen werden. So ermöglicht diese Methode es, die in der Synthesephase des Zellzyklus befindlichen bzw. neu entstandenen Zellen einer Zellpopulation zu erkennen.

Zunächst wurden die Zellen für $24 \mathrm{~h}$ in Minimalmedium inkubiert, um eine Synchronisation des Zellzyklus herzustellen. Dann wurden pro Vertiefung der 96-wellMikrotiterplatte 5000 Zellen ausgesetzt und mit $225 \mu 1$ Medikament in entsprechender Konzentration behandelt. Eine Menge von $25 \mu 1$ BrdU-Labeling-Solution wurde hinzupipettiert. Nach Ablauf der Inkubationszeit wurden die Zellen durch $200 \mu 1$ der ethanolhaltigen Fixdenat Lösung für $30 \mathrm{~min}$ bei Raumtemperatur fixiert und anschließend mit $100 \mu \mathrm{l}$ monoklonalem Maus-anti-BrdU-Antikörper (1:100 mit 
Antibody-labeling-solution versetzt) für eine Stunde bei Raumtemperatur inkubiert. Nach Ablauf der Stunde folgte dreimaliges Waschen mit PBS und schließlich wurden $100 \mu \mathrm{l}$ Tetramethylbenzidin-Substratlösung hinzugegeben. Nach fünf Minuten Inkubation wurde diese Reaktion durch $1 \mathrm{M} \mathrm{H}_{2} \mathrm{SO}_{2}(25 \mu \mathrm{l} /$ Vertiefung) gestoppt, was durch einen Farbumschlag von blau nach gelb sichtbar wurde. Weitere fünf Minuten später konnte die Farbintensität bei 650 nm photometrisch im ELISA-Reader gemessen werden.

\subsubsection{Mitochondriales Membranpotential (JC-1)}

Das Absinken des mitochondrialen Membranpotentials ist ein wichtiger Vorgang beim Ablauf des intrinsischen Weges der Apoptose. Der Fluoreszenzfarbstoff JC-1 (5,5',6,6'tetrachloro-1,1',3,3'-tetrabenzimidazolo-carbocyaninjodid) kann zur Messung des mitochondrialen Membranpotentials genutzt werden, da er in Abhängigkeit vom Membranpotential aggregiert und dabei seine Fluoreszenzeigenschaften ändert. Als Monomer emittiert JC-1 bei $525 \mathrm{~nm}$ grüne Fluoreszenz. Nach der Aggregation entstehen Dimere, die bei $590 \mathrm{~nm}$ rot-orangefarbenes Licht emittieren. Mittels Durchflusszytometrie kann diese Fluoreszenzänderung gemessen werden.

Nach der Inkubationszeit mit Thymoquinon wurden die Zellen mit Trypsin/EDTA abgelöst und bei Raumtemperatur für $10 \mathrm{~min}$ bei $1000 \mathrm{rpm}$ zentrifugiert. Der Überstand wurde verworfen, das Zellpellet wurde weiterbehandelt.

Auf fertige, tiefgekühlte JC-1 Lösung wurde $990 \mu 1$ warmes Nährmedium gegeben und für $1 \mathrm{~min}$ bei $13000 \mathrm{rpm}$ zentrifugiert. Danach wurde der Überstand in ein neues Eppendorf Cup pipettiert und hiervon jeweils $500 \mu 1$ auf die Zellpellets gegeben. Diese Lösung inkubierte für 15 min bei $37^{\circ} \mathrm{C}$ und wurde daraufhin bei Raumtemperatur für 5 min bei $400 \mathrm{rpm}$ zentrifugiert. Der Überstand wurde verworfen. Diese Arbeitsschritte erfolgten nach Möglichkeit unter Lichtabschluss.

Hierauf folgten zwei Waschgänge mit 1x Assay Puffer, bei denen jeweils für 5 min bei $400 \mathrm{rpm}$ zentrifugiert und der Überstand jeweils verworfen wurde. Zuletzt wurden die Pellets in $200 \mu 1 \mathrm{1x}$ Assay Puffer resuspendiert und am Durchflußzytometer mittels FSC-SSC Diagramm gemessen. Für jede Probe wurden drei unabhängige Experimente mit je 10.000 gemessenen Ereignissen durchgeführt.

Die Versuche wurden nicht für alle Konzentrationen durchgeführt, sondern nur für aussagekräftige Konzentrationen zu bestimmten Zeitpunkten. 


\subsubsection{Qualitativer Apoptosenachweis durch Immunfluoreszenzfärbung von Zytokeratin-18-Fragmenten (M30-Antikörper)}

Das Zytokeratin-18 hat im nativen Zustand keine Bindungsstelle für M30-CytodeathAntikörper. Wird das Zytokeratin-18 in einem frühen Stadium der Apoptose durch Caspasen fragmentiert, entstehen Bindungsstellen für den Antikörper.

Durch Immunfluoreszenz mittels sekundärem anti-Maus Antikörper wird die Bindung des M30-Antikörpers an die in Apoptose befindlichen Zellen nachgewiesen und unter dem Fluoreszenzmikroskop beurteilt.

Die Messungen erfolgten bei allen 3 Zelllinien zum Zeitpunkt $24 \mathrm{~h}$ mit den Konzentrationen $100 \mu \mathrm{M}, 10 \mu \mathrm{M}$ und einer Negativkontrolle, sowie zum Zeitpunkt $48 \mathrm{~h}$ mit der Konzentration $10 \mu \mathrm{M}$.

Die Zellen wurden auf Chamber-Slides ausgesetzt und laut Protokoll mit Medikament behandelt.

Das Nährmedium wurde entfernt und die Zellen in $-20^{\circ} \mathrm{C}$ kaltem Methanol für $30 \mathrm{~min}$ fixiert. Danach wurden sie zwei Mal für 10 min in Waschpuffer gewaschen und ein Mal für 10 min in Blockierpuffer inkubiert. Nach erneutem 10-minütigem Waschen wurden die Objektträger mit $100 \mu$ M30-Primärantikörper (bei 1:50 Verdünnung mit Inkubationspuffer, siehe 3.1.6 Lösungen und Puffer) beschichtet und für $60 \mathrm{~min}$ bei Raumtemperatur in der feuchten Kammer inkubiert.

Nach weiterem 2-maligem Waschen werden die Objektträger 30 min lang bei Raumtemperatur unter Alufolienabdeckung mit sekundärem Antikörper (Anti-mouseFITC 1: 40 gelöst in 1x PBS mit 0,5\% BSA) bedeckt.

Danach folgte kurzes Ausschwenken der Objektträger in Waschpuffer, Benetzten mit Antifading-Eindeckmedium der Firma Dako Cytomatics und Abdecken der Objektträger mit Deckgläschen.

Mit einem Zeiss Axioplan-Mikroskop bei $519 \mathrm{~nm}$ und 400 bis 1000 facher Vergrößerung wurden die Präparate begutachtet. Die Nachbearbeitung und Herstellung digitaler Bilder erfolgte mittels Openlab Software (Improvision, Heidelberg, Deutschland).

\subsubsection{Semiquantitativer Westernblot}

Mittels semiquantitativem Westernblot wurde die Änderung der Expression von apoptoserelevanten Proteinen unter dem Einfluss von Thymoquinon gemessen.

Zunächst erfolgte die Proteinisolation aus den Zellen. Hierzu wurden die Zellen in üblicher Weise von den Zellkulturflaschen abgelöst. Sowohl die in Trypsin/EDTA 
gelösten Zellen, als auch das verbrauchte Nährmedium und der PBS Dulbecco`s Puffer wurden in $15 \mathrm{ml}$ Falcon Tubes gesammelt und für $10 \mathrm{~min}$ bei $10.000 \mathrm{rpm}$ und $4{ }^{\circ} \mathrm{C}$ zentrifugiert. Der Überstand wurde verworfen und das Zellpellet in $200 \mu 1$ Jie's-Lyse Puffer in einem Eppendorf Cup resuspendiert, so das eine Durchmischung und Zelllyse erfolgte. Die Eppendorf Cups wurden für 30 min auf Eis gestellt und zwischendurch 2-3 Mal mittels Vortex durchmischt. Zuletzt wird die Lösung für $30 \mathrm{~min}$ und $13.000 \mathrm{rpm}$ bei $4{ }^{\circ} \mathrm{C}$ zentrifugiert. Der Überstand, der die Proteine enthält, wird bei $-80{ }^{\circ} \mathrm{C}$ tiefgefroren, die Pellets werden verworfen.

Die Bestimmung des Proteinanteils der Proben erfolgte nach Behandlung mit BCA (protein assay reagent) und photometrischer Messung mittels ELISA Reader bei $490 \mathrm{~nm}$. Dazu wurden die zur Verfügung gestellten Lösungen nach Angabe des Herstellers gemischt und mit $15 \mu \mathrm{l}$ Zelllysat für $30 \mathrm{~min}$ bei $37{ }^{\circ} \mathrm{C}$ inkubiert. Die Proteinkonzentration konnte anhand einer Standardkurve bestimmt werden.

Vor der Elektrophorese mussten den Proteinen verschiedene Gebrauchslösungen der Firma Invitrogen zugesetzt werden. Um eine Lösungsmenge von $20 \mu \mathrm{zu}$ erhalten, wurde auf $13 \mu 1$ Proteinprobe jeweils $2 \mu 1$ Sample Reducing Agent und $5 \mu$ LDS Sample Buffer pipettiert. Die Lösung wurde dann für 10 min auf $70^{\circ} \mathrm{C}$ erhitzt.

Die fertigen Proteingebrauchslösungen wurden in äquivalenten Proteinmengen in die Gelkammern der 12 \% Bis-Tris Gele der Firma Invitrogen pipettiert. In die jeweils erste Kammer des Gels wurden $10 \mu 1$ Größenstandard gegeben. Elektrophoretisch getrennt wurden die Proteine über einen Zeitraum von 50 min mit dem Programm 200 V, 125 mA.

Zum Blotten der Proteine wurde das Gel auf eine Schicht mit Transferpuffer getränkter Nitrocellulosemembran gelegt. Sowohl unter der Nitrocellulosemembran, als auch auf das Gel wurden 2 Schichten Filterpapier gelegt, welche auch mit Transferpuffer getränkt wurden. Geblottet wurden die Proteine für $30 \mathrm{~min}$ bei $100 \mathrm{~V}$ und $125 \mathrm{~mA}$.

Zum Nachweis der Proteine auf der Nitrocellulosemembran wurde die Membran nach dem Blotvorgang kurz in 1x PBS 0,1\% Twen 20 geschwenkt und dann für 2-3 min in Pancaeu-Rot-Lösung gelegt.

Nach weiteren 10 min Waschen in 1x PBS 0,1\% Twen 20 wurden die Blots in $50 \mathrm{ml}$ Falcon Tubes mit Blockierpuffer gelegt. Vor dem Hinzufügen der Primärantikörper mussten die Blots entweder für 30 min bei Raumtemperatur oder über Nacht bei $4{ }^{\circ} \mathrm{C}$ im Kühlraum gelagert werden. Nach dem Lagern in Blockierpuffer wurde ein dreimaliger Waschvorgang mit 1x PBS 0,1\% Twen 20 für jeweils $10 \mathrm{~min}$ bei Raumtemperatur vorgenommen. Darauf folgte ein 30-minütiges Inkubieren mit 
primärem Antikörper bei Raumtemperatur. Vor und auch nach dem Inkubieren mit sekundärem Antikörper für $90 \mathrm{~min}$, wurden die Blots erneut dreimaligen Waschvorgängen mit 1x PBS 0,1\% Twen 20 unterzogen.

Entwickelt wurden die Blots mit selbst hergestelltem ECL-Chemilumineszenz-Reagenz in der Dunkelkammer.

\subsubsection{Bestimmung der Caspase-3 Aktivität}

Die Caspase-3 ist ein zentrales Enzym in der Signaltransduktion der Apoptose. Die Caspase-3 ist eine sogenannte Effektorcaspase. Das Enzym liegt inaktiv vor und wird selbst erst während der Apoptose durch sogenannte Initiatorcaspasen aktiviert, um dann weitere Reaktionen der Signaltransduktion zu katalysieren.

Zur Caspase-3 Bestimmung wurden equivalente Proteinmengen in 96-well Platten pipettiert. Caspase-Glo 3/7 Substrat und Caspase-Glo 3/7 Buffer wurden in den vom Hersteller vorgegebenen Mengen miteinander vermischt und $100 \mu 1$ dieser Lösung wurde jeweils auf die Proben pipettiert.

Die Lumineszenzmessung erfolgte über $3 \mathrm{~h}$ in Abständen von 30 min im Luminometer bei einer Temperatur von $37^{\circ} \mathrm{C}$. 


\section{Ergebnisse und Daten}

\subsection{Bestimmung der Zellzahl}

Die Bestimmung der Zellzahl erfolgte bei allen 3 Zelllinien nach einer Inkubation mit Thymoquinon zu den Zeitpunkten 24 h, 48 h, 72 h, 96 h und 120 h. Es wurden Medikamentenkonzentrationen zwischen $0,1 \mu \mathrm{M}$ und $1000 \mu \mathrm{M}$ gewählt.

Bei der Zelllinie Hep3B zeigte sich ab einer Medikamentenkonzentration von $100 \mu \mathrm{M}$ ein Abfall der Zellzahl. Nach 24 Stunden betrug dieser Abfall 95,4 \% gemessen am Wachstum der unbehandelten Kultur und steigerte sich kontinuierlich auf 99,3\% nach 120 Stunden.

Bei einer höheren Konzentration von $1000 \mu \mathrm{M}$ sank die Zellzahl nach 24 Stunden bereits um 93,1\%, um nach 120 Stunden um weitere ca. $5 \%$ auf 99,8 \% zu sinken. Nach einem Absinken der Zellzahl auf 53,8 \% im Vergleich zur Kontrolle bei einer Konzentration von $50 \mu \mathrm{M}$ nach $72 \mathrm{~h}$, erholte sich die Zellkultur und es kam zu einem Wiederanstieg der Zellzahl auf 105,3 \% nach $96 \mathrm{~h}$ und 82,2 \% nach $120 \mathrm{~h}$. Konzentrationen von $10 \mu \mathrm{M}$ führten $2 \mathrm{Mal}$ zu signifikantem Absinken der Zellzahl. Zum Zeitpunkt 24 h auf 69,8 \% und zum Zeitpunkt 96 h auf 69,9\%.

Bei Inkubation von Zellen mit $1 \mu$ molarer Thymoquinonlösung sank nach 72 Stunden die Zellzahl auf 71,3\% im Vergleich zur unbehandelten Kontrolle, stieg dann aber wieder an und erreichte bei $120 \mathrm{~h}$ ein Maximum von 106 \%. Die Schwankungen der Zellzahlmenge bei $0,1 \mu \mathrm{M}$ sind im Bereich der Kontrolle und unsignifikant.

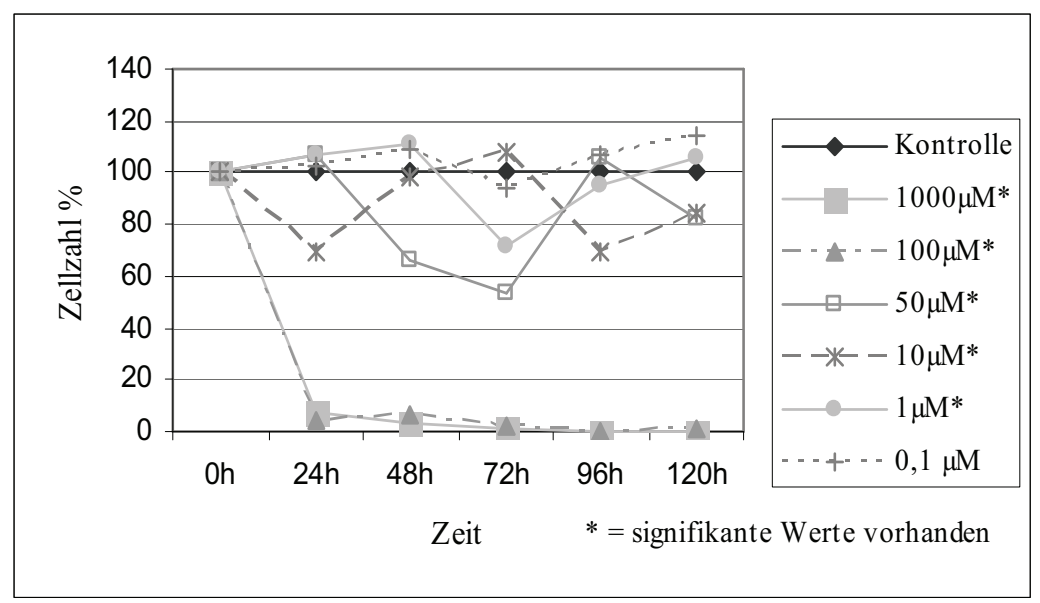

Abbildung 4: Zellzahl der Hep3B-Zellen nach Inkubation mit Thymoquinon

Bei Zellen der HepG2-Kultur zeigte sich bei Konzentrationen von $50 \mu \mathrm{M}, 100 \mu \mathrm{M}$ und $1000 \mu \mathrm{M}$ ein kontinuierliches Absinken der Zellzahl. Sowohl bei der $100 \mu \mathrm{M}$, als auch bei der $1000 \mu \mathrm{M}$-Lösung lag der Abfall der Zellzahl nach $24 \mathrm{~h}$ bereits bei über $99 \%$ und blieb bei den späteren Zeitwerten konstant auf diesem Niveau. Die Zellzahl fiel bei 
der $50 \mu \mathrm{M}$-Lösung nach $24 \mathrm{~h}$ auf 40,7\% und schließlich nach $120 \mathrm{~h}$ auf 9,9\% vitale Zellen im Vergleich zur Kontrolle.

Bei Konzentrationen $\leq 50 \mu \mathrm{M}$ zeigten sich nur jeweils $\mathrm{zu}$ einzelnen Zeitpunkten signifikante Abfälle der Zellzahl, die sich wieder erholten.

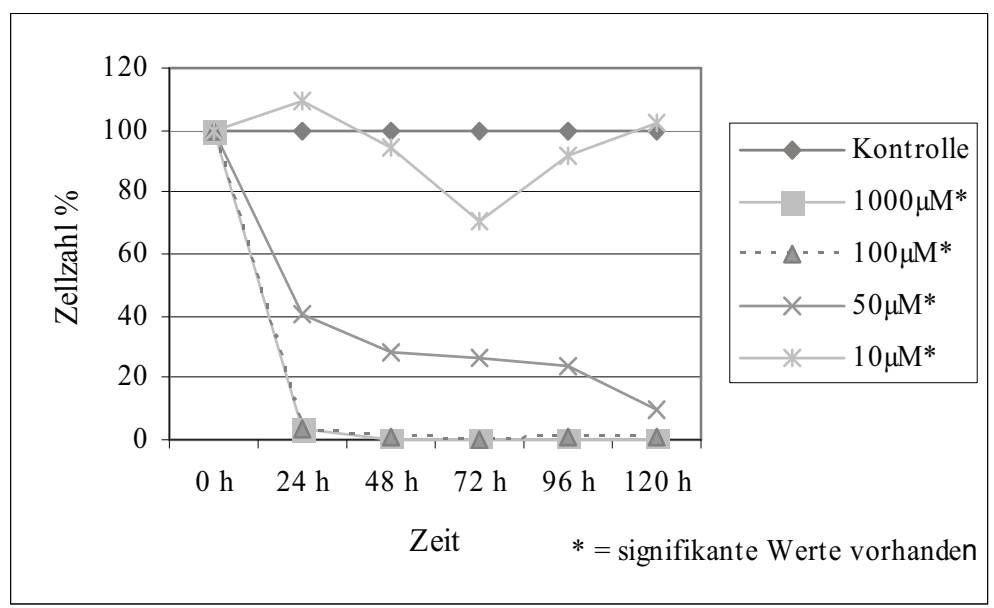

Abbildung 5: Zellzahl der HepG2-Zellen nach Inkubation mit Thymoquinon

Bei einer Konzentration von $1000 \mu \mathrm{M}$ waren bei den HF-Zellen bereits nach $24 \mathrm{~h}$ keine vitalen Zellen mehr nachweisbar. Bei einer Medikamentenkonzentration von $100 \mu \mathrm{M}$ zeigte sich ein Abfall der Zellzahl um 98,3 \% schon nach 24 h, nach 120 h wurden 98,7 \% erreicht. Die HF-Zellen zeigten bei $50 \mu \mathrm{M}$-Lösung zunächst einen signifikanten Anstieg der Zellzahl auf 164,2 \% nach 24 Stunden und 217,6 \% nach 96 Stunden, um dann nach 120 h auf einen unsignifikanten Wert von 133,1 \% abzufallen. Die humanen Fibroblasten zeigten bei Konzentrationen $\leq 10 \mu \mathrm{M}$ keine signifikanten Wachstumsveränderungen im Vergleich zur unbehandelten Kontrolle.

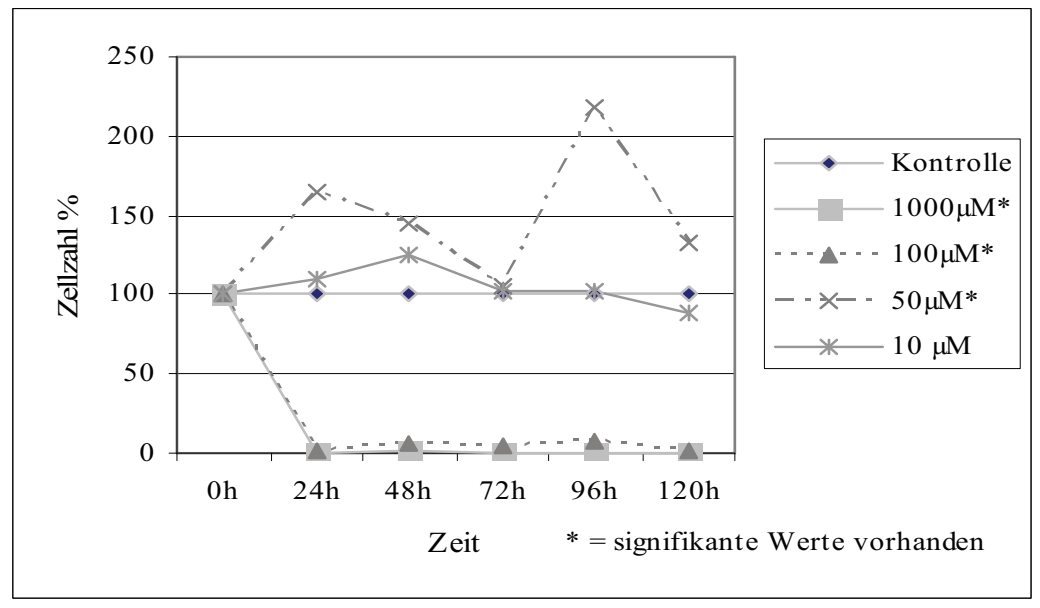

Abbildung 6: Zellzahl der HF-Zellen nach Inkubation mit Thymoquinon 


\subsection{Bestimmung der Apoptoseinduktion mittels FACS-Analyse}

Mittels Durchflußzytometer (FACS) wurde die Apoptoserate nach Applikation von Thymoquinon quantifiziert. Alle 3 Zelllinien wurden hierbei zu den Zeitpunkten $24 \mathrm{~h}$, $48 \mathrm{~h}, 72 \mathrm{~h}, 96 \mathrm{~h}$ und $120 \mathrm{~h}$ zusätzlich zu einer Kontrolle mit Medikamentenkonzentrationen zwischen $0,1 \mu \mathrm{M}$ und $1000 \mu \mathrm{M}$ behandelt.

Bei allen drei Zelllinien zeigten sich bei den ersten Messungen wider Erwarten relativ gleich hohe Apoptoseraten für alle Konzentrationen inklusive der Probe ohne TQZusatz. Beispielhaft in Abbildung 7 gezeigt.

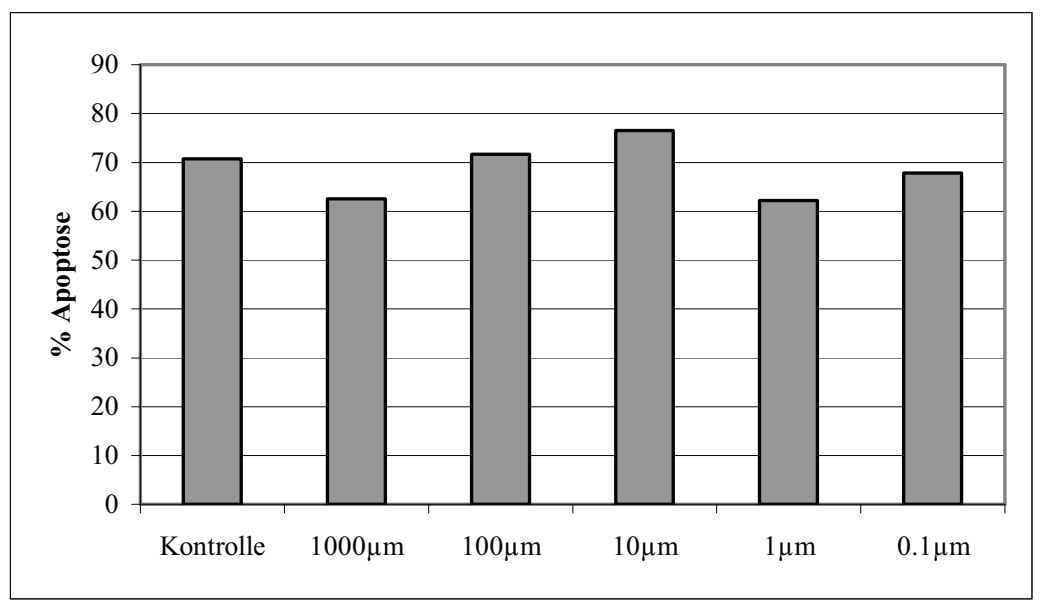

Abbildung 7: HepG2 nach 96 h TQ-Inkubation

Dies ließ auf einen Fehler bei den Materialien oder der Durchführung der Versuche schließen. Daraufhin wurden sowohl Nährmedien und Thymoquinonlösungen, als auch die Brutschränke auf mögliche Kontamination untersucht. Die Versuchsabläufe und Handlungen wurden erneut evaluiert und als fehlerfrei befunden. Schließlich wurde vermutet, dass TQ bei Brutschranktemperatur teilweise verdampft und dann in benachbarten wells der 6-well-Platten wieder kondensiert. So ließen sich die hohen Apoptoseraten in der Negativkontrolle und den niedrigen Konzentrationen erklären. Um diese Vermutung zu verifizieren wurden daraufhin immer nur Proben mit gleichen TQKonzentrationen in einer 6-well-Platte angesetzt. Mit diesem Versuchsaufbau zeigten sich erwartungsgemäß niedrige Apoptoseraten in den Negativkontrollen. Die Ergebnisse der verschiedenen Konzentrationsansätze korrelierten mit den Ergebnissen der relativen Zellzahlbestimmung, bei der von vornherein die Konzentrationen getrennt voneinander angesetzt waren. Im weiteren wurden die Versuche unter Berücksichtigung dieser Erkenntnis durchgeführt.

Auf die Zellen der Hep3B-Linie begann die Wirkung von Thymoquinon bereits nach $24 \mathrm{~h}$ einzusetzen. Bei einer Konzentration von $1000 \mu \mathrm{M}$ betrug die Apoptoserate $45,97 \%$ nach $24 \mathrm{~h}$, nach $48 \mathrm{~h}$ wurde ein Maximum von 84,81\% erreicht. 
Auch bei der $100 \mu \mathrm{M}$-Lösung wurde nach $24 \mathrm{~h}$ mit einer Apoptoserate von 41,24 \% ein erster Effekt erreicht, der mit 91,01 \% Apoptosrate nach $48 \mathrm{~h}$ nochmals mehr als verdoppelt wurde. Die 120-stündige Inkubation erbrachte mit 61,02 \% keinen Vorteil mehr gegenüber dem $96 \mathrm{~h}$ Wert.

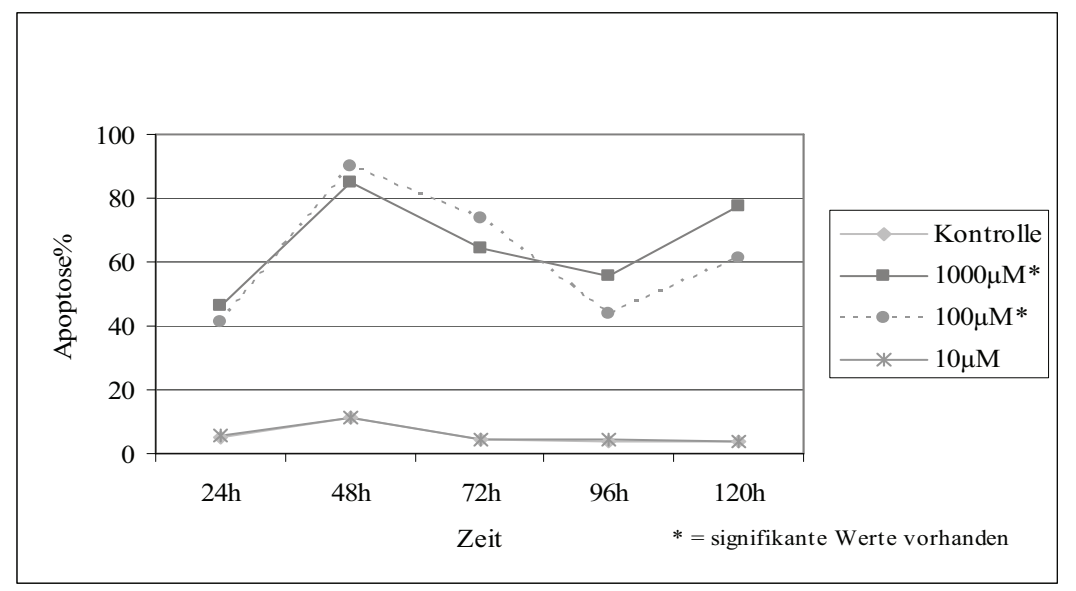

Abbildung 8: Apoptoserate in \% der Hep3B-Zellen nach Inkubation mit Thymoquinon

Um besser eingrenzen zu können, ab welcher Konzentration signifikante Wirkung eintritt, wurde bei einer späteren Passage der Kultur eine weitere Messung mit 50 $\mu$ molarer Lösung zusätzlich vorgenommen. Hier zeigte sich neben vergleichsweise hohen Apoptoserate in der Kontrolle erstmals nach $120 \mathrm{~h}$ ein signifikanter Anstieg der Apoptoserate auf $13,15 \%$ bei $50 \mu \mathrm{M}$.

Konzentrationen $\leq 50 \mu \mathrm{M}$ zeigten keine Signifikanz.

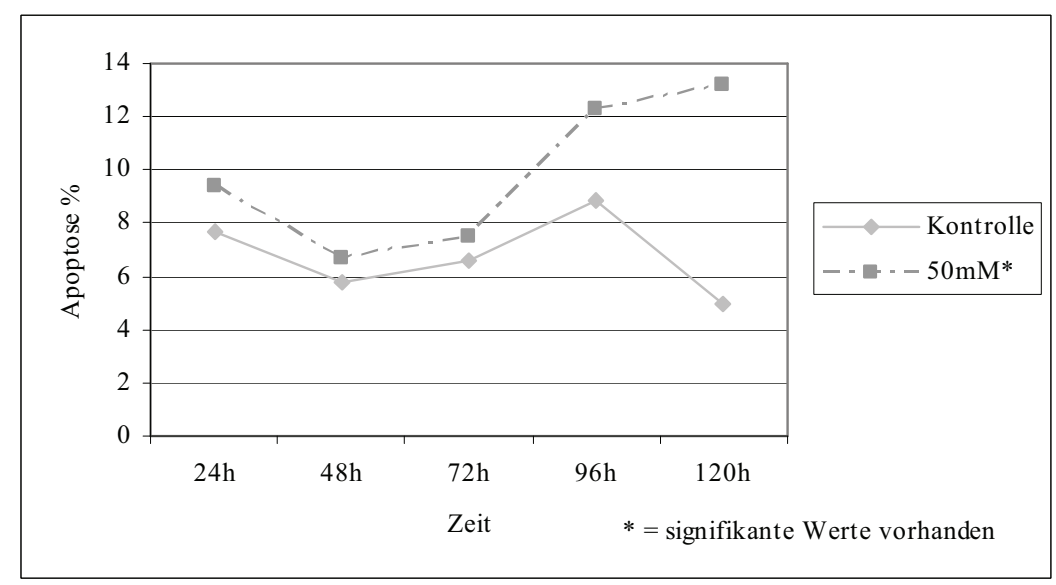

Abbildung 9: Apoptoserate in \% der Hep3B-Zellen nach Inkubation mit Thymoquinon

Das Wachstum der HepG2-Zellen zeigte bei $100 \mu \mathrm{M}$ und $1000 \mu \mathrm{M}$ ebenfalls nach $24 \mathrm{~h}$ erste Veränderungen. Bei Inkubation mit der $1000 \mu \mathrm{M}$-Lösung ergab sich eine Apoptoserate von 15,65 \%, bei $100 \mu \mathrm{M}$ sogar von 30,9 \%. Nach längerer Inkubationszeit konnte eine weitere Steigerung der Apoptoserate gezeigt werden. Bei 
Inkubation mit $1000 \mu \mathrm{M}$ wurde nach $48 \mathrm{~h}$ ein Anstieg auf 26,9\% und nach $72 \mathrm{~h}$ auf $31,5 \%$ erreicht.

Bei der $100 \mu \mathrm{M}$-Lösung stieg die Rate von 30,9\% bei der ersten Messung nach $24 \mathrm{~h}$ Inkubationszeit auf 52,7 \% nach $48 \mathrm{~h}$ und nach $120 \mathrm{~h}$ auf ein Maximum von 57, 8 \%.

Auch bei der HepG2-Zelllinie wurde die $50 \mu \mathrm{m}$ Konzentration bei einer fortgeschrittenen Passage nachgemessen. Lediglich der 24-Stunden-Wert mit 13,23 \% Apoptose war signifikant, zu späteren Zeitpunkten war die Rate im Bereich der Kontrolle. Konzentrationen $\leq 50 \mu \mathrm{M}$ zeigten keine Signifikanz.

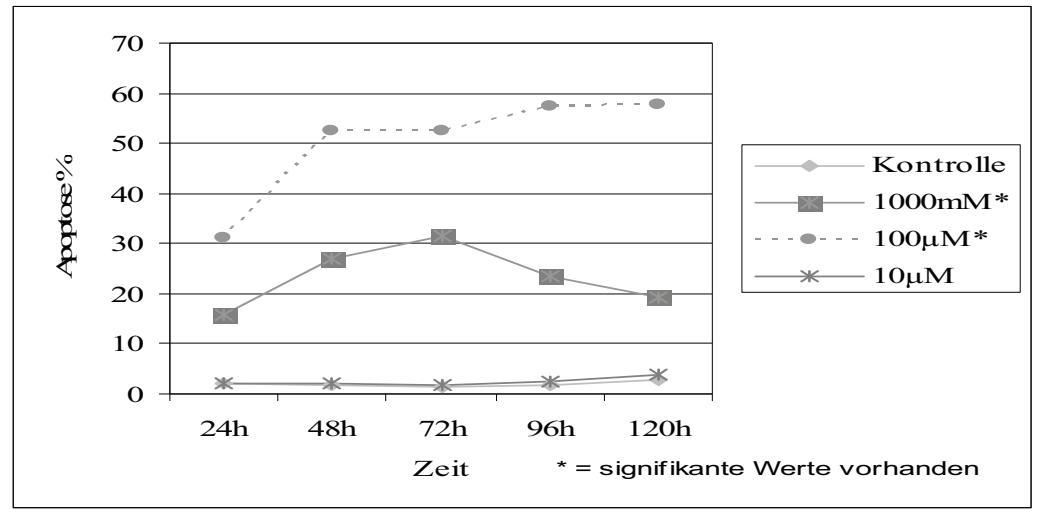

Abbildung 10: Apoptoserate in \% der HepG2-Zellen nach Inkubation mit Thymoquinon

Das Wachstum der HF-Zellen zeigte im Vergleich zur Kontrolle bei Konzentrationen $\leq$ $10 \mu \mathrm{M}$ keine signifikanten Veränderungen. Bei der $50 \mu \mathrm{M}$ Lösung dagegen stieg die Apoptoserate abrupt nach $96 \mathrm{~h}$ auf 93,44 \% und nach $120 \mathrm{~h}$ auf 81,23\% an.

Bei der $100 \mu \mathrm{M}$ Konzentration stieg die Apoptoserate bereits nach $24 \mathrm{~h}$ auf 77,98 \% an. Sie stieg dann mit Ausnahme eines Ausreißers zum Zeitpunkt 48 h kontinuierlich bis schließlich 99,31\% an.

Bei Inkubation mit $1000 \mu$ molarer Lösung kam es zu einem stetigen Ansteigen der Apoptoserate von 18,67\% nach 24 h über 36,96\% nach 72 h bis auf 79,29\% zum Zeitpunkt $120 \mathrm{~h}$.

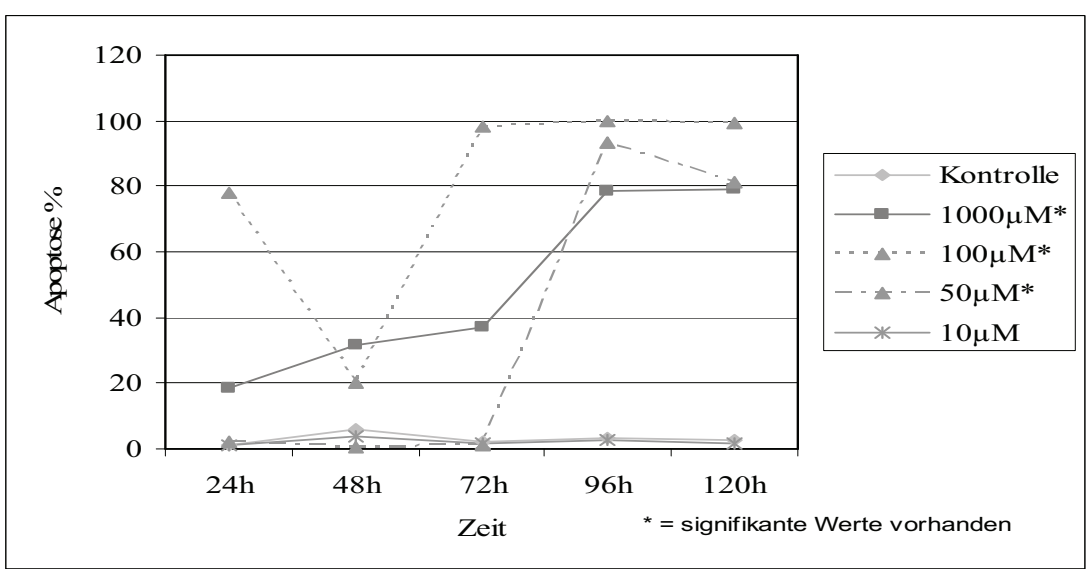

Abbildung 11: Apoptoserate in \% der HF-Zellen nach Inkubation mit Thymoquinon 


\subsection{Ergebnisse BrdU-Inkorporations-ELISA}

Mit Hilfe des BrdU-Inkorporations-Elisas können durch Einbau von Pyrimidinanaloga neu entstandene bzw. in der Synthesephase des Zellzyklus befindliche Zellen nachgewiesen werden.

Die Messung erfolgte bei allen drei Zelllinien zum Zeitpunkt 24 Stunden bei Konzentrationen zwischen $0,1 \mu \mathrm{M}$ und $1000 \mu \mathrm{M}$.

Bei der HF-Zelllinie konnten bei $1000 \mu \mathrm{M}$ und $100 \mu \mathrm{M}$ signifikant weniger BrdUPyrimidinanaloga nachgewiesen werden als bei der Kontrolle. Bei der höheren Konzentration lag der relative Wert bei $54,8 \%$, bei $100 \mu \mathrm{M}$ sogar nur bei $44 \%$. Konzentrationen $\leq 10 \mu \mathrm{M}$ blieben ohne Signifikanz.

Die Zellen der HepG2-Kultur zeigten nur bei einer Konzentration von $1000 \mu \mathrm{M}$ einen signifikant geringeren Einbau des Pyrimidinanalogons nach 24 Stunden. So lag der Wert 18,2 \% unter dem der Kontrolle. Bei $100 \mu$ molarer Lösung war ein Mindereinbau von $14,7 \% \mathrm{zu}$ verzeichnen, dieser war jedoch wie auch die Werte der niedrigeren Konzentrationen nicht signifikant.

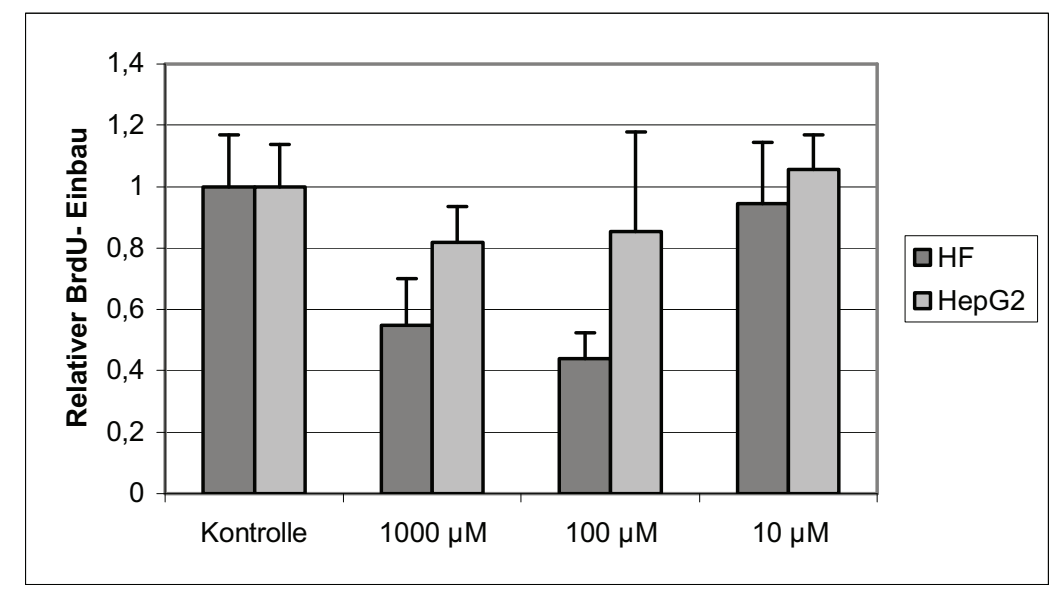

Abbildung 12: Relativer BrdU-Einbau bei HepG2- und HF-Zellen nach 24 h Inkubation mit Thymoquinon

Die Messungen der Hep3B-Zelllinie zeigten überraschend bei allen Konzentrationen signifikante Ergebnisse. Hier lassen sich jedoch vor allem bei Betrachtung der Grafik beträchtliche Unterschiede ausmachen. So liegt der BrdU-Einbau bei $1000 \mu \mathrm{M}$ und 100 $\mu \mathrm{M}$ mit $49 \%$ bzw. 46,9 \% im Vergleich zur Kontrolle weitaus geringer als bei Konzentrationen $\leq 10 \mu \mathrm{M}$. Hier zeigt sich immerhin noch ein Einbau von 82,7 \% bis hin zu 90,4 \% im relativen Vergleich zu unbehandelten Kontrolle. 


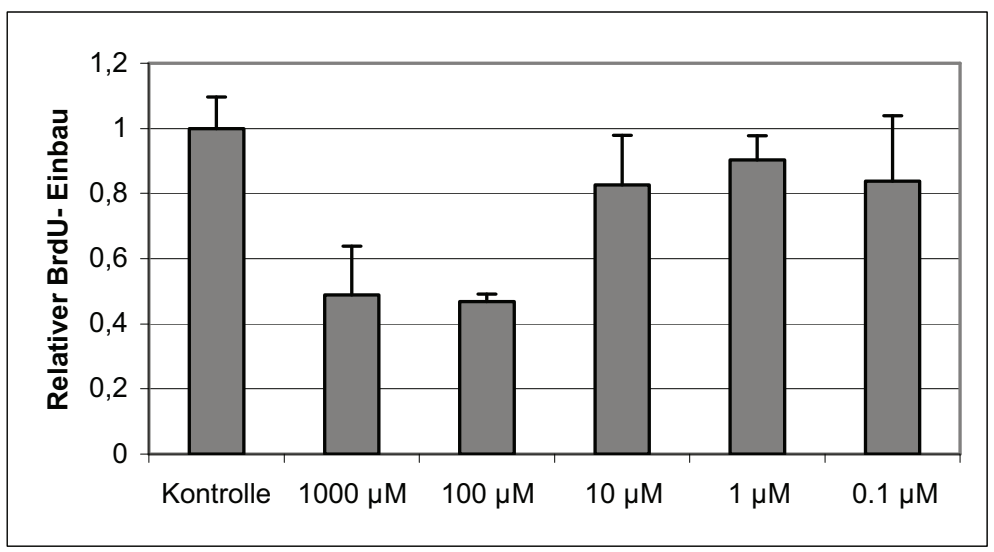

Abbildung 13: Relativer BrdU-Einbau bei Hep3B-Zellen nach 24 h Inkubation mit Thymoquinon

\subsection{Ergebnisse mitochondriales Membranpotential (JC-1)}

Beim Ablauf der Apoptose kommt es zum Absinken und schließlich zum Zusammenbruch des mitochondrialen Membranpotentials $\left(\Delta \Psi_{\mathrm{m}}\right)$.

Dieser Vorgang kann mittels des Fluoreszenzfarbstoffes JC-1 nachgewiesen werden, der durch Aggregation seine Fluoreszenzeigenschaften verändert. Mit Hilfe des Durchflusszytometers wurden diese Veränderungen der Fluoreszenz zum Zeitpunkt $24 \mathrm{~h}$ bei der HepG2- und Hep3B-Zelllinie für je eine Kontrolle, sowie $100 \mu \mathrm{M}$ und 10 $\mu \mathrm{M}$ bestimmt.

Bei 525 nm emittiert JC-1 als Monomer grüne Fluoreszenz. Nach Aggregation abhängig vom Membranpotential entstehen Dimere, die bei $590 \mathrm{~nm}$ rot-orangefarbenes Licht emittieren, was als Maß intakter Mitochondrien gilt.

Nach 24 Stunden Inkubation wurde bei der unbehandelten Hep3B-Zelllinie eine rote Fluoreszenz als Maß an intakten Mitochondrien von 44,23 \% nachgewiesen. Die mit $100 \mu$ molarer Lösung behandelten Zellen zeigten ein massives Absinken der roten Fluoreszenz auf 2,57\%. Diese Werte korrelierten mit den ebenfalls gemessenen Apoptosewerten, die bei der Kontrolle bei 1,99\% lagen und bei $100 \mu \mathrm{M}$ auf $31 \%$ anstiegen. Bei $10 \mu \mathrm{M}$ Konzentration war die Apoptoserate mit 2,18 \% im Bereich der Kontrolle und passend hierzu war auch die Anzahl intakter Mitochondrien mit 62,23 \% sehr hoch. 


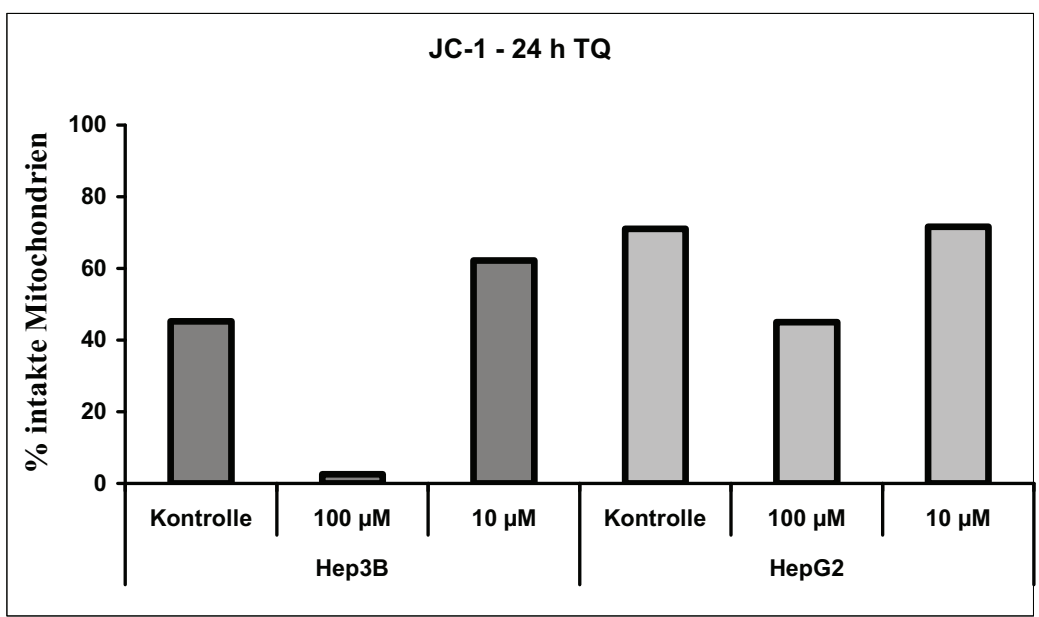

Abbildung 14: Nachweis intakter Mitochondrien durch JC-1-Fluoreszenz bei HepG2- und Hep3BZellen

Ähnlich verhielt es sich bei den HepG2-Zellen. Die unbehandelte Kontrolle zeigte eine rote Fluoreszenz von $71,05 \%$, ebenso wie die Zellen der $10 \mu$ molaren Lösung mit einem Wert von 71,67\%. Bei $100 \mu \mathrm{M}$ Konzentration war auch hier mit $45 \%$ eine deutliche Abnahme roter Fluoreszenz nachweisbar.

Die Apoptosewerte zeigten passend zum Abfall roter Fluoreszenz einen Anstieg der Rate von ca. $1 \%$ bei Kontroll- und $10 \mu \mathrm{M}$-Lösungspopulation auf 77,98 \% bei $100 \mu \mathrm{M}$ Lösung.

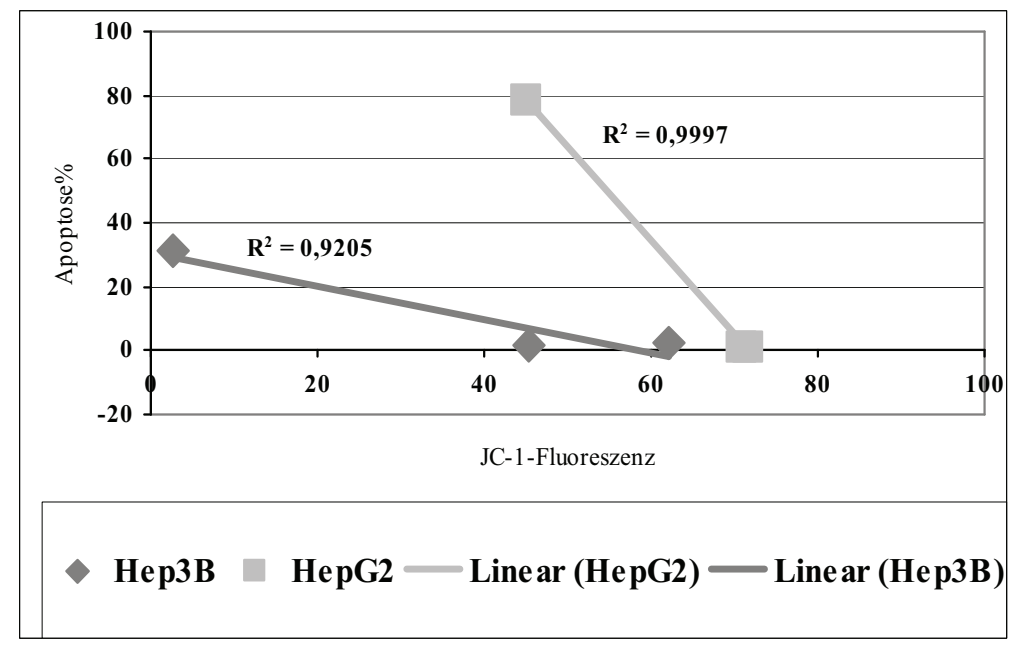

Abbildung 15: Apoptosewerte und JC-1-Fluoreszenz bei HepG2- und Hep3B-Zellen

Wie Abbildung 15 zeigt, fanden sich hohe Korrelationskoeffizienten von $\mathrm{R}^{2}=0,9205$ bei den HepB3-Zellen und $\mathrm{R}^{2}=0,9997$ bei den HepG2-Zellen in Bezug auf die Parameter Apoptose und JC-1-Fluoreszenz. 


\subsection{Ergebnisse der Immunfluoreszenzfärbung von Zytokeratin-18-Fragmenten} (M30-Antikörper)

Zytokeratin-18 wird im frühen Stadium der Apoptose durch die Effektorcaspasen 3 und

7 gespalten. An die hierbei entstehenden Fragmente können die M30-CytodeathAntikörper und in einem zweiten Schritt Fluoreszein-gekoppelte sekundäre Antikörper binden.

Die Präparate wurden mit Hilfe des Fluoreszenzmikroskops Zeiss Axioplan bei einer Filterung von $519 \mathrm{~nm}$ beurteilt.

Bei allen drei Zelllinien wurde zum Zeitpunkt 24 h eine unbehandelte Kontrolle, eine Konzentration von $100 \mu \mathrm{m}$ und eine $10 \mu$ molare Zellkultur betrachtet. Zusätzlich erfolgte nach $48 \mathrm{~h}$ bei allen verwendeten Zelllinien eine Auswertung von Präparaten mit $10 \mu$ molarer Konzentration.

Die mikroskopische Untersuchung der Hep3B-Zellen zeigte in der unbehandelten Kontrolle zum Zeitpunkten 24 Stunden einen dichten Zellrasen ohne signifikante M30Signale. Bei Behandlung der Zellen mit $10 \mu \mathrm{M}$ Thymoquinon lässt sich nach $24 \mathrm{~h}$ neben einer Reduktion der Zelldichte, eine Abkugelung der Zellen mit angehobenem M30Signal erkennen. Ein ähnliches Bild zeigt sich bei gleicher Konzentration nach 48 Stunden Inkubationszeit. Eine hohe Konzentration von $100 \mu \mathrm{M}$ führt praktisch zu einem kompletten Fehlen vitaler Zellen.

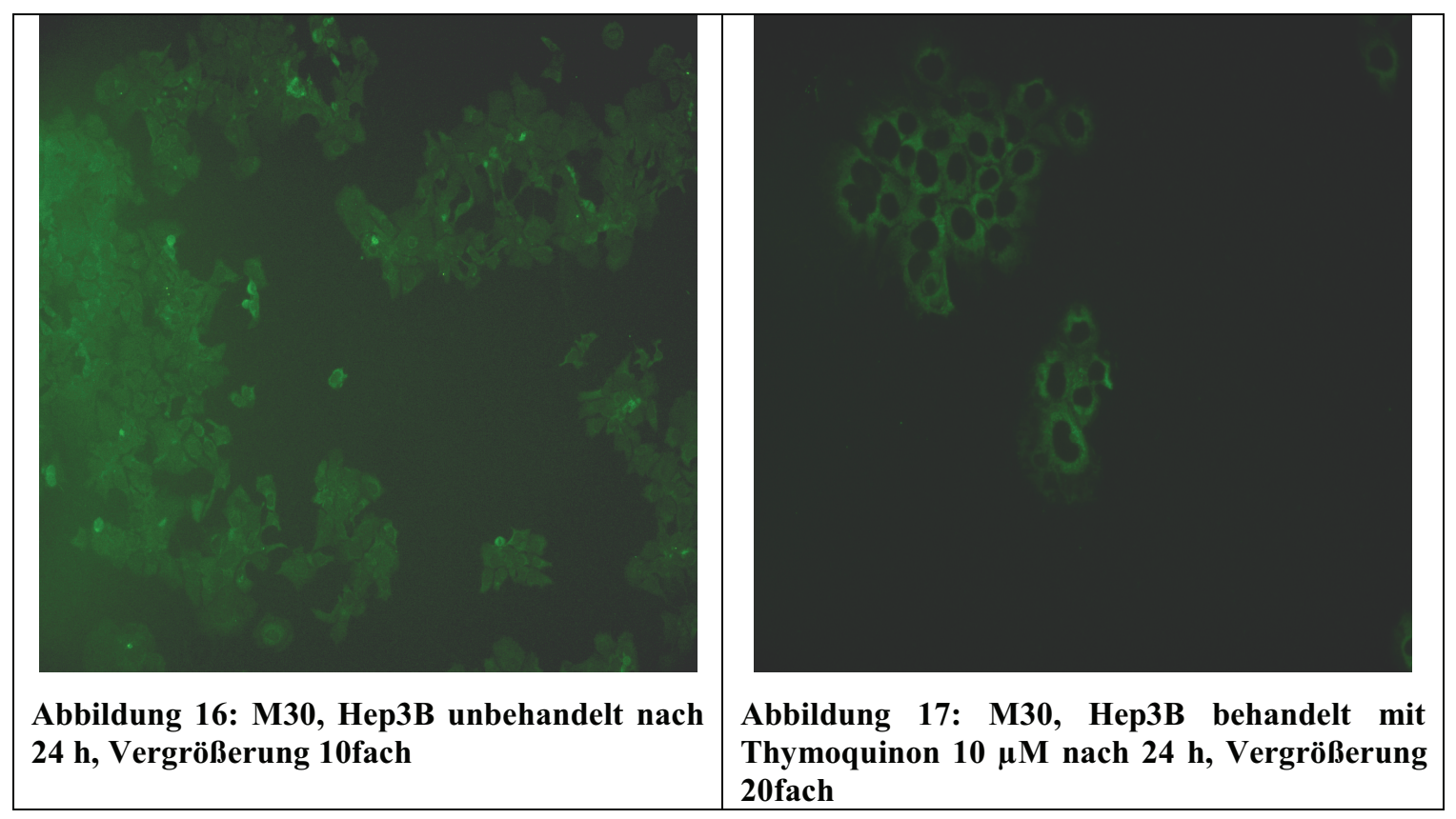




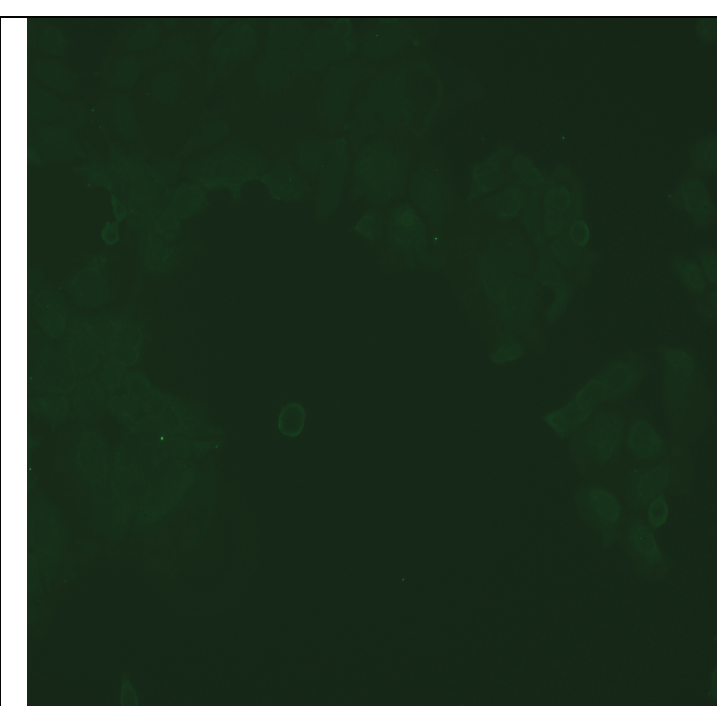

Abbildung 18: M30, Hep3B behandelt mit Thymoquinon $10 \mu \mathrm{M}$ nach $48 \mathrm{~h}$, Vergrößerung 20 fach

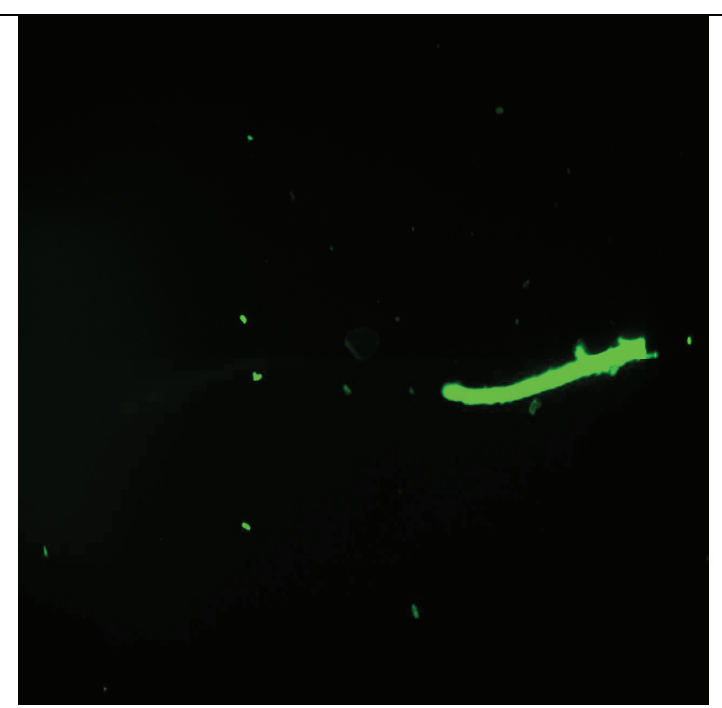

Abbildung 19: M30, Hep3B behandelt mit Thymoquinon $100 \mu \mathrm{M}$ nach $24 \mathrm{~h}$, Vergrößerung 5 fach

Die HF-Zellen zeigen sowohl in der unbehandelten Kontrolle, als auch bei $10 \mu \mathrm{M}$ keine M30-Signale und eine dichte Zellpopulation bei 24 und 48 Stunden Inkubationszeit. Bei $100 \mu \mathrm{M}$ Konzentration kommt es neben einer Ausdünnung der Zelldichte auch zu einer Abkugelung der Zellen und einer vermehrter M30-Signalintensität.

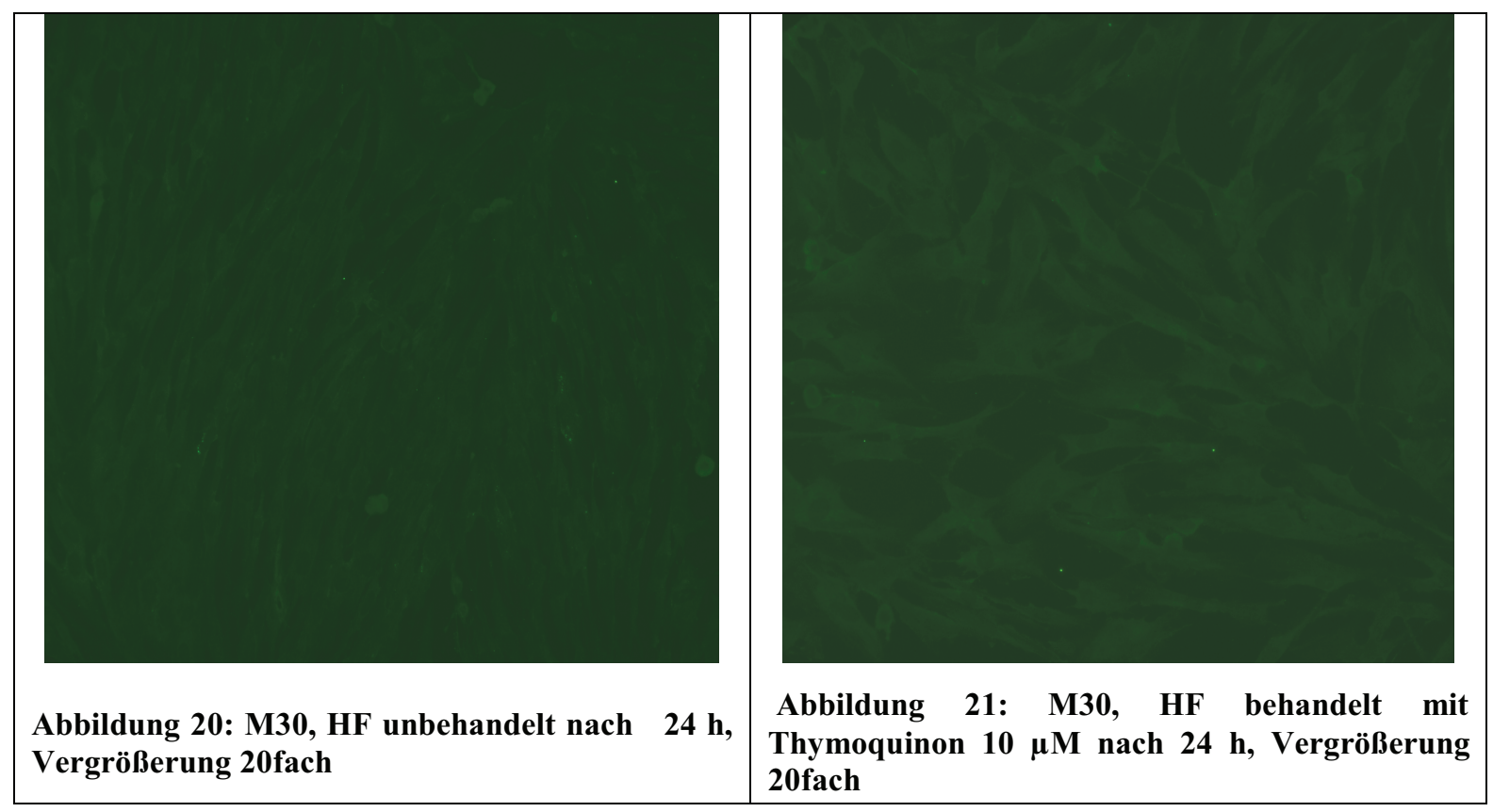




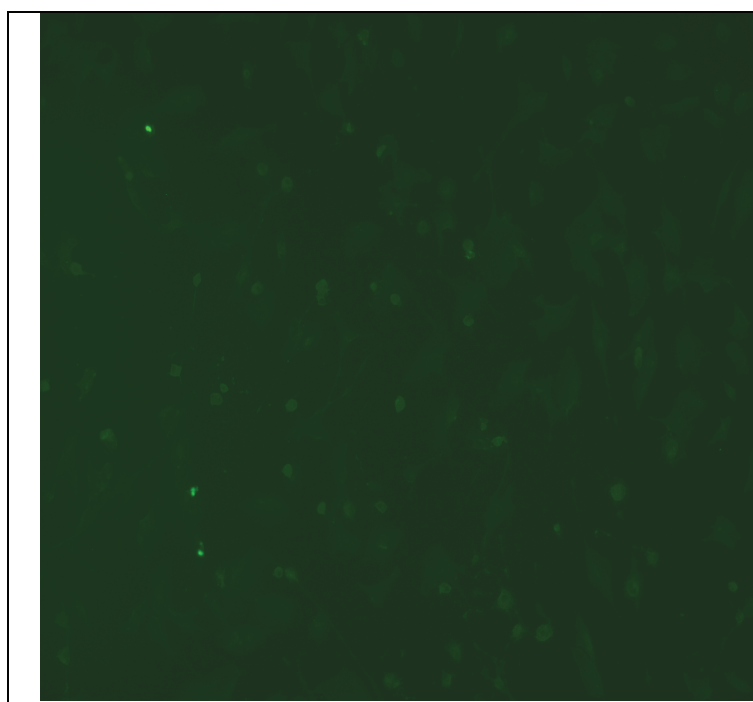

Abbildung 22: M30, HF behandelt mit Thymoquinon $100 \mu \mathrm{M}$ nach $24 \mathrm{~h}$, Vergrößerung 10 fach

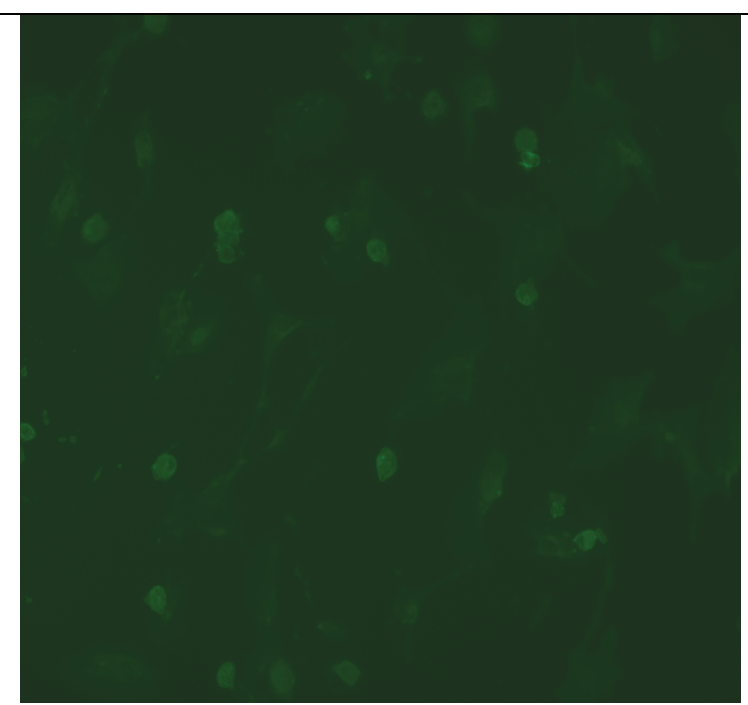

Abbildung 23: M30, HF behandelt mit Thymoquinon $100 \mu \mathrm{M}$ nach $24 \mathrm{~h}$, Vergrößerung $20 \mathrm{fach}$

Ähnlich wie bei den HF-Zellen bewirkt eine $10 \mu \mathrm{m}$ Konzentration auch bei den HepG2 Zellen keine vermehrte Fluoreszenz. Die höhere Konzentration von $100 \mu \mathrm{M}$ bewirkt hingegen ein komplettes Auslöschen vitaler Zellen.

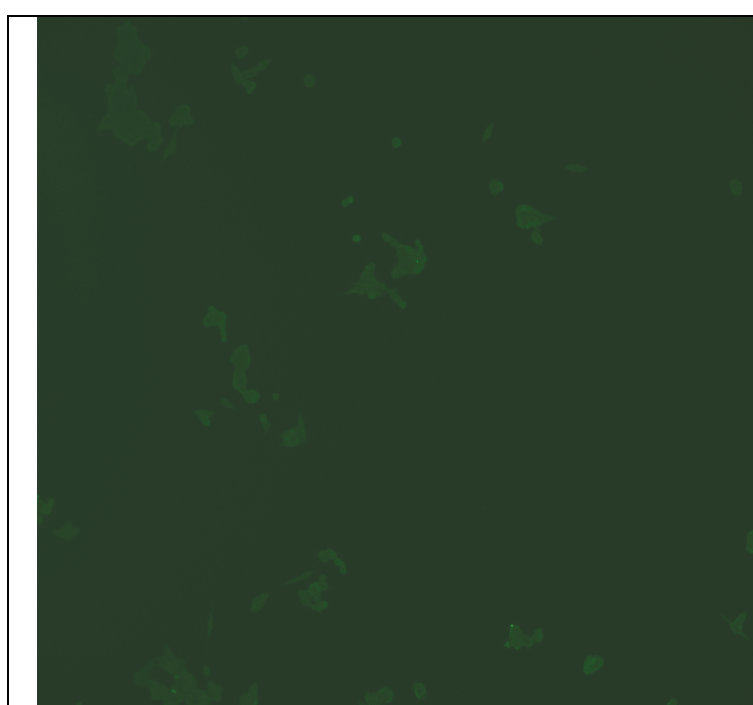

Abbildung 24: M30, HepG2 behandelt mit Thymoquinon $10 \mu \mathrm{M}$ nach $48 \mathrm{~h}$, Vergrößerung 10 fach

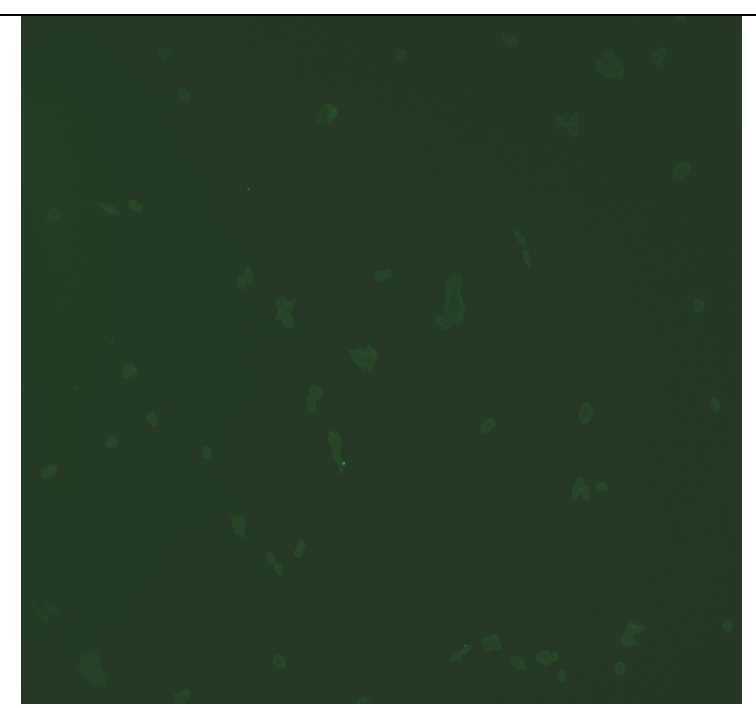

Abbildung 25: M30, HepG2 unbehandelt nach 24 h, Vergrößerung 10 fach

\subsection{Ergebnisse Caspase 3/7-Assay}

Die Caspase 3 ist eine Effektorcaspase, die beim Ablauf der Apoptose von sogenannten Initiatorcaspasen aktiviert wird und daraufhin als Katalysator weiterer Reaktionen dient. Nach 24 und 48 Stunden Inkubationszeit wurden Lumineszenzmessungen bei den 
Hep3B-, HepG2- und HF-Zellen bei $50 \mu \mathrm{M}, 100 \mu \mathrm{M}$ und einer unbehandelten Kontrolle vorgenommen. Diese Messungen erfolgten über einen Zeitraum von ca. 4 Stunden in halbstündigen Abständen.

Die drei Zelllinien zeigten hierbei nach 24 Stunden Inkubation mit $50 \mu \mathrm{M}$ Lösung ähnliche Ergebnisse. Sie wiesen zunächst eine Caspaseaktivität mit ähnlich hohem Niveau wie bei der Kontrolle auf.

Nach 48 Stunden zeigte sich dann bei den Hep3B-Zellen eine 1,5fach erhöhte Caspaseaktivität im Vergleich zur Kontrolle, bei den HepG2-Zellen sogar ein Anstieg um das 1,8fache. Ausschließlich bei den HF-Zellen sank die Aktivität auf einen Wert von $0,82 \mathrm{ab}$.

Konzentrationen von $100 \mu \mathrm{M}$ ließen die Caspaseaktivität aller verwendeter Zelllinien bereits nach 24 Stunden massiv abfallen, so dass man hier an einen Prozess im Sinne einer Nekrose denken könnte.

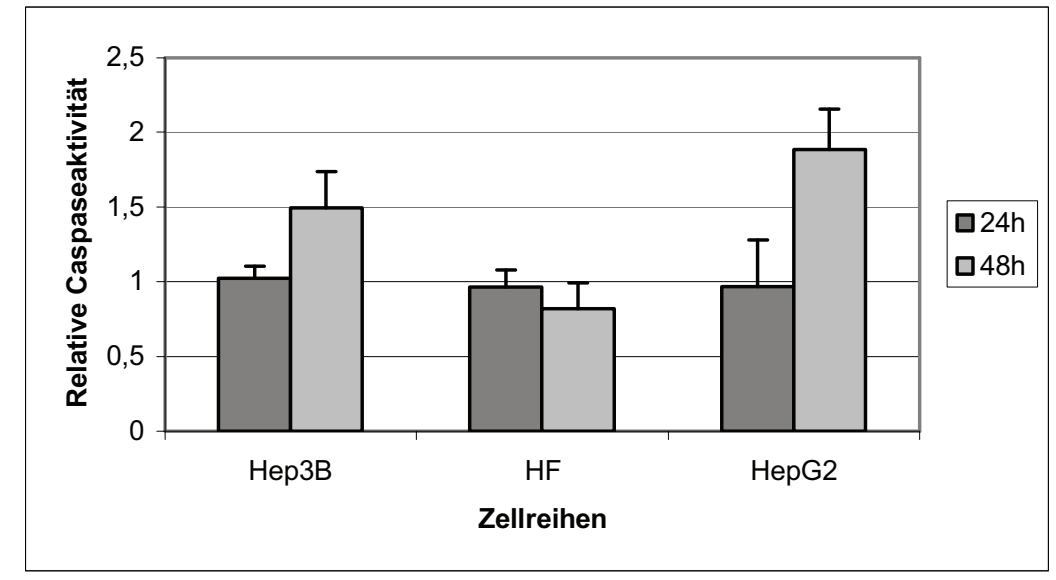

Abbildung 26: Relative Caspaseaktivität nach Inkubation mit $50 \mu \mathrm{M}$ Thymoquinon nach 24 und 48 Stunden

\subsection{Semiquantitativer Westernblot}

Der semiquantitative Westernblot diente zur Ermittlung der Expression apoptose- bzw. proliferationsrelevanter Proteine. Zur Vorbereitung musste zunächst das Gesamtprotein isoliert werden, das dann auf Gele pipettiert und schließlich elektrophoretisch aufgetrennt wurde. Schließlich wurden spezifische Antikörper aufgetragen und geblottet. Die spezifischen Antikörper richteten sich gegen das sogenannte „housekeeping“ Protein $ß$-Aktin sowie gegen das proapoptotische Protein Bax und das antiapoptotische Protein Bcl-2.

Gemessen wurden bei allen drei Zelllinien die Konzentrationen $100 \mu \mathrm{M}, 50 \mu \mathrm{M}$ und eine unbehandelte Kontrolle zu den Zeitpunkten 24 und 48 Stunden. Bei der Kontrolle 
ohne TQ-Zusatz wurde eine Probe je Zeitpunkt mitgeführt, bei $50 \mu \mathrm{M}$ waren es zwei und bei $100 \mu \mathrm{M}$ drei Vergleichsproben.

Bei den HF-Zellen konnte bei der unbehandelten Kontrolle und bei der $50 \mu \mathrm{M}$ Konzentration $\mathrm{zu}$ beiden Zeitpunkten eine B-Aktin Expression in Form einer breiten Bande nachgewiesen werden (siehe Abbildung 27). Wobei zum Zeitpunkt $48 \mathrm{~h}$ die Expression bei $50 \mu \mathrm{M}$ geringer zu sein scheint, erkennbar an der abnehmenden Breite im Vergleich zu 24 Stunden. Bei der hohen Konzentration von $100 \mu \mathrm{M}$ werden nur sehr dezente Banden sichtbar, am besten zu sehen in der jeweils ersten Vergleichprobe. Beim Blotten der Antikörper gegen Bax zeigten sich für die unbehandelte Kontrolle und die $50 \mu \mathrm{M}$ Konzentration $\mathrm{zu}$ beiden Zeitpunkten ähnlich breite Banden, folglich vergleichbar hohe Expression von Bax. $100 \mu \mathrm{M}$ TQ Konzentration ergab zum Messpunkt $24 \mathrm{~h}$ prominentere Banden, nach 48 h hingegen schwächere Expression.

\section{B-Aktin}

$24 \mathrm{~h}$

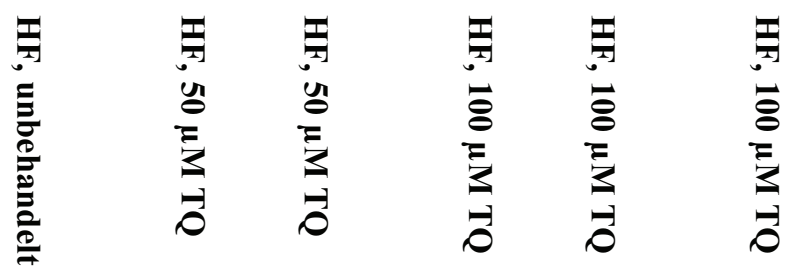

Bax

$24 \mathrm{~h}$

B-Aktin

$48 \mathrm{~h}$

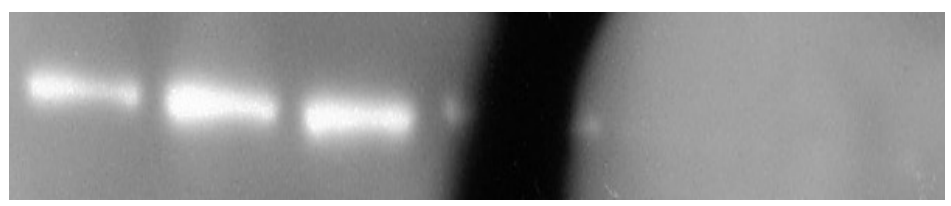

Bax

$48 \mathrm{~h}$
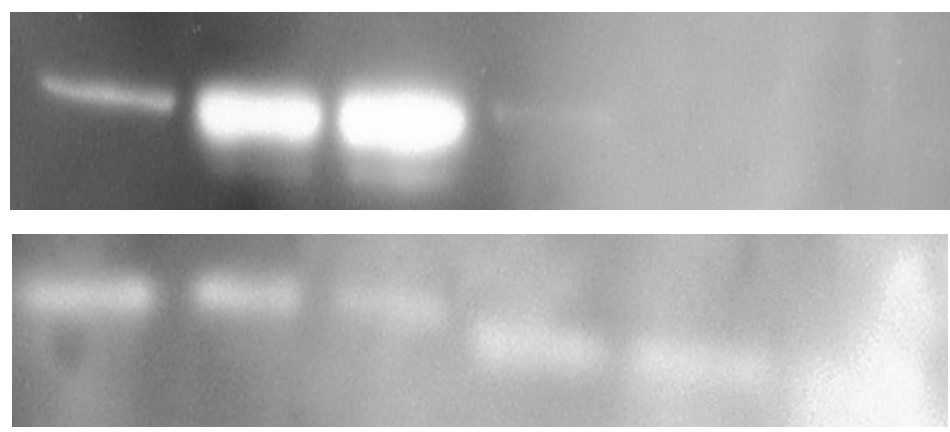

Abbildung 27: Semiquantitativer Westernblot zum Nachweis von B-Aktin und Bax. Abgebildet sind unbehandelte, mit $50 \mu \mathrm{M}$ und $100 \mu \mathrm{M}$ TQ behandelte HF-Zellen zu den Zeitpunkten 24 h und 48 h.

Messung der Bcl-2 Expression ergab keine verwertbaren Ergebnisse, es waren keine Banden an erwarteter Position nachweisbar. 
Die Hepatomzelllinie HepG2 zeigte bei den unbehandelten Kontrollen zu beiden Zeitpunkten eindeutige Banden, die bei $50 \mu \mathrm{M}$ Konzentration etwas schwächer ausfielen. Bei $100 \mu \mathrm{M}$ Konzentration zeigt sich sehr geringe Expression von ß-Aktin, sichtbar durch schwächere Banden. Beim Blotten der Antikörper gegen Bax wurde in der unbehandelten Kontrolle und bei $50 \mu \mathrm{M}$ Konzentration bei 24 und $48 \mathrm{~h}$ eine schwache Expression ermittelt. Die hohe Konzentration zeigt ausschließlich bei $48 \mathrm{~h}$ sehr diskrete Banden, wie in Abbildung 28 zu sehen ist.

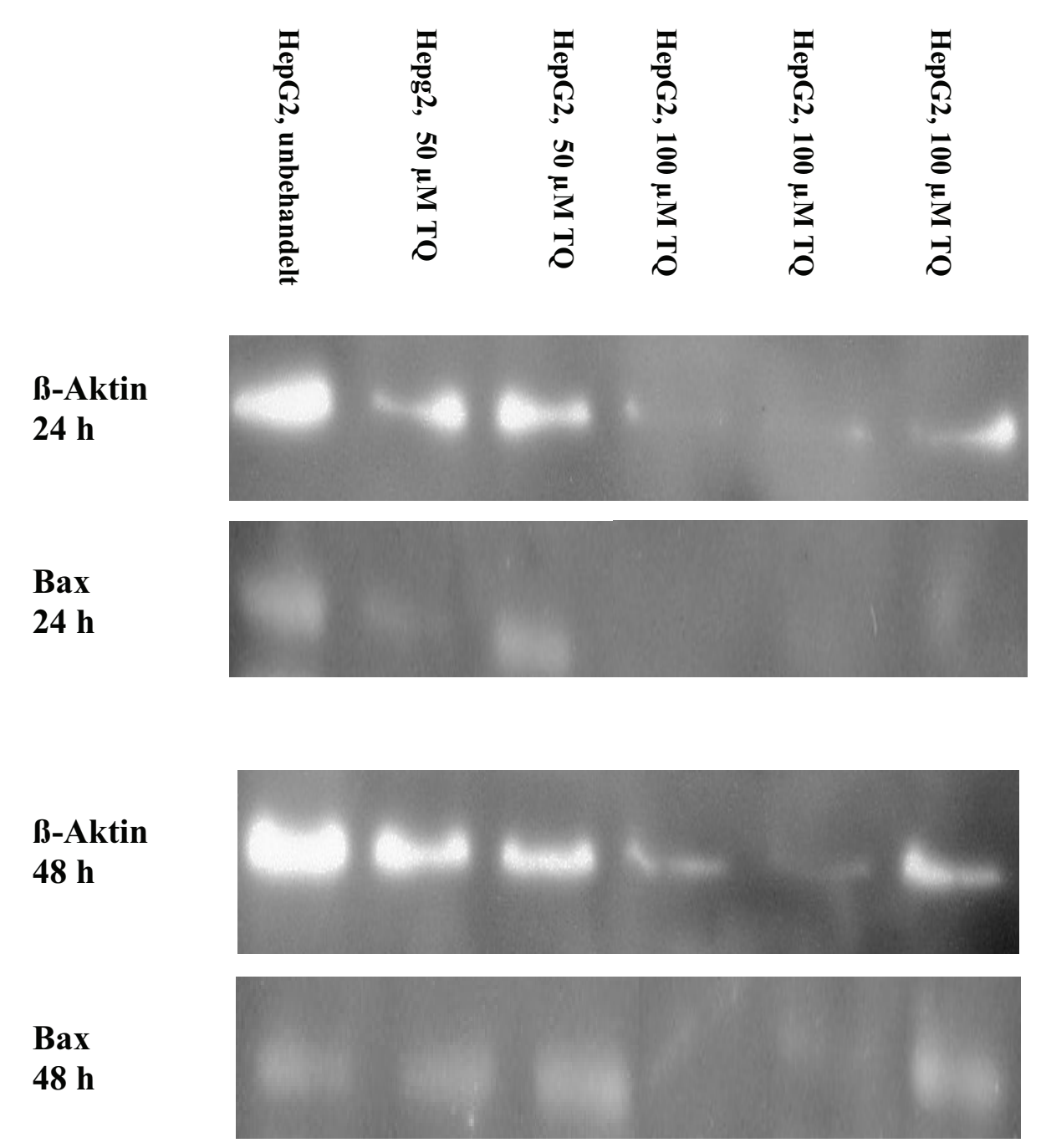

Abbildung 28: Semiquantitativer Westernblot zum Nachweis von B-Aktin und Bax. Abgebildet wurden unbehandelte, mit $50 \mu \mathrm{m}$ und mit $100 \mu \mathrm{m}$ TQ behandelte HepG2-Zellen zu den Zeitpunkten 24 und 48 h.

Auch die Hep3B-Zellen weisen für die unbehandelte Kontrolle und die geringere TQ Konzentration markante Banden entsprechend einer starken Expression des housekeeping Proteins bei 24 und 48 Stunden auf. $100 \mu \mathrm{M}$ Konzentration führt zu kaum erkennbaren Banden. Für Bax zeigen sich bei der unbehandelten Kontrolle zu beiden 
Zeitpunkten markante Banden, die bei $50 \mu \mathrm{M}$ eine noch etwas deutlichere Expression zeigen (eine der $50 \mu \mathrm{M}$-Vergleichsproben zum Zeitpunkt $24 \mathrm{~h}$ ist fehlerhaft und zeigt keine Bande). $100 \mu \mathrm{M}$ Konzentrationen führen nur nach $24 \mathrm{~h} \mathrm{zu}$ schwach sichtbaren Banden.

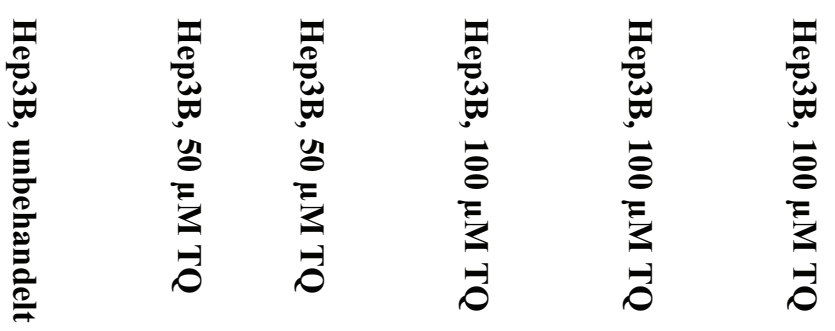

\section{B-Aktin}

$24 \mathrm{~h}$

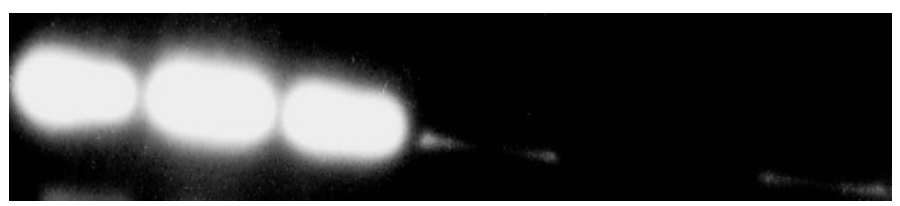

Bax

$24 \mathrm{~h}$

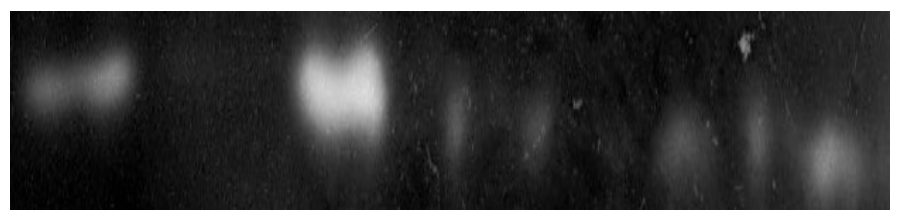

B-Aktin

$48 \mathrm{~h}$

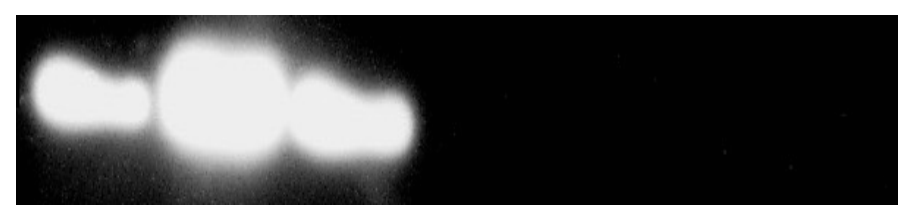

Bax

$48 \mathrm{~h}$

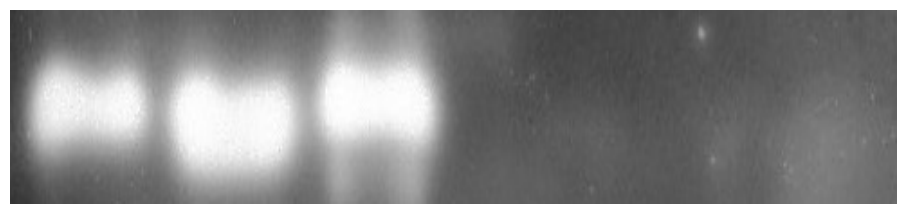

Abbildung 29: Semiquantitativer Westernblot zur Abbildung von B-Aktin und Bax. Abgebildet sind unbehandelte, mit $50 \mu \mathrm{M}$ und mit $100 \mu \mathrm{M}$ TQ behandelte Hep3B-Zellen zu den Zeitpunkten 24 und $48 \mathrm{~h}$.

Bei beiden Hepatomzelllinien konnten keine aussagekräftigen Banden für das Bcl-2Protein gefunden werden. 


\section{Diskussion}

\subsection{Diskussion der Methoden}

Die Wirkung von Thymoquinon auf die Hepatomzellen und Hautfibroblasten wurde in sieben verschiedenen in vitro Versuchen evaluiert. Die Versuche bauten aufeinander auf und dienten dazu einander zu bestätigen, bzw. die Ergebnisse möglichst genau einzugrenzen und zu spezifizieren.

So wurde die Proliferationsrate zum einen relativ mittels BrdU-Inkorporations-ELISA bestimmt, bei dem der Einbau eines Pyrimidinanalogons in neu synthetisierte DNAStränge photometrische dargestellt wird. Zum anderen wurde die absolute Zellzahl durch Auszählen in der Neubauer-Zählkammer bestimmt. Durch beide Methoden konnte der Einfluss von TQ auf das Zellwachstum beurteilt werden.

Ergänzend hierzu wurden auch die apoptotischen Zellen dargestellt. Hierzu wurde den Zellen der DNA-Interkalationsfarbstoff Propidiumjodid zugesetzt, der sich unspezifisch in DNA-Doppelstränge einlagert. Dieser Farbstoff emittiert eine rote Fluoreszenz, die durchflußzytometrisch erfasst wurde. Im FACS wurden alle Zellen mit fragmentierter DNA, also subdiploidem DNA-Satz als apoptotisch gewertet.

Als Bestätigung der FACS-Ergebnisse wurden die Änderungen in der Expression apoptoserelevanter Proteine mittels semiquantitativem Westernblot untersucht. Es wurden das proapoptotische Bax und das antiapoptotische Bcl-2 geblottet. Beides sind Proteine, die maßgeblich an der Signaltransduktion der Apoptose beteiligt sind. Ergänzend wurde auch die Aktivität des Enzyms Caspase-3 als Katalysator des kontrollierten Zelltodes bestimmt.

Ein frühes Ereignis in der Aktivierung des intrinsischen Apoptoseweges ist der Zusammenbruch des mitochondrialen Membranpotentials. Diese Potentialänderung wurde bei den Hepatom- und den HF-Zellen mittels JC-1-Färbung im Durchflusszytometer nachgewiesen.

Als qualitativer Apoptosenachweis diente die Immunfluoreszenzfärbung von Zytokeratin-18-Fragmenten (M30). Wird das Zytokeratin-18 in einem frühen Stadium der Apoptose durch Caspasen fragmentiert, entstehen Bindungsstellen für den M30 Cytodeath-Antikörper. An diesen Antikörper können wiederum Fluoreszein-gekoppelte Anti-Maus-Antikörper ansetzen, deren Fluoreszenz durch UV-Licht Anregung sichtbar gemacht wurde.

Bei den durchflußzytometrischen Apoptosemessungen (FACS) zeigten sich, wie bereits in Kapitel 4.2 erläutert, falsch hohe Apoptoseraten bei allen TQ Konzentrationen inklusive der Negativkontrolle. Dies führte zu der Vermutung, dass TQ in der genutzten 
chemischen Lösung bei entsprechend hohen Temperaturen leicht vom flüssigen in den gasförmigen Zustand übergehen kann. Verifiziert wurde dies durch ein komplettes Umstellen des Versuchsaufbaus, nachdem andere Fehlerquellen ausgeschlossen werden konnten. In den weiteren Versuchen wurde dies stets berücksichtigt.

In den Versuchen wurde das pulverisierte TQ der Firma Sigma Aldrich Chemie GmbH mit DMSO und Nährmedium versetzt, in anderen Arbeiten wäre es sinnvoll die Substanz anderweitig in Lösung $\mathrm{zu}$ bringen und $\mathrm{zu}$ testen, ob ebenfalls ein leicht flüchtiges chemisches Verhalten zu beobachten ist. In der Literatur lassen sich Arbeiten finden, in denen neben TQ auch strukturverwandte Substanzen ausgetestet wurden (5). Hier ist zum einen das tertiäre Butylhydroquinon (THBQ) und das Dihydrothymoquinon zu nennen (36).

\subsection{Diskussion der Ergebnisse}

Thymoquinon an Zellen des hepatozellulären Karzinoms $\mathrm{zu}$ testen erscheint aus mehrerer Hinsicht sinnvoll. Zum einen ist das HCC leider auch derzeit noch ein Tumor, der im fortgeschrittenen Stadium nicht zufriedenstellend therapiert werden kann, so dass hier weitere Forschung nötig ist. Zum anderen hat TQ schon an verschiedenen Tumorzelllinien eindrucksvoll seine anti-tumoralen Eigenschaften gezeigt.

Die zu Beginn durchgeführten Versuche evaluierten das Wachstum und die Zellvitalität der Zelllinien. Hierzu gehörten die FACS-Analyse, der BrdU-ELISA und die Bestimmung der absoluten Zellzahl. Was alle drei Versuche bestätigten, war, dass die Wirkung von TQ bereits in den ersten $24 \mathrm{~h}$ einsetzt. Eine derart schnell einsetzende Wirkung passt $\mathrm{zu}$ den Beobachtungen von Shoieb et. al, die erste proapoptotische Effekte auf COS31-Zellen (Osteosarkom des Hundes) schon nach 6 h Inkubationszeit feststellten (50).

Ebenfalls übereinstimmend bei diesen Experimenten war die Tatsache, dass die Anzahl vitaler Zellen in allen drei Zelllinien bei Konzentrationen von $1000 \mu \mathrm{M}$ und $100 \mu \mathrm{M}$ schon nach $24 \mathrm{~h}$ unter $90 \%$ abfielen. Bestätigt wurde dies durch die durchflußzytometrische Apoptosemessung, die entsprechend ab $24 \mathrm{~h}$ ansteigende Raten ermittelte.

Auffällig war bei den HepG2- und den HF-Zellen, dass hier die Behandlung mit 100 $\mu \mathrm{M}$ Konzentration kontinuierlich mehr apoptotische Zellen ergab, als die mit $1000 \mu \mathrm{M}$ behandelten Zellen. Hierfür gibt es verschiedene Erklärungsansätze. Einerseits könnte die $100 \mu \mathrm{M}$ Konzentration tatsächlich bei beiden Zelllinien zu höheren Apoptoseraten führen als $1000 \mu \mathrm{M}$. Andererseits ist es denkbar, dass das Ergebnis ein durch die 
Technik des FACS Calibur Gerätes bedingter Fehler ist. Durchflußzytometrisch wurde die Apoptoserate nach Propidiumjodidfärbung der DNA gemessen. $1000 \mu \mathrm{M}$ ist eine sehr hohe Konzentration für in vitro Versuche und könnte sich teilweise zytotoxisch im Sinne einer Nekrose auf die Zellen ausgewirkt haben. Da hierbei, anders als bei der Apoptose keine kontrollierte DNA-Fragmentierung abläuft, kann auch die PI-Färbung nur unzureichend erfolgen. Dies führt bei einem relativ hohen Anteil an nicht-vitalen Zellen zu einem verhältnismäßig geringen Signal.

Dass Konzentrationen $\leq 10 \mu \mathrm{M}$ keine Auswirkungen haben zeigten die Versuche übereinstimmend. Was die $50 \mu \mathrm{M}$ Konzentration angeht, so zeigen sich teils widersprüchliche, nicht vollkommen klar abzugrenzende Ergebnisse. Beispielsweise konnte in der Zellzahlbestimmung bei den HepG2-Zellen ein kontinuierlicher und signifikanter Abfall der vitalen Zellen im Vergleich zur Kontrolle festgestellt werden, der sich dann in der FACS-Analyse nicht bestätigen ließ. Hier wurde nur nach $24 \mathrm{~h}$ eine signifikante Apoptoserate gefunden. Die Wirksamkeitsgrenze könnte somit durchaus in einem Bereich zwischen 50 und $100 \mu \mathrm{M}$ liegen. Gali-Muhtasib et al. fanden nach $24 \mathrm{~h}$ eine Wirkung auf HCT116 Zellen ab $60 \mu \mathrm{M}$ Konzentration (20).

In einigen Arbeiten wird neben der Wirksamkeit gegenüber den Tumorzelllinien auch beschrieben, dass TQ die nicht-malignen Kontrollen kaum beeinträchtigt (21,50). Dies konnte in unseren Experimenten nicht bestätigt werden. Zwar zeigten die HF-Zellen in der Zellzahl keine Beeinträchtigung durch $50 \mu \mathrm{m}$ TQ-Zusatz, dafür waren bei der durchflußzytometrischen Apoptosemessung die Raten im Vergleich $\mathrm{zu}$ den Hepatomzellen am höchsten.

Um die proapoptotische Wirkung der Substanz $\mathrm{zu}$ verifizieren, wurden die Immunfluoreszenzfärbung des Zyrokeratin-18-Fragmentes (M30 Cytodeath) und die JC-1-Färbung zur Messung des mitochondrialen Membranpotentials vorgenommen.

Die JC-1-Färbung konnte die vorangegangenen Versuche bestätigen, da bei $100 \mu \mathrm{M}$ hohe Apoptoseraten und ein massiver Abfall an roter Fluoreszenz gemessen wurde, wohingegen bei $10 \mu \mathrm{m}$ Konzentration die Ergebnisse denen der Kontrolle entsprachen. Im M30 Cytodeath wird dieser Trend bestätigt. Bemerkenswert ist, dass hier bei den Hepatomzelllinien unter dem Mikroskop bei $100 \mu \mathrm{M}$ praktisch keine vitalen Zellen mehr zur erkennen sind (siehe Abbildung 19). Es finden sich nur noch Zellfragmente. Bei den nicht-malignen Kontrollzellen hingegen ist die Resistenz gegen das TQ größer. Zwar ist die Zelldichte vermindert und das M30 Signal verstärkt, aber es sind noch vitale Zellen vorhanden (siehe Abbildung 23). Im Westernblot bestätigte sich, dass die $100 \mu \mathrm{M}$ Konzentration nur wenige vitale Zellen zurücklässt, erkennbar an der geringen 
Expression des B-Aktins. Beim Blotten des Bax zeigte sich bei den HF-Zellen nach $24 \mathrm{~h}$ und $100 \mu \mathrm{M}$ eine kräftigere Expression als bei der $50 \mu \mathrm{M}$ Konzentration und der unbehandelten Kontrolle. Die Hep3B-Zellen zeigten bei $50 \mu \mathrm{M}$ wiederum stärkere BaxBanden als in der Kontrolle. Nur bei den HepG2-Zellen lassen sich zwischen unbehandelter Kontrolle und $50 \mu \mathrm{M}$ keine klaren Unterschiede ausmachen. Diese Ergebnisse lassen einen Trend zu einer erhöhten Bax-Expression in den behandelten Zelllinien vermuten.

Die Veränderung des Bax/Bcl-2-Quotienten beim programmierten Zelltod ist ein physiologischer Schritt in der Signaltransduktion. Bax steht hierbei für die Aktivierung der Apoptose durch erhöhte Ausschüttung von Cytochrom c aus dem Mitochondrium. Cytochrom c wiederum bindet an das zytoplasmatische Protein Apaf-1 und führt so zu einer Aktivierung von Caspasen. Das Bcl-2-Protein dagegen dichtet das Mitochondrium ab, so das Cytochrom c nicht austreten kann, was die Apoptose verhindert. Das Niveau von Bax kann beispielsweise durch Strahlung, Chemotherapeutika und DNA-Schäden angehoben werden, das Niveau von Bcl-2 durch Wachstumsfaktoren (26).

El-Mahdy et. al beschreiben eine Erhöhung des Bax/Bcl-2-Quotienten nach Behandlung von HL-60-Zellen (myeloblastische Leukämie) mit TQ infolge einer Hochregulation von Bax und einer Downregulation von Bcl-2. Sie schließen daraus, dass im weiteren Ablauf eine Aktivierung von Caspasen zum Zelltod führt (14). Auch Gali-Muhtasib et al. können diese Veränderung des Bax/Bcl-2-Quotienten nach TQ-Behandlung bei Tumorzellen bestätigen und beschreiben vor allem eine Abnahme des antiapoptotischen Proteins Bcl-xL (21).

Eine Aktivierung der Caspasen bildet auf dem Weg zum programmierten Zelltod sozusagen die Endstrecke. El-Mahdy et al. kommen zu dem Ergebnis, dass eine Aktivierung von Caspase-3 und -8 auf die TQ-Wirkung zurückzuführen ist. In unseren Versuchen zeigte sich nach 48 Stunden Inkubationszeit bei $50 \mu \mathrm{M}$ Konzentration bei den Hepatomzelllinien ein 1,5-1,8facher Anstieg der Caspaseaktivität. Die HF-Zellen und die kürzere Inkubationszeit von 24 Stunden erbrachten Werte im Bereich der Kontrolle. Bei $100 \mu \mathrm{M}$ lag die Aktivität sehr gering. Dies lässt sich am ehesten dadurch erklären, dass diese hohe Konzentration wie bereits beschrieben kaum vitale Zellen zurücklässt und die Wirkung dermaßen zytotoxisch ist, dass hier wohl auch der Vorgang der Nekrose eine Rolle spielt.

Eine weitere Fähigkeit des TQ, die 2008 von Yi et. al anhand von in vitro und in vivo Versuchen an PC3-Zellen (Prostatakarzinom) und Umbilikalvenenendothelien beschrieben wird, ist die Hemmung der Angiogenese und Tumorangiogenese. 
Endothelzellen spielen eine entscheidende Rolle bei der Tumorangiogenese (58). Beim Wachstum, der Proliferation und Migration der Endothelzellen spielen zwei wichtige Signaltransduktionswege eine Rolle. Dies sind der PI3K-AKT- und der Raf (receptor activation factor)-MEK (mitogen extracellular kinase)-ERK (extracellular signalrelated-kinase)-Signalweg. PI3K steht hierbei für Phosphoinositid-3-Kinase, AKT stellt das Gen für die Proteinkinasen B dar, die eine zentrale Rolle in der Homöostase der Zellen haben. Die Raf-Kinase beispielsweise ist in mehreren Tumoren überexpremiert, so im Nierenzellkarzinom, nicht-kleinzelligen Lungenkrebs und auch im HCC (22). Yi et. al stellten fest, dass TQ durch Suppression der Aktivierung der AKT- und ERKSignalwege die de novo-Angiogese unterbindet (58). Diese Wirkung am HCC zu untersuchen wäre sehr sinnvoll, da neuere Therapien auch in eben diese Signalwege eingreifen. $\mathrm{Zu}$ nennen ist hier das Sorafenib, das ein Inhibitor der Raf-Kinase und des vascular endothelial growth factor Rezeptors (VEGFR) ist. Da einige Studien für Sorafenib ein verlängertes Überleben im Vergleich zur Best Supportiv Care zeigten, konnte sich das Medikament vor allem in den USA gut etablieren.

Neben diesen antitumoralen Eigenschaften, könnte TQ auch einen präventiven Nutzen aufweisen. Das HCC ist ein Tumor, der auf dem Boden chronischer Entzündung entsteht. TQ hat nachweislich antiinflammatorische und antioxidative Wirkung, was der Entzündung entgegenwirken und somit die Tumorentstehung möglicherweise zumindest hinauszögern könnte. Eine präventive, protektive Wirkung an Leberzellen konnte jedenfalls in einer Studie festgestellt werden (34). Durch Zugabe von TQ in das Trinkwasser von Mäusen wurde hier die Hepatotoxizität von Carbon-Tetrachlorid gesenkt, was nach einmaliger Gabe normalerweise zu einer massiven Leberschädigung führt.

Die Säulen der Chemotherapie des HCC bilden aktuell Doxorubicin, Sorafinib oder Kombinationstherapien, wie das PIAF-Protokoll (Cisplatin, INF-alpha, Doxorubicin, 5Fluorouracil) oder Gemcitabine plus Cisplatin (53). Limitiert werden die Therapien durch die unerwünschten Nebenwirkungen. Beim HCC sind diese wegen der schlechten Leberfunktion meist stark ausgeprägt. Ob TQ hier die chemotherapeutische Wirkung verbessern und sich protektiv auf die Leberfunktion auswirken kann, sollte ein Ansatzpunkt für weitere Forschung sein. Einen Hinweis hierauf geben kann eine Studie von 1997, bei der neben einer verbesserten antitumoralen Aktivität von Cisplatin an Ehrlich Ascites Karzinomen der Maus auch gleichzeitige eine TQ-vermittelte verminderte Nephrotoxizität nachgewiesen wurde (6). 


\subsection{Zusammenfassung der Diskussion}

Thymoquinon zeigt in unseren Experimenten ab einer Konzentration von $100 \mu \mathrm{M}$ eindeutig proapoptotische und antiproliferative Wirkung. Da dies für in vitro Versuche eine relativ hohe Konzentration darstellt, muss sich zeigen, inwieweit TQ auch am Menschen einsetzbar ist. In einzelnen Versuchen gab es durchaus Hinweise auf eine Wirksamkeit bei niedrigeren Konzentrationen. Dies an Hepatomzelllinien näher einzugrenzen sollte Bestandteil weiterer Forschung sein. Ebenso sollte getestet werden, ob TQ in einer anderen Form der Suspension ein ähnlich flüchtiges Verhalten bei $37{ }^{\circ} \mathrm{C}$ zeigt, wie in unserer Arbeit. Bisher war in der Literatur nicht davon berichtet worden.

Es konnte in unserer Arbeit zwar keine ausgeprägte Resistenz der nicht-malignen Zellen bestätigt werden, wie das in anderen Studien der Fall war $(21,50)$. Dennoch konnten wir, was die Signaltransduktion und Expression apoptoserelevanter Proteine angeht andere Arbeiten bestätigend ergänzen.

Da Thymoquinon neben den antitumoralen auch antiinflammatorische und antioxidative Effekte hat, bietet sich für die Substanz in Zukunft ein weites Feld an Einsatzmöglichkeiten. Hier sollten nicht nur mögliche Tumortherapien, sondern, wie bereits erläutert, auch ein präventiver Nutzen des Thymoquinons evaluiert werden. 


\section{Literaturverzeichnis}

1. "A new prognostic system for hepatocellular carcinoma: a retrospective study of 435 patients: the Cancer of the Liver Italian Program (CLIP) investigators." (1998) Hepatology, $28(3), 751-5$

2. "Prospective validation of the CLIP score: a new prognostic system for patients with cirrhosis and hepatocellular carcinoma. The Cancer of the Liver Italian Program (CLIP) Investigators." (2000) Hepatology, 31(4), 840-5

3. Abdalla, E.K. a S., K.E., (2009) "Overview of treatment approaches for hepatocellular carcinoma." 17.2, 1-13, up to date database

4. Badary, O.A., Al-Shabanah, O.A., Nagi, M.N., Al-Rikabi, A.C. and Elmazar, M. M. (1999). "Inhibition of benzo(a)pyrene-induced forestomach carcinogenesis in mice by thymoquinone." Eur J Can Prev, 8(5), 435-5

5. Badary, O.A., Taha, R.A., Gamal el-Din, A.M., and Abdel-Wahab, M.H. (2003). "Thymoquinone is a potent superoxide anion scavenger." Drug Chem Toxicol, 26(2), $87-98$

6. Badary, O. A., al-Shabanah, O. A.; al-Sawaf, H. A.; al-Sohaibani, M. O.; al-Bekairi, A.M. (1997). "Thymoquinone ameliorates the nephrotoxicity induced by cisplatin in rodents and potentiates its antitumor activity." Can J Physiol Pharmacol, 75(12), 1356-61

7. Blum, H. E. u. H., U.T. (2003). "Hepatozelluläres Karzinom: Pathogenese und das Problem der Multizentrizität." Der Chirurg; Springer Berlin/ Heidelberg, 74, Number 08, August 2003, 709-716

8. Bouza, C., Lopez-Cuadrado, T., Alcazar, R., Saz-Parkinson, Z., and Amate, J.M. (2009). "Meta- analysis of percutaneous radiofrequency ablation versus ethanol injection in hepatocellular carcinoma." BMC Gastroenterol, 9, 31

9. Bravi, F., Bosetti, C., Tavani, A., Bagnardi, V., Gallus, S., Negri, E., Franceschi, S., and La Vecchia, C. (2007). "Coffee drinking and hepatocellular carcinoma risk: a metaanalysis." Hepatology, 46(2), 430-5

10. Bruix, J., and Sherman, M. (2005). "Management of hepatocellular carcinoma." Hepatology, 42(5), 1208-36

11. Caselmann, W.H., Spengler, U., Fischer, H.P. und Sauerbruch, T. (1997). "Leberzirrhose als Präkanzerose." Der Internist, Springer Berlin/ Heidelberg, 928- 936

12. Cheng, A.L., Kang, Y.K., Chen, Z., Tsao, C.J., Qin, S., Kim, J.S., Luo, R., Feng, J., Ye, S., Yang, T.S., Xu, J., Sun, Y., Liang, H., Liu, J., Wang, J., Tak, W.Y., Pan, H., Burock, K., Zou, J., Voliotis, D., and Guan, Z. (2009). "Efficacy and safety of sorafenib in patients in the Asia-Pacific region with advanced hepatocellular carcinoma: a phase III randomised, double-blind, placebo-controlled trial." Lancet Oncol, 10(1), 25-34

13. Deuffic, S., Poynard, T., Buffat, L., and Valleron, A.J. (1998). "Trends in primary liver cancer." Lancet, 351(9097), 214-5 
14. El-Mahdy, M.A.; Wang, Q. E.;Wani, G.;Wani, A.A. (2005). "Thymoquinone ～induces apoptosis through activation of caspase-8 and mitochondrial events in p53-null myeloblastic leukemia HL-60 cells." Int J Cancer, 117(3), 409-17

15. El-Serag, H.B. (2001). "Epidemiology of hepatocellular carcinoma." Clin Liver Dis, 5(1), 87-107,vi

16. El-Serag, H.B. (2002). "Hepatocellular carcinoma: an epidemiologic view." J Clin Gastroenterol, 35(5 Suppl 2), S72-8

17. El-Serag, H.B., Davila, J.A., Petersen, N.J., and McGlynn, K.A. (2003). "The continuing increase in the incidence of hepatocellular carcinoma in the United States: an update." Ann Intern Med, 139(10), 817-23

18. Fuss, M., Salter, B.J., Herman, T.S., and Thomas, C.R., Jr. (2004). "External beam radiation therapy for hepatocellular carcinoma: potential of intensity-modulated and image-guided radiation therapy." Gastroenterology, 127(5 Suppl 1), S206-17

19. Gaiani, S., Celli, N., Cecilioni, L., Piscaglia, F., and Bolondi, L. (2003). "Review article: percutaneous treatment of hepatocellular carcinoma." Aliment Pharmacol Ther, 17 Suppl 2, 103-10

20. Gali-Muhtasib, H., Diab-Assaf, M., Boltze, C., Al-Hmaira, J., Hartig, R., Roessner, A., and Schneider-Stock, R. (2004a). "Thymoquinone extracted from black seed triggers apoptotic cell death in human colorectal cancer cells via a p53-dependent mechanism." Int J Oncol, 25(4), 857-66

21. Gali-Muhtasib, H.U., Abou Kheir, W.G., Kheir, L.A., Darwiche, N., and Crooks, P.A. (2004b). "Molecular pathway for thymoquinone-induced cell-cycle arrest and apoptosis in neoplastic keratinocytes." Anticancer Drugs, 15(4), 389-99

22. Gollob, J.A., Wilhelm, S., Carter, C., and Kelley, S.L. (2006). "Role of Raf kinase in cancer: therapeutic potential of targeting the Raf/MEK/ERK signal transduction pathway." Semin Oncol, 33(4), 392-406

23. Gomaa, A.I., Khan, S.A., Leen, E.L., Waked, I., and Taylor-Robinson, S.D. (2009). "Diagnosis of hepatocellular carcinoma." World J Gastroenterol, 15(11), 1301-14

24. Henderson, J., Sherman, M., Tavill, A., Abecassis, M., Chejfec, G., and Gramlich, T. (2003). "AHPBA/AJCC consensus conference on staging of hepatocellular carcinoma: consensus statement." HPB (Oxford), 5(4), 243-50

25. Hochster, H.S., Green, M.D., Speyer, J., Fazzini, E., Blum, R., and Muggia, F.M. (1985). "4' Epidoxorubicin (epirubicin): activity in hepatocellular carcinoma." J Clin Oncol, $3(11), 1535-40$

26. Hoffbrand, A.V.P., J.E.; Moss, P.H.A.; Hoelzer, D. (2003). "Grundkurs Hämatologie." Blackwell Verlag, 2. Auflage, 7-8 
27. Lai, C.L., Lau, J.Y., Wu, P.C., Ngan, H., Chung, H.T., Mitchell, S.J., Corbett, T.J., Chow, A.W., and Lin, H.J. (1993). "Recombinant interferon-alpha in inoperable hepatocellular carcinoma: a randomized controlled trial." Hepatology, 17(3), 389-94

28. Larsson, S.C., and Wolk, A. (2007). "Coffee consumption and risk of liver cancer: a metaanalysis." Gastroenterology, 132(5), 1740-5

29. Llovet, J.M., Bru, C., and Bruix, J. (1999a). "Prognosis of hepatocellular carcinoma: the BCLC staging classification." Semin Liver Dis, 19(3), 329-38

30. Llovet, J.M., and Bruix, J. (2008). "Novel advancements in the management of hepatocellular carcinoma in 2008." J Hepatol, 48 Suppl 1, S20-37

31. Llovet, J.M., Fuster, J., and Bruix, J. (1999b). "Intention-to-treat analysis of surgical treatment for early hepatocellular carcinoma: resection versus transplantation." Hepatology, 30(6), 1434-40

32. Llovet, J. M., Ricci, S., Mazzaferro, V., Hilgard, P., Gane, E., Blanc, J. F., de Oliveira, A. C., Santoro, A., Raoul, J. L., Forner, A., Schwartz, M., Porta, C., Zeuzem, S., Bolondi, L., Greten, T. F., Galle, P. R., Seitz, J. F., Borbath, I., Haussinger, D., Giannaris, T., Shan, M., Moscovici, M., Voliotis, D., and Bruix, J. (2008). "Sorafenib in advanced hepatocellular carcinoma." N Engl J Med, 359(4), 378-90

33. Lodato, F., Mazzella, G., Festi, D., Azzaroli, F., Colecchia, A., and Roda, E. (2006). "Hepatocellular carcinoma prevention: a worldwide emergence between the opulence of developed countries and the economic constraints of developing nations." World $\mathrm{J}$ Gastroenterol, 12(45), 7239-49

34. Mansour, M.A. (2000). "Protective effects of thymoquinone and desferrioxamine against hepatotoxicity of carbon tetrachloride in mice." Life Sci, 66(26), 2583-91

35. Mansour, M.A., Ginawi, O.T., El-Hadiyah, T., El-Khatib, A.S., Al-Shabanah, O.A., and Al-Sawaf, H.A. (2001). "Effects of volatile oil constituents of Nigella sativa on carbon tetrachloride-induced hepatotoxicity in mice: evidence for antioxidant effects of thymoquinone." Res Commun Mol Pathol Pharmacol, 110(3-4), 239-51

36. Mansour, M.A., Nagi, M.N., El-Khatib, A.S., and Al-Bekairi, A.M. (2002). "Effects of thymoquinone on antioxidant enzyme activities, lipid peroxidation and DT-diaphorase in different tissues of mice: a possible mechanism of action." Cell Biochem Funct, 20(2), 143-51

37. Marelli, L., Stigliano, R., Triantos, C., Senzolo, M., Cholongitas, E., Davies, N., Yu, D., Meyer, T., Patch, D.W., and Burroughs, A.K. (2006). "Treatment outcomes for hepatocellular carcinoma using chemoembolization in combination with other therapies." Cancer Treat Rev, 32(8), 594-606

38. Mazzaferro, V., Regalia, E., Doci, R., Andreola, S., Pulvirenti, A., Bozzetti, F., Montalto, F., Ammatuna, M., Morabito, A., and Gennari, L. (1996). "Liver transplantation for the 
treatment of small hepatocellular carcinomas in patients with cirrhosis." N Engl J Med, 334(11), 693-9

39. McGlynn, K.A., Tsao, L., Hsing, A.W., Devesa, S.S., and Fraumeni, J.F., Jr. (2001). "International trends and patterns of primary liver cancer." Int J Cancer, 94(2), 290-6

40. Nagahama, H., Okada, S., Okusaka, T., Ishii, H., Ikeda, M., Nakasuka, H., and Yoshimori, M. (1997). "Predictive factors for tumor response to systemic chemotherapy in patients with hepatocellular carcinoma." Jpn J Clin Oncol, 27(5), 321-4

41. Nowak, A.K., Stockler, M.R., Chow, P.K., and Findlay, M. (2005). "Use of tamoxifen in advanced-stage hepatocellular carcinoma. A systematic review." Cancer, 103(7), 140814

42. Okamoto. K; Neureiter, D; Ocker, M (2009). "Biomarkers for novel targeted therapies of hepatocellular carcinoma." Histology and Histopathology 24, 493-502

43. Okuda, K. (1993). "Intratumor ethanol injection." J Surg Oncol Suppl, 3, 97-9

44. Okuda, K. (2000). "Hepatocellular carcinoma." J Hepatol, 32(1 Suppl), 225-37

45. Orlando, A., Leandro, G., Olivo, M., Andriulli, A., and Cottone, M. (2009). "Radiofrequency thermal ablation vs. percutaneous ethanol injection for small hepatocellular carcinoma in cirrhosis: meta-analysis of randomized controlled trials." Am J Gastroenterol, 104(2), 514-24

46. Pereira, P.L. (2009). "Interventionelle Radiologie bei HCC." Hepatitis \& more, Fortbildung, $1 / 2009,18-21$

47. Perry, J.F., Strasser, S.I., George, J., Farrell, G.C., and McCaughan, G.W. (2003). "Pharmacotherapy of hepatocellular carcinoma." Expert Opin Pharmacother, 4(12), 2175-85

48. Rozan, L.M., and El-Deiry, W.S. (2007). "p53 downstream target genes and tumor suppression: a classical view in evolution." Cell Death Differ, 14(1), 3-9

49. Schwartz, J. a. C., RL. (2009). "Epidemiology and etiologic associations of hepatocellular carcinoma". City, pp. 6

50. Shoieb, A.M., Elgayyar, M., Dudrick, P.S., Bell, J.L., and Tithof, P.K. (2003). "In vitro inhibition of growth and induction of apoptosis in cancer cell lines by thymoquinone." Int J Oncol, 22(1), 107-13

51. Simonetti, R.G., Camma, C., Fiorello, F., Politi, F., D'Amico, G., and Pagliaro, L. (1991). "Hepatocellular carcinoma. A worldwide problem and the major risk factors." Dig Dis Sci, 36(7), 962-72

52. Spangenberg, H. (2007). "Hepatozelluläres Karzinom." Falk Gastro- Kolleg, 1/2007, 35-48

53. Stuart, K. E. (2009). "Systemic treatment for advanced hepatocellular carcinoma." Up to date database 
54. Van Rensburg, S.J., Cook-Mozaffari, P., Van Schalkwyk, D.J., Van der Watt, J.J., Vincent, T.J. and Purchase, I.F. (1985). "Hepatocellular carcinoma and dietary aflatoxin in Mozambique and Transkei." Br J Cancer, 51(5), 713-26

55. Verslype, C., Van Cutsem, E.,Dicato, M., Arber, N. (2008). "The management of hepatocellular carcinoma. Current expert opinion and recommendations derived from the 10th World Congress on Gastrointestinal Cancer, 2008, Barcelona." Symposium article, annals of oncology 20 (suppl 7)

56. Yan, B.C., and Hart, J.A. (2009). "Recent developments in liver pathology." Arch Pathol Lab Med, 133(7), 1078-86

57. Yeo, W., Mok, T.S., Zee, B., Leung, T.W., Lai, P.B., Lau, W.Y., Koh, J., Mo, F.K., Yu, S.C., Chan, A.T., Hui, P., Ma, B., Lam, K.C., Ho, W.M., Wong, H.T., Tang, A., and Johnson, P.J. (2005). "A randomized phase III study of doxorubicin versus cisplatin/interferon alpha-2b/doxorubicin/fluorouracil (PIAF) combination chemotherapy for unresectable hepatocellular carcinoma." J Natl Cancer Inst, 97(20), $1532-8$

58. Yi, T.C.; Yi, Z.; Pang, X.; Rodriguez, M.; Wang, Y.; Sethi, G.; Aggarwal, B.B.; Liu, M. (2008). "Thymoquinone inhibits tumor angiogenesis and tumor growth through suppressing AKT and extracellular signal-regulated kinase signaling pathways." Mol Cancer Ther, 7(7), 1789-96

\section{Abkürzungsverzeichnis}

$\begin{array}{ll}\text { AFP } & \text { Alpha-Fetoprotein } \\ \text { AKT } & \text { Gen der Proteinkinasen B } \\ \text { DMSO } & \text { Dimethylsulfoxid } \\ \text { ERK } & \text { extracellular signal-related kinase } \\ \text { FACS } & \text { Fluorescence } \\ \text { h } & \text { Stunden } \\ \text { HBV } & \text { Hepatitis B Virus } \\ \text { HCV } & \text { Hepatitis C virus } \\ \text { HDV } & \text { Hepatitis D Virus } \\ \text { MW } & \text { Mittelwert } \\ \text { PI3K } & \text { Phosphoinositid-3-Kinase } \\ \text { Raf } & \text { receptor activation factor } \\ \text { SD } & \text { Standardabweichung } \\ \text { TQ } & \text { Thymoquinon }\end{array}$




\section{Anhang}

Tabelle 10: Schweregradeinteilung der Leberzirrhose nach Child-Pugh

\begin{tabular}{|l|c|c|c|}
\hline & 1 Punkt & 2 Punkte & 3 Punkte \\
\hline Bilirubin (mg/dl) & $<2$ & $2-3$ & $>3$ \\
\hline Albumin (g/d) & $>3,5$ & $3-3,5$ & $<3$ \\
\hline Quick \%/ INR & $>65 /<1,7$ & $40-65 / 1,7-2,3$ & $<40 />2,3$ \\
\hline $\begin{array}{l}\text { Hepatische } \\
\text { Enzephalopathie }\end{array}$ & nein & gering (Stadium 1-2) & Schwer (Stadium 3-4) \\
\hline Aszites & nein & $\begin{array}{c}\text { Leicht, medikamentös } \\
\text { therapierbar }\end{array}$ & Schwer, therapierefraktär \\
\hline
\end{tabular}

Grad A: 5-7 Punkte

Grad B: 8-10 Punkte

Grad C: 11-15 Punkte

Tabelle 11: Barcelona Clinic Liver Cancer (BCLC)-Klassifikation nach Llovet et al. (2000)

\begin{tabular}{|c|c|c|c|c|}
\hline Stadium & ECOG & Tumor & Okuda & Leberfunktion \\
\hline \multicolumn{5}{|l|}{ A: frühes Stadium } \\
\hline A1 normal & 0 & solitär & I & Keine PH, Bili \\
\hline A2 & 0 & solitär & I & PH, Bili normal \\
\hline A3 & 0 & solitär & I & PH und Bili erhöh \\
\hline A4 & 0 & 3 Tumoren $<3 \mathrm{~cm}$ & I-II & Child-Pugh A-B \\
\hline $\begin{array}{l}\text { B: intermediäres } \\
\mathrm{HCC}\end{array}$ & 0 & Mutilokulär, groß & I-II & Child-Pugh A-B \\
\hline $\begin{array}{l}\text { C: } \\
\text { fortgeschrittenes } \\
\text { HCC }\end{array}$ & $1-2$ & $\begin{array}{l}\text { Gefäßinvasion } \\
\text { oder } \\
\text { Fernmetastasen }\end{array}$ & I-II & Child-Pugh A-B \\
\hline D: Endstadium & $3-4$ & alle & & Child-Pugh C \\
\hline
\end{tabular}

ECOG entspricht der ECOG-Klassifikation des „performance status“

PH entspricht portaler Hypertension

Stadium A, B: alle Kriterien sollten erfüllt sein

Stadium C: erfüllt, wenn ECOG oder Tumorkriterien zutreffen 
Stadium D: erfüllt, wenn mindestens 1 der 4 Kriterien zutrifft

\subsection{Ergebnisse Zellzahl}

Bestimmung der Zellzahl in der Neubauer-Zählkammer.

\subsubsection{Ergebnisse Hep3B}

Hep3B TQ Oh

24h

Kontrolle

$1000 \mu \mathrm{M}$

$100 \mu \mathrm{M}$

$50 \mu \mathrm{M}$

$10 \mu \mathrm{M}$

$1 \mu \mathrm{M}$

$0.1 \mu \mathrm{M}$

\section{$48 h$}

Kontrolle

$1000 \mu \mathrm{M}$

$100 \mu \mathrm{M}$

$50 \mu \mathrm{M}$

$10 \mu \mathrm{M}$

$1 \mu \mathrm{M}$

$0.1 \mu \mathrm{M}$

$72 \mathrm{~h}$

Kontrolle

$1000 \mu \mathrm{M}$

$100 \mu \mathrm{M}$

$50 \mu \mathrm{M}$

$10 \mu \mathrm{M}$

$1 \mu \mathrm{M}$

$0.1 \mu \mathrm{M}$

\section{6h}

Kontrolle

$1000 \mu \mathrm{M}$

$100 \mu \mathrm{M}$

$50 \mu \mathrm{M}$

$10 \mu \mathrm{M}$

$1 \mu \mathrm{M}$

$0.1 \mu \mathrm{M}$

\section{0h}

Kontrolle

$1000 \mu \mathrm{M}$

$100 \mu \mathrm{M}$

$50 \mu \mathrm{M}$

$10 \mu \mathrm{M}$

$1 \mu \mathrm{M}$

$0.1 \mu \mathrm{M}$

$$
\begin{array}{r}
42500 \\
5000 \\
2500 \\
50000 \\
37500 \\
50000 \\
50000
\end{array}
$$

65000
7500
12500
45000
67500
80000
97500

$$
\begin{array}{r}
160000 \\
2500 \\
5000 \\
77500 \\
125000 \\
120000 \\
105000
\end{array}
$$

262500
2500
5000
215000
282500
280000
320000

130000
2500
5000
72000
110000
127500
90000

95000
0
2500
75000
107500
115000
127500

96666,6667

3333,33333

6666,66667

64000

95000

107500

105000

162500
2500
2500
105000
187500
112500
192500

165000

0

2500

80000

215000

115000

160000

162500
$\mathbf{1 6 6 6 , 6 6 6 6 7}$
$\mathbf{3 3 3 3 , 3 3 3 3 3}$
$\mathbf{8 7 5 0 0}$
175833,333
$\mathbf{1 1 5 8 3 3 , 3 3 3}$
152500

2500
1443,37567
1443,37567

15206,9063

46120,3137

3818,81308

44229,515

5,92197E-07

6,12264E-07

0,00587081

0,333205755

$8,26311 \mathrm{E}-05$

0,366659477

$\begin{array}{rr}227500 & 200000 \\ 0 & 0 \\ 2500 & 0 \\ 165000 & 220000 \\ 105000 & 140000 \\ 155000 & 235000 \\ 205000 & 232500\end{array}$

187500

8

262500

185000

197500

220000

833,333333

215833,333

143333,333

195833,333

219166,667

340000
0
2500
262500
305000
395000
390000

317500
$\mathbf{8 3 3 , 3 3 3 3 3 3}$
$\mathbf{2 5 0 0}$
260833,333
268333,333
336833,333
363333,333

47893,1102

$1443,37567 \quad 0,003748121$

$2500 \quad 0,00374533$

$45023,1422 \quad 0,104976752$

$45437,6863 \quad 0,133386208$

$57511,593 \quad 0,339222712$

$37859,389 \quad 0,133390677$ 


\subsubsection{Ergebnisse HepG2}

\begin{tabular}{|c|c|c|c|c|c|c|}
\hline HepG2 & TQ & $0 \mathrm{~h}$ & 50000 & & & \\
\hline $24 \mathrm{~h}$ & & & & Mittelwert & SD & Ttest \\
\hline Kontrolle & 67500 & 80000 & 70000 & 72500 & 6614,37828 & \\
\hline $1000 \mu \mathrm{M}$ & 5000 & 2500 & 0 & 2500 & 2500 & 0,0005183 \\
\hline $100 \mu \mathrm{M}$ & 5000 & 0 & 2500 & 2500 & 2500 & 0,0005183 \\
\hline $50 \mu \mathrm{M}$ & 33500 & 40000 & 15000 & 29500 & 12971,1218 & 0,0073832 \\
\hline $10 \mu \mathrm{M}$ & 57500 & 80000 & 100000 & 79166,6667 & 21262,2514 & 0,3241310 \\
\hline $1 \mu \mathrm{M}$ & 75000 & 77500 & 70000 & 74166,6667 & 3818,81308 & 0,364574 \\
\hline $0.1 \mu \mathrm{M}$ & 67000 & 62500 & 77500 & 69000 & 7697,40216 & 0,291573 \\
\hline
\end{tabular}

$48 \mathrm{~h}$

Kontrolle

$1000 \mu \mathrm{M}$

$100 \mu \mathrm{M}$

$50 \mu \mathrm{M}$

$10 \mu \mathrm{M}$

$1 \mu \mathrm{M}$

$0.1 \mu \mathrm{M}$

$\begin{array}{rr}215000 & 215000 \\ 2500 & 0 \\ 2500 & 0 \\ 55000 & 77500 \\ 237500 & 252500 \\ 200000 & 262500 \\ 147500 & 172500\end{array}$

280000

0

2500

65000

180000

212500

180000

72 h

Kontrolle

$1000 \mu \mathrm{M}$

$100 \mu \mathrm{M}$

$50 \mu \mathrm{M}$

$10 \mu \mathrm{M}$

$1 \mu \mathrm{M}$

$0.1 \mu \mathrm{M}$

$96 \mathrm{~h}$

Kontrolle $1000 \mu \mathrm{M}$

$100 \mu \mathrm{M}$

$50 \mu \mathrm{M}$

$10 \mu \mathrm{M}$

$1 \mu \mathrm{M}$

$0.1 \mu \mathrm{M}$

\section{$120 \mathrm{~h}$}

Kontrolle $1000 \mu \mathrm{M}$ $100 \mu \mathrm{M}$

$50 \mu \mathrm{M}$

$10 \mu \mathrm{M}$

$1 \mu \mathrm{M}$

$0.1 \mu \mathrm{M}$

$\begin{array}{rr}517500 & 630000 \\ 0 & 0 \\ 0 & 0 \\ 150000 & 132500 \\ 335000 & 435000 \\ 397000 & 410000 \\ 565000 & 440000\end{array}$

490000 0

147500

385000

445000

620000

860000

5000

227500

607500

787500

$\begin{array}{rr}1192500 & 1757500 \\ 0 & 0 \\ 12500 & 5000 \\ 157500 & 142500 \\ 1332500 & 1292500 \\ 1125000 & 2020000 \\ 1122500 & 1392500\end{array}$

$\begin{array}{rrr}236666,667 & 37527,7675 & \\ \mathbf{8 3 3 , 3 3 3 3 3 3} & 1443,37567 & 0,00413081 \\ \mathbf{1 6 6 6 , 6 6 6 6 7} & 1443,37567 & 0,00415987 \\ \mathbf{6 5 8 3 3}, \mathbf{3 3 3 3} & 11273,1244 & 0,00527953 \\ 223333,333 & 38269,875 & 0,34438972 \\ 225000 & 33071,8914 & 0,35360272 \\ \mathbf{1 6 6 6 6 6 , 6 6 7} & 17017,1482 & 0,03303552\end{array}$

$545833,333 \quad 74176,0294$

$\begin{array}{ll}0 & 0,00304978\end{array}$

$0 \quad 0,00304978$

143333,333

385000

417333,333

541666,667

9464,84724

0,00509981

$50000 \quad 0,02135694$

$24826,0616 \quad 0,04155624$

$92240,6273 \quad 0,47721743$
803333,333
$\mathbf{0}$
$\mathbf{4 1 6 6 , 6 6 6 6 7}$
$\mathbf{1 9 0 0 0 0}$
734166,667
$\mathbf{2 2 5 8 3 3 , 3 3 3}$
978333,333

49328,8286

$0 \quad 0,00062725$

7500

162500

720000

462500

1157500

1440000
2500
7500
135000
1855000
1605000
1105000

1463333,33

$\mathbf{8 3 3}, \mathbf{3 3 3 3 3 3}$

8333,33333

145000

1493333,33

1583333,33

1206666,67
283221,792

$1443,37567 \quad 0,00613479$

$3818,81308 \quad 0,00619198$

$11456,4392 \quad 0,00745972$

$313850,416 \quad 0,45408147$

$447893,216 \quad 0,35917542$

161174,078

0,13061184

\subsubsection{Ergebnisse HF}

$\begin{array}{lrrr}\mathbf{H F} & \text { TQ } & \text { 0h } \\ \mathbf{2 4 h} & & \\ \text { Kontrolle } & 62500 & 30000 \\ 1000 \mu \mathrm{m} & 0 & 0 \\ 100 \mu \mathrm{M} & 0 & 2500 \\ 50 \mu \mathrm{M} & 80000 & 80000\end{array}$

50000

$\begin{array}{rrrl} & \text { Mittelwert } & \text { SD } & \text { Ttest } \\ 47500 & 46666,6667 & 16266,0177 & \\ 0 & \mathbf{0} & 0 & 0,01909623 \\ 0 & \mathbf{8 3 3 , 3 3 3 3 3 3} & 1443,37567 & 0,01929234 \\ 70000 & \mathbf{7 6 6 6 6 , 6 6 6 7} & 5773,50269 & 0,03609839\end{array}$




$\begin{array}{lrrrrrr}10 \mu \mathrm{M} & 62500 & 52500 & 37500 & 50833,3333 & 12583,0574 & 0,37220017 \\ 1 \mu \mathrm{M} & 20000 & 35000 & 50000 & 35000 & 15000 & 0,20654388 \\ 0,1 \mu \mathrm{M} & 25000 & 52500 & 62500 & 46666,6667 & 19418,6337 & 0,5\end{array}$

$48 \mathrm{~h}$

Kontrolle $1000 \mu \mathrm{m}$

$100 \mu \mathrm{M}$

$50 \mu \mathrm{M}$

$10 \mu \mathrm{M}$

$1 \mu \mathrm{M}$

$0,1 \mu \mathrm{M}$

$\begin{array}{rr}70000 & 77500 \\ 2500 & 0 \\ 5000 & 2500 \\ 105000 & 115000 \\ 105000 & 92500 \\ 80000 & 92500 \\ 75000 & 72500\end{array}$

$72 \mathrm{~h}$

Kontrolle

$1000 \mu \mathrm{m}$

$100 \mu \mathrm{M}$

$50 \mu \mathrm{M}$

$10 \mu \mathrm{M}$

$1 \mu \mathrm{M}$

$0,1 \mu \mathrm{M}$

96h

Kontrolle

$1000 \mu \mathrm{m}$

$100 \mu \mathrm{M}$

$50 \mu \mathrm{M}$

$10 \mu \mathrm{M}$

$1 \mu \mathrm{M}$

$0,1 \mu \mathrm{M}$

\section{$120 \mathrm{~h}$}

Kontrolle

$1000 \mu \mathrm{m}$

$100 \mu \mathrm{M}$

$50 \mu \mathrm{M}$

$10 \mu \mathrm{M}$

$1 \mu \mathrm{M}$

$0,1 \mu \mathrm{M}$

$\begin{array}{rr}112500 & 112500 \\ 0 & 0 \\ 7500 & 1000 \\ 135000 & 127500 \\ 142500 & 137500 \\ 100000 & 115000 \\ 162500 & 157500\end{array}$

160000

10000

140000

112500

105000

135000

128333,333

0

134166,667

130833,333

106666,667

151666,667

67500
0
7500
150000
67500
67500
90000

70833,3333

87500
0
2500
137500
70000
77500
82500

77500

$\begin{array}{rr}147500 & 90000 \\ 0 & 0 \\ 2500 & 2500 \\ 167500 & 145000 \\ 120000 & 112500 \\ 147500 & 92500 \\ 97500 & 150000\end{array}$

$$
\begin{array}{r}
67500 \\
0 \\
5000 \\
90000 \\
72500 \\
60000 \\
102500
\end{array}
$$

0

71666,6667

$\mathbf{8 3 3 , 3 3 3 3 3 3}$

4166,66667

103333,333

90000

77500

83333,3333

5204,165

$1443,37567 \quad 0,00045991$

$1443,37567 \quad 0,00051377$

$12583,0574 \quad 0,01711695$

$16393,5963 \quad 0,09230699$

$16393,5963 \quad 0,30376389$

$16645,8203 \quad 0,17465599$

27424,1378

0,00744141

$4645,78662 \quad 0,00718422$

$6291,5287 \quad 0,37548536$

$16072,7513 \quad 0,44985008$

$7637,62616 \quad 0,15148925$

$14648,6632 \quad 0,14151087$

15275,2523

$0 \quad 0,00757517$

$2500 \quad 0,00775395$

$\mathbf{1 5 4 1 6 6 , 6 6 7} \quad 19094,0654 \quad 0,00238665$

$\begin{array}{lll}72500 & 6614,37828 & 0,43719527\end{array}$

$\begin{array}{lll}84166,6667 & 20816,66 & 0,21293355\end{array}$

$83333,3333 \quad 6291,5287 \quad 0,14584709$

\begin{tabular}{|c|c|c|c|c|c|}
\hline \multirow[t]{2}{*}{ Hep3B } & \multirow[t]{2}{*}{ FACS } & Apoptoseraten & & & \\
\hline & & $48 \mathrm{~h}$ & $72 \mathrm{~h}$ & $96 \mathrm{~h}$ & $120 \mathrm{~h}$ \\
\hline Kontrolle & 5,05 & 11,01 & 4,37 & 3,72 & 3,69 \\
\hline $1000 \mu \mathrm{M}$ & 45,97 & 84,81 & 64,51 & 55,78 & 77,69 \\
\hline $100 \mu \mathrm{M}$ & 41,24 & 90,01 & 73,44 & 43,88 & 61,0 \\
\hline $50 \mu \mathrm{M}$ & 9,41 & 6,65 & 7,53 & 12,32 & 13,1 \\
\hline $10 \mu \mathrm{M}$ & 5,71 & 10,97 & 4,08 & 4,36 & 3, \\
\hline $1 \mu \mathrm{M}$ & 5,59 & 10,86 & 3,47 & 3,85 & 3,8 \\
\hline $0,1 \mu \mathrm{M}$ & 5,6 & 6,89 & 3,47 & 3,23 & 3,95 \\
\hline
\end{tabular}

$\begin{array}{rrrr}125000 & 120833,333 & 28975,5644 & \\ 0 & \mathbf{0} & 0 & 0,0093168 \\ 0 & \mathbf{1 6 6 6 , 6 6 6 6 7} & 1443,37567 & 0,00946819 \\ 170000 & 160833,333 & 13768,9264 & 0,06201684 \\ 87500 & 106666,667 & 17017,1482 & 0,25730134 \\ 102500 & 114166,667 & 29297,3264 & 0,39659987 \\ 122500 & 123333,333 & 26259,9188 & 0,45860562\end{array}$

\subsection{Ergebnisse FACS}

Durchflußzytometrische Bestimmung der Apoptoseraten.

\subsubsection{Ergebnisse Hep3B}




\subsubsection{Ergebnisse HepG2}

\begin{tabular}{|c|c|c|c|c|c|}
\hline \multirow[t]{2}{*}{ HepG2 } & \multicolumn{2}{|c|}{ Apoptoseraten } & \multirow[b]{2}{*}{$72 \mathrm{~h}$} & \multirow[b]{2}{*}{$96 \mathrm{~h}$} & \multirow[b]{2}{*}{$120 \mathrm{~h}$} \\
\hline & $24 \mathrm{~h}$ & $48 \mathrm{~h}$ & & & \\
\hline Kontrolle & 1,99 & 1,64 & 1,4 & 1,71 & 2,7 \\
\hline $1000 \mu \mathrm{M}$ & 15,65 & 26,89 & 31,5 & 23,53 & 19,09 \\
\hline $100 \mu \mathrm{M}$ & 31 & 52,66 & 52,4 & 57,47 & 57,82 \\
\hline $50 \mu \mathrm{M} *$ & 13,23 & 8,23 & 5,72 & 18,87 & 22,04 \\
\hline $10 \mu \mathrm{M}$ & 2,18 & 1,93 & 1,67 & 2,32 & 3,8 \\
\hline $1 \mu \mathrm{M}$ & 2,06 & 1,74 & 1,47 & 4,16 & 3,7 \\
\hline $0,1 \mu \mathrm{M}$ & 1,75 & 1,84 & 1,59 & 7,3 & 3,8 \\
\hline
\end{tabular}

* hier wurde nachgemessen: die Werte werden statistisch auf eine andere Kontrollgruppe bezogen

\subsubsection{Ergebnisse HF}

HF FACS Apoptoseraten

$\begin{array}{lrrrrr} & \mathbf{2 4 h} & \mathbf{4 8 h} & \mathbf{7 2 h} & \mathbf{9 6 h} & \mathbf{1 2 0 h} \\ \text { Kontrolle } & 1,31 & 6,07 & 2,36 & 3,42 & 2,82 \\ 1000 \mu \mathrm{M} & \mathbf{1 8 , 6 7} & \mathbf{3 1 , 8 2} & \mathbf{3 6 , 9 6} & \mathbf{7 8 , 5 2} & \mathbf{7 9 , 2 9} \\ 100 \mu \mathrm{M} & \mathbf{7 7 , 9 8} & \mathbf{2 0 , 1 2} & \mathbf{9 8 , 0 7} & \mathbf{9 9 , 6 3} & \mathbf{9 9 , 3 1} \\ 50 \mu \mathrm{M} & 2,03 & 0,81 & 0,99 & \mathbf{9 3 , 4 4} & \mathbf{8 1 , 2 3} \\ 10 \mu \mathrm{M} & 1,06 & 3,68 & 1,66 & 2,64 & 1,68 \\ 1 \mu \mathrm{M} & 1,21 & 2,95 & 1,44 & 3,95 & 3,35 \\ 0,1 \mu \mathrm{M} & 1,08 & 3,8 & 1,17 & 5,98 & 3,4\end{array}$

\subsection{Ergebnisse BrdU}

Bestimmung der relativen Proliferationsrate durch Einbau von BrdU.

\subsubsection{Ergebnisse Hep3B}

\begin{tabular}{|c|c|c|c|c|c|c|}
\hline Нер3В & & $\begin{array}{l}\text { TQ } \\
1000 \mu \mathrm{M}\end{array}$ & $\begin{array}{l}\mathbf{2 4} \mathbf{h} \\
100 \mu \mathrm{M}\end{array}$ & $\begin{array}{l}\text { BrdU } \\
10 \mu \mathrm{M}\end{array}$ & $1 \mu \mathrm{M}$ & \\
\hline & $\begin{array}{l}\text { Kontrolle } \\
0,115\end{array}$ & 0,078 & $\begin{array}{r}\mu, 067 \\
0.01\end{array}$ & 0,09 & 0,111 & $\begin{array}{r}0.1 \mu \mathrm{M} \\
0,081\end{array}$ \\
\hline & 0,137 & 0,066 & 0,066 & 0,099 & 0,131 & 0,093 \\
\hline & 0,145 & 0,065 & 0,063 & 0,137 & 0,13 & 0,124 \\
\hline & 0,136 & 0,082 & 0,064 & 0,116 & 0,125 & 0,134 \\
\hline & 0,151 & 0,055 & 0,066 & 0,126 & 0,12 & 0,132 \\
\hline & 0,15 & 0,062 & 0,065 & 0,122 & 0,137 & 0,135 \\
\hline MW & 0,139 & 0,068 & 0,06516667 & 0,115 & 0,12566667 & 0,1165 \\
\hline SD & 0,01334166 & 0,01013903 & 0,00147196 & 0,01752712 & 0,00920145 & 0,02348404 \\
\hline Relativ & 1 & 0,48920863 & 0,46882494 & 0,82733813 & 0,90407674 & 0,8381295 \\
\hline ttest & & $9,8738 \mathrm{E}-07$ & $1,6995 \mathrm{E}-05$ & 0,0124461 & 0,03756586 & 0,03797614 \\
\hline
\end{tabular}

\subsubsection{Ergebnisse HepG2}

\begin{tabular}{|c|c|c|c|c|c|c|}
\hline HepG2 & Kontrolle & $\begin{array}{l}\text { TQ } \\
1000 \mu \mathrm{M}\end{array}$ & $\begin{array}{l}\mathbf{2 4 h} \\
100 \mu \mathrm{M}\end{array}$ & $\begin{array}{l}\text { BrdU } \\
10 \mu \mathrm{M}\end{array}$ & $1 \mu \mathrm{M}$ & $0.1 \mu \mathrm{M}$ \\
\hline & 0,078 & 0,06 & 0,057 & 0,075 & 0,073 & 0,075 \\
\hline & 0,07 & 0,076 & 0,12 & 0,08 & 0,073 & 0,074 \\
\hline & 0,092 & 0,074 & 0,06 & 0,094 & 0,091 & 0,085 \\
\hline & 0,077 & 0,08 & 0,065 & 0,098 & 0,093 & 0,097 \\
\hline & 0,099 & 0,066 & 0,066 & 0,094 & 0,089 & 0,099 \\
\hline & 0,095 & 0,062 & 0,068 & 0,099 & 0,09 & 0,093 \\
\hline MW & 0,08516667 & 0,06966667 & 0,07266667 & 0,09 & 0,08483333 & 0,08716667 \\
\hline SD & 0,01168617 & 0,00814043 & 0,02354287 & 0,01001998 & 0,00926103 & 0,01092551 \\
\hline Relativ & 1 & 0,81800391 & 0,85322896 & 1,05675147 & 0,99608611 & 1,02348337 \\
\hline
\end{tabular}




\subsubsection{Ergebnisse HF-Zellen}

\begin{tabular}{lrrrrrr} 
HF & \multicolumn{2}{c}{ TQ } & $\mathbf{2 4} \mathbf{h}$ & BrdU & & \\
& Kontrolle & $1000 \mu \mathrm{M}$ & $100 \mu \mathrm{M}$ & $10 \mu \mathrm{M}$ & $1 \mu \mathrm{M}$ & $0.1 \mu \mathrm{M}$ \\
& 0,126 & 0,058 & 0,056 & 0,111 & 0,102 & 0,139 \\
& 0,113 & 0,076 & 0,053 & 0,097 & 0,09 & 0,112 \\
& 0,124 & 0,082 & 0,055 & 0,135 & 0,126 & 0,111 \\
& 0,108 & 0,062 & 0,057 & 0,102 & 0,097 & 0,167 \\
& 0,151 & 0,085 & 0,058 & 0,139 & 0,13 & 0,15 \\
MW & 0,165 & 0,068 & 0,067 & 0,16 & 0,133 & 0,146 \\
SD & 0,13116667 & $\mathbf{0 , 0 7 1 8 3 3 3 3}$ & $\mathbf{0 , 0 5 7 6 6 6 6 7}$ & 0,124 & 0,113 & 0,1375 \\
Relativ & 0,02228378 & 0,01092551 & 0,00488535 & 0,02459268 & 0,01878297 & 0,02215175 \\
ttest & 1 & 0,5476493 & 0,43964422 & 0,94536213 & 0,86149936 & 1,04828463 \\
& & 0,00027201 & 0,00017087 & 0,3042397 & 0,0793239 & 0,31607998
\end{tabular}

\subsection{Ergebnisse Caspase-3/7-Assay}

Messung der Aktivität der Caspase.

\subsubsection{Ergebnisse Hep3B}

Hep3B Caspase 3/7

Verwendete Cycles: 1,2,4, 6,8,10

Mittelwerte verwendet aus Proben mit gleicher Konzentration und Zeitwert

24h

$\begin{array}{lrrrrrr} & 0 \mathrm{~h} & 0,5 \mathrm{~h} & 1,5 \mathrm{~h} & 2,5 \mathrm{~h} & 3,5 \mathrm{~h} & 4,5 \mathrm{~h} \\ \text { Kontrolle } & 1070 & 5573 & 4982 & 4977 & 4952 & 4921 \\ 50 \mu \mathrm{M} & 1421 & 6078,5 & 5278,5 & 5087 & 5056 & 4896 \\ 100 \mu \mathrm{M} & 722,66 & 2200,33 & 1933,66 & 1923 & 1949,33 & 1906,66\end{array}$

$48 h$

$\begin{array}{lrrrrrr} & \text { h } & 0,5 \mathrm{~h} & 1,5 \mathrm{~h} & 2,5 \mathrm{~h} & 3,5 \mathrm{~h} & 4,5 \mathrm{~h} \\ \text { Kontrolle } & 1462 & 6237 & 5429 & 5161 & 4968 & 4914 \\ 50 \mu \mathrm{M} & 1961,5 & 9310,5 & 8098,5 & 7721 & 7542,5 & 7316 \\ 100 \mu \mathrm{M} & 800,66 & 2773,33 & 2487 & 2417 & 2470,66 & 2485\end{array}$

\subsubsection{Ergebnisse HepG2}

HepG2 Caspase3/7

Mittelwerte verwendet aus Proben mit gleicher Konzentration und Zeitwert.

Verwendete Cycles: 1,2,4, 6,8,10

24h

\begin{tabular}{|c|c|c|c|c|c|c|}
\hline & & $0,5 \mathrm{~h}$ & $1,5 \mathrm{~h}$ & 2,5 & 3,5 & 4,5 \\
\hline Kontrolle & 2592 & 16421 & 16169 & 15407 & 15098 & 14329 \\
\hline $50 \mu \mathrm{M}$ & 2370,5 & 15499,5 & 15467,5 & 14933 & 14402,5 & 14009,5 \\
\hline $100 \mu \mathrm{M}$ & 1328,33 & 12719 & 12879,33 & 12415,66 & 11746,33 & 11096 \\
\hline \multicolumn{7}{|l|}{$48 h$} \\
\hline & Oh & $0,5 \mathrm{~h}$ & $1,5 \mathrm{~h}$ & $2,5 \mathrm{~h}$ & $3,5 \mathrm{~h}$ & $4,5 \mathrm{~h}$ \\
\hline Kontrolle & 1626 & 8547 & 6810 & 1932 & 1081 & 312 \\
\hline $50 \mu \mathrm{M}$ & 1491,5 & 7161,5 & 6412 & 3643,5 & 1465,5 & 991,5 \\
\hline $100 \mu \mathrm{M}$ & 745,33 & 2867,66 & 1136,33 & 486,66 & 328,33 & 246,66 \\
\hline
\end{tabular}




\subsubsection{Ergebnisse HF-Zellen}

HF Caspase3/7

Mittelwerte verwendet aus Proben mit gleicher Konzentration und Zeitwert.

24h

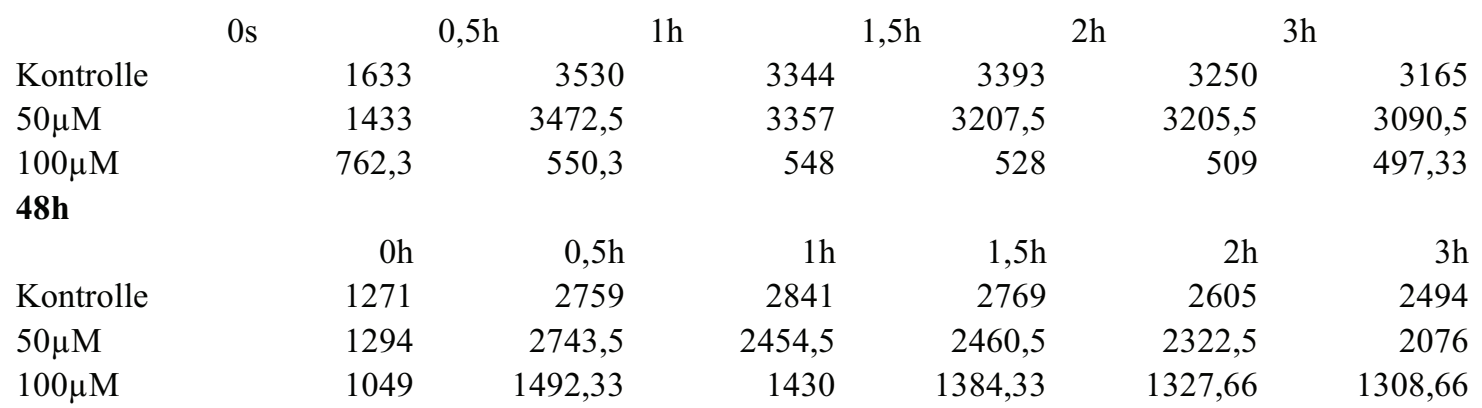

\subsection{Ergebnisse JC-1}

Messung des Anteils intakter Mitochondrien.

\subsubsection{Ergebnisse HepG2 und Hep3B}

$\begin{array}{llrr}\text { JC-1 } & & \text { JC-1 } & \text { Apoptose } \\ \text { Hep3B } & \text { Kontrolle } & 45,23 & 1,98666667 \\ & 100 \mu \mathrm{M} & \mathbf{2 , 5 7} & \mathbf{3 0 , 9 9 6 6 6 6 7} \\ & 10 \mu \mathrm{M} & 62,23 & 2,17666667 \\ \text { HepG2 } & \text { Kontrolle } & 71,05 & 1,31 \\ & 100 \mu \mathrm{M} & \mathbf{4 5 , 0 5} & \mathbf{7 7 , 9 7 6 6 6 6 7} \\ & 10 \mu \mathrm{M} & 71,67 & 1,06333333\end{array}$




\section{Danksagung}

Mein besonderer Dank gilt Prof. Dr. med. Matthias Ocker für die Überlassung des Dissertationsthemas und vor allem für die immer freundlich hilfsbereite und präsente Unterstützung während der gesamten Zeit der Dissertationsanfertigung. 